\title{
QUANTIFICATION OF WINE FAULT MARKERS AND THEIR RELATION WITH
}

RISK FACTORS

A Thesis
presented to
the Faculty of the Graduate School
at the University of Missouri-Columbia
In Partial Fulfillment
of the Requirements for the Degree
Master of Science
by
PAULA GROSSI
Dr. Misha T. Kwasniewski, Thesis Supervisor
DECEMBER 2017


The undersigned, appointed by the dean of the Graduate School, have examined the thesis entitled

\section{QUANTIFICATION OF WINE FAULT MARKERS AND THEIR RELATION WITH RISK FACTORS}

presented by Paula Grossi,

a candidate for the degree of master of science,

and hereby certify that, in their opinion, it is worthy of acceptance.

Professor Misha T. Kwasniewski

Professor Christine Costello

Professor Ingolf Gruen 


\section{ACKNOWLEDGEMENTS}

As I begin to reflect on all the steps taken towards the completion this project, I am reminded of the incredible amount of support and teamwork that kindly came with it. I feel humbled and grateful.

To Dr. Misha Kwasniewski, thank you for your guidance during the program, support throughout the writing process, and patience. Special thanks for allowing me to hone in my knowledge in analytical work and research with freedom, and for making part of my research visiting wineries across Missouri, and working in a research winery. Thanks are also due to Dr. Ingolf Gruen and Dr. Christine Costello, for your valuable inputs and invitation to think critically about my work. It has been an honor working with you.

I would like to acknowledge the contribution of Connie Liu to this thesis. Connie, I will be forever grateful for your selfless help and friendship. Thank you for helping me build such an extensive database, for teaching me about sample preparation, and for pleasant times at the lab. I could not have done it without you.

To my fellow graduate students Stephanie, Courtney, Mani, Meghan, and Brian. For your friendship, kindness, and sense of humor, thank you very much. Our experiences together were essential in the completion of my program and thesis.

To my family, who believed in me and celebrated every little success. My deepest gratitude for listening, advising, cheering and sending your love from the other side of the world and overseas.

To my dear fiancé Sam, thank you for your encouragement and for not letting me give up ever. Your love and support throughout my academic career were indispensable. I am stronger now that I met you. 


\section{TABLE OF CONTENTS}

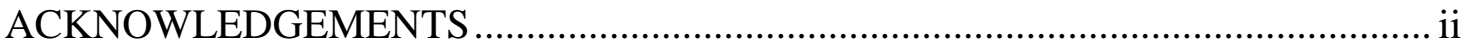

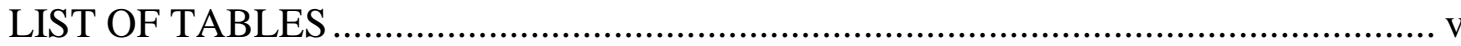

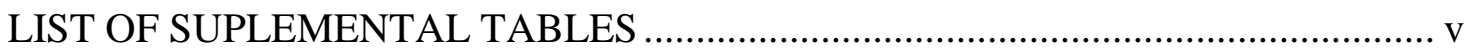

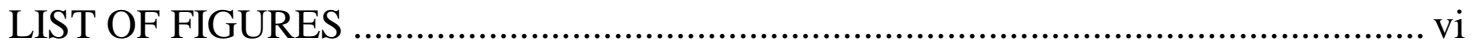

LIST OF SUPLEMENTAL FIGURES ............................................................ vi

CHAPTER 1 - INTRODUCTION TO WINE QUALITY, WINE FAULTS AND RISK

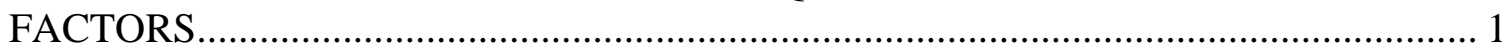

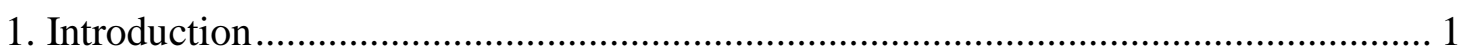

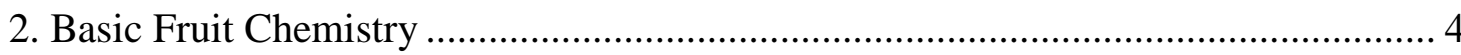

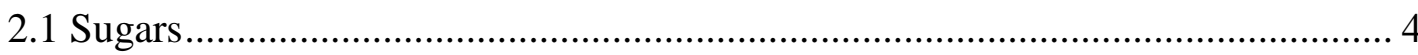

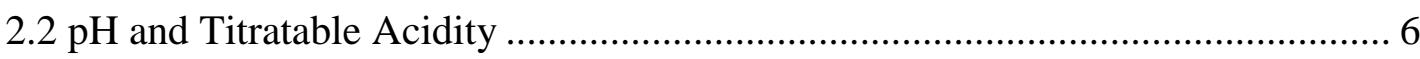

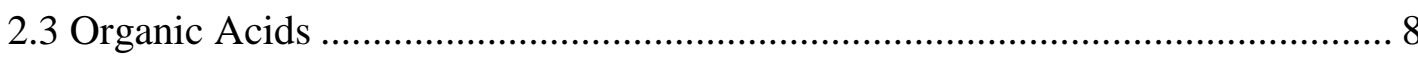

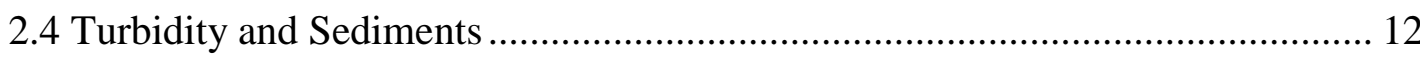

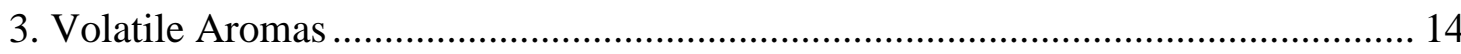

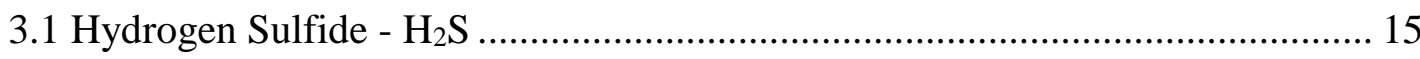

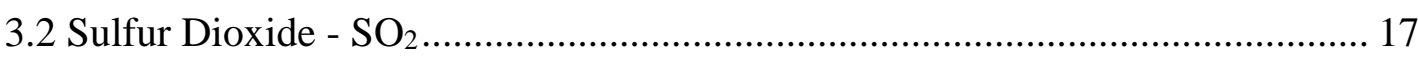

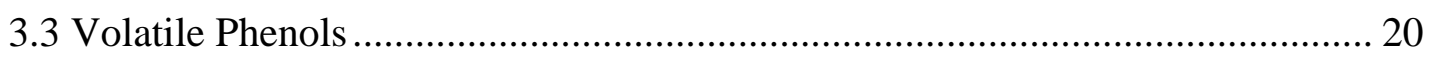

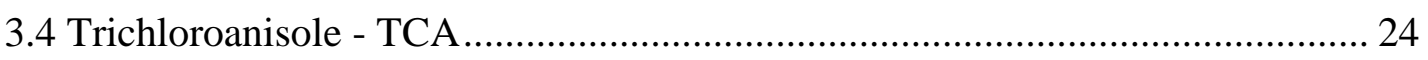

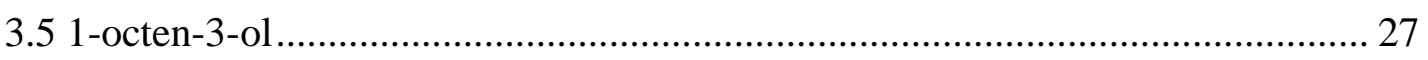

3.6 The "good" Volatile Aromas - $\beta$-damascenone ………………………………... 28

3.7 Measurement of Trace Volatile Compounds ...................................................... 29

4. The Wine Industry ...................................................................................... 32

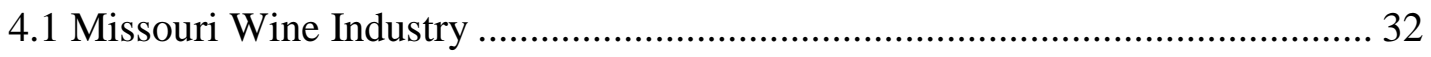

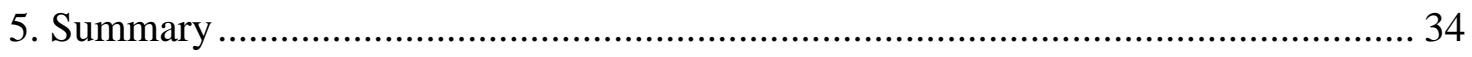

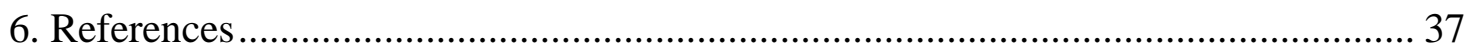

CHAPTER 2 - WINE FAULTS AND RISK FACTORS CHEMISRY IN MISSOURI

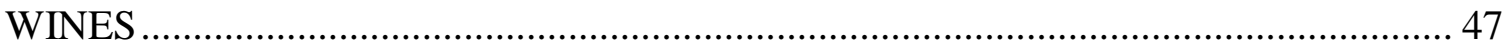

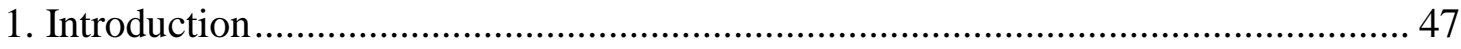

2. Materials and Methods..................................................................................... 51

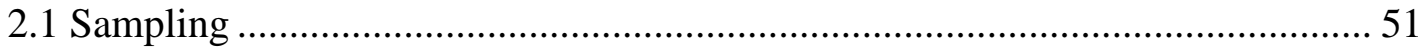

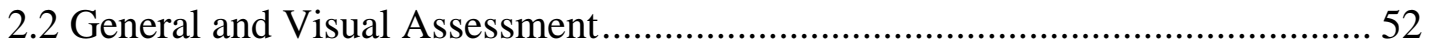

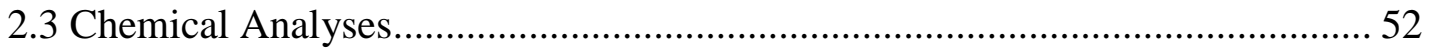

2.4. Statistical Analysis and Data Treatment ....................................................... 56

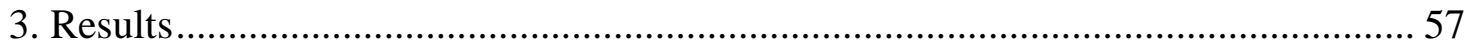


3.1 Overview and Overall Fault Incidence and Categorical Data

3.2 Wine TA and Organic Acid Content ............................................................ 59

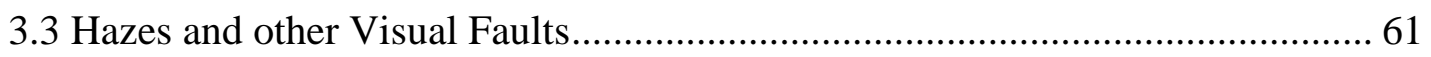

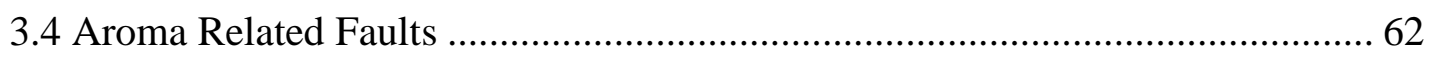

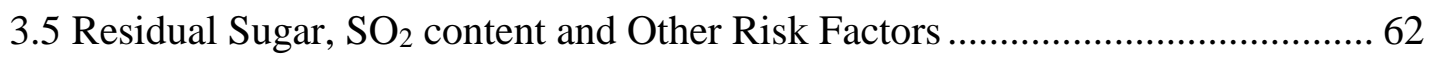

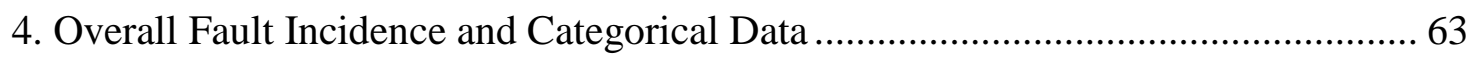

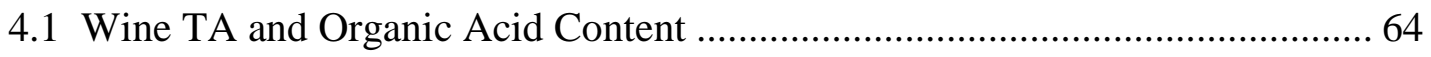

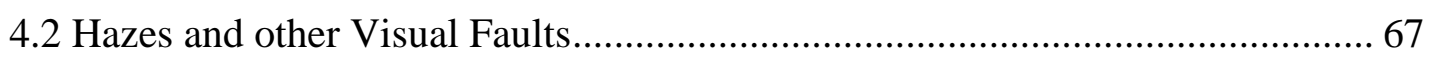

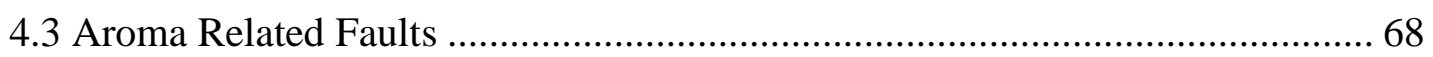

4.4 Residual Sugar, $\mathrm{SO}_{2}$ content and Other Risk Factors ................................... 71

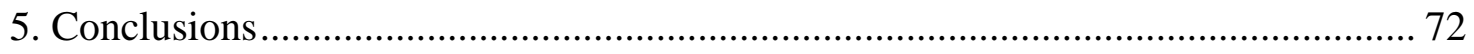

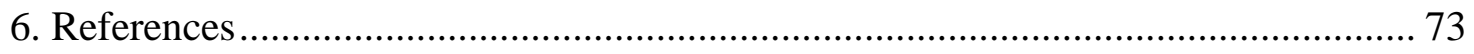

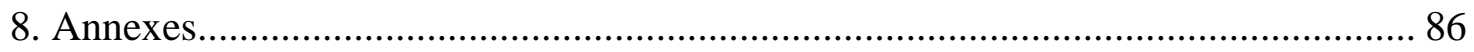




\section{LIST OF TABLES}

Table 1. Incidence of categorical variables of assessment. ........................................ 83

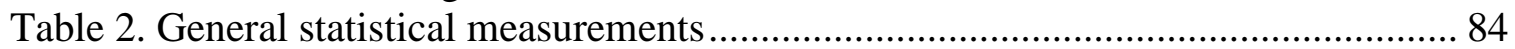

Table 3. Organic acids concentration per wine style. ............................................. 85

Table 4. Trace volatile aroma threshold and incidence in all sampled wines.................. 86

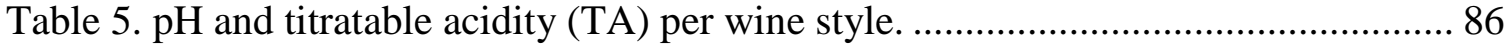

\section{LIST OF SUPLEMENTAL TABLES}

Supplemental Table A. Basic statistics of wine styles versus categorical variables of assessment.....

Supplemental Table B. Basic statistics of residual sugars versus categorical variables of

assessment.

Supplemental Table C. Basic statistics of fill volume versus categorical variables of assessment.

Supplemental Table D. Basic statistics of closure type versus categorical variables of assessment. 89

Supplemental Table E. R square values for all wines............................................. 90

Supplemental Table F. R square values for white wines........................................ 91

Supplemental Table G. R square values for red wines. .......................................... 92

Supplemental Table H. R square values for rosé wines............................................ 93

Supplemental Table I. R square values for specialty wines....................................... 94

Supplemental Table J. Incidence of faults per wine. .................................................... 95

Supplemental Table K. Incidence of Risk Factors per wine........................................... 96 


\section{LIST OF FIGURES}

Figure 1. The ionization process of organic acids (reproduced from Jackson 2014), ........ 8

Figure 2. Forms of sulfur dioxide in wine (reproduced from Jackson 2014). ................. 19

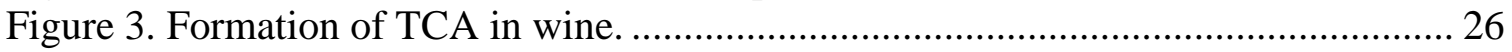

Figure 4. Concentration of (1) Tartaric, (2) Malic, (3) Lactic, and (4) Citric acids in all wine samples $(n=100)$. All organic acids were measured with HPLC. Mean concentration for each acid, in $\mathrm{g} / \mathrm{L}:$ tartaric $=2.32$, malic $=2.04$, lactic $=1.80$, acetic $=$ 0.87 , citric $=0.36$, and succinic $=0.76$.

Figure 5. Means and standard deviations of organic acids per wine style. Population sizes: red $n=40$, rosé $n=9$, specialty $n=9$, white $n=46$.

Figure 6. Concentration of (1) Free $\mathrm{SO}_{2}$ and (2) Total $\mathrm{SO}_{2}$ in $\mathrm{mg} / \mathrm{L}$ for different wine styles. Population sizes: red $n=40$, rosé $n=9$, specialty $n=9$, white $n=46$. Sulfur Dioxide measurements were performed via Aeration Oxidation.

\section{LIST OF SUPLEMENTAL FIGURES}

Supplemental Figure A. Concentration of residual sugars (g/L) in different wine styles. 97

Supplemental Figure B. Incidence of faults and risk factors. ..................................... 97

Supplemental Figure C. Incidence of Turbidity (NTU) in different wine styles............. 98 


\section{CHAPTER 1 - INTRODUCTION TO WINE QUALITY, WINE FAULTS AND RISK FACTORS}

\section{Introduction}

It has been said that a really great wine originates, ultimately, from the heart and mind of those who created it (Kennard 2014). It would, however, be an error to think that the world's greatest wines are exclusively a result of tradition (Ribereau-Gayon et al. 2006). Nevertheless, why can one bottle of wine be so much more special than another? What is the genesis of wine quality? Conversely, what are the points during the winemaking process that prevent the creation of a bad wine? The truth is the making of a good wine relies on numerous components and interactions between those components, with much of the system yet to be completely understood. According to Charters 2003, wine's botanical origin and microbial transformation, the genetics of the vine, yeasts and bacteria are the birthplace of world class wines. For Moreno-Arribas and Polo (2009), the quality of the final wine depends on the type and intensity of reactions taking place, with the whole process being a series of chemical and bio-chemical reactions, that are guided by growers and winemakers, but not fully controlled. Unquestionably, the making of a good wine starts with good viticulture practices, but it also requires optimum vinification and storage. However, even when following the best known practices not all wines are great, or even good.

What constitutes wine quality can be quite subjective; however, there are components that are legally regulated or that are associated with negative quality that are critical to consumer acceptance. The 'faults' such as off aromas, taints, hazes and other fundamental flaws are quantifiable and if they exceed acceptable ranges a wine clearly is of low quality. Some elements even fall into what the legal definition of wine is, such as 
acetic acid levels, which if they exceed the limit for a given style, the product is not legal for sale. There is a large chasm between what is a bad or 'faulted' wine and a great wine and on that spectrum is a huge variation in consumer, or even wine expert opinion (De Mets et al. 2017).

Unfortunately, and despite many references to wine quality, the real contribution that climate, sites and viticultural practices impart to wine quality is still shadowed with confusion. Grape culture, wine production and sensory analysis - the three pillars of wine science - are subjects commonly covered separately despite the evident value of a joint discussion that could not only reinforce their natural relationship, but also aid in viticulture and winemaking improvement. Individual work disregarding the knowledge that specialists in different scientific branches bring can condemn winemaking efforts of achieving high quality, and progress remains erratic or limited (Jackson et al. 1993; Charters 2003; Hoemmen 2013).

It is important to mention that the advances that science has brought to winemaking have not resulted in standardization or leveling of quality. On the contrary, by making it possible to correct defects and eliminate technical imperfections, scientific winemaking has revealed the specific qualities of the grapes harvested in different vineyards, directly related to the variety and terroir, more than ever before (Ribereau-Gayon et al. 2006). In addition, caution must be taken when extrapolating scientific and empiric data given the inherent variabilities associated with climate, soil, varieties etc.; no technique is without drawback (Jackson et al. 1993).

Within certain constraints, winemakers have the ability to strongly influence wine composition during production. They can adjust nutrients, choose between different yeast 
for alcoholic fermentation, different strains of bacteria for malolactic fermentation, control temperature, sugar and $\mathrm{SO}_{2}$ addition; through tartaric acid additions winemakers can manipulate $\mathrm{pH}$ to adjust juice, must and wine to the desired acidity, and remove faults by reverse osmosis. In certain regions, the addition of sugar prior alcoholic fermentation, or chaptalization, is allowed (Bekker et al. 2016a).

Ultimately, the evaluation of quality factors and quality determination is made by sight, smell and taste. Although quantitative data can be collected from sensory analyses based on these parameters (Vannier et al. 1999), sensory attributes are inherently variable from taster to taster. Thus, a more reliable method of evaluation is necessary, making chemical analysis critical (Charters 2003; De Mets et al. 2017). There are pros and cons for both chemical analysis and sensory evaluation. Aside from being more controllable, chemical analysis of wines can be linked and complementary to sensory evaluation. If on one hand sensory evaluation actually captures the impression of an individual, on the other there is huge variability in response and opinion among individuals, which is good and bad. Good because not even state-of-the-art analytical equipment can replicate human perceptions and bad because winemaking practices intended to yield high quality wines, cannot be based on staggered and subjective parameters. Analytical or other physical measurement of the chemical composition of a wine is at least consistent; however, by solely relying on chemical analysis, one risks missing the broader picture that sensory evaluation provides. Additionally, we are gaining a greater understanding of the acceptable ranges of certain compounds in wine and grape to make a wine that is free of problems. When it comes to analytical methods, indicators like $\mathrm{SO}_{2}$, soluble solids and $\mathrm{pH}$ are widely available for a simple winery laboratory. Others, such as organic acids and volatile 
compounds are more complex, technical and expensive, therefore not as accessible and employed. Analytical methods at this time are stronger at recognizing a bad wine rather than being able to assess what makes a good wine. While those romanticizing wine focus on the elite top products that are generally deemed as great, the larger impact on overall wine quality comes from improving the wines of unacceptable quality, to acceptable. Through modern analytical techniques and the knowledge of what makes a wine bad, based on objective and measurable parameters, it is now possible to assess the landscape of how many wines have problems and potentially point to what could be done in the future to avoid creating any faulted wine.

\section{Basic Fruit Chemistry}

\subsection{Sugars}

The main sugars found in grapes are hexoses, glucose and fructose. They usually occur in equal proportions when berries are ripe, however, over-mature grapes may show higher proportion of fructose. Sugar content and concentration depend on the species, variety, maturity, and health of the fruit, and can also be considered a component of quality; such is the case with late season Rieslings and Sauternes. Vitis vinifera cultivars, for example, can reach $20 \%$ or more of sugar before harvest (Wu et al. 2011).

Sugar content is usually measured in ${ }^{\circ}$ Brix, which is a measure of soluble solids in a given solution. In finished wines, unfermented sugars are called residual sugars. More specifically, residual sugars are the simple sugars (monosaccharides such as glucose and fructose) that were not fermented by Saccharomyces cerevisiae during the alcoholic fermentation of wines. These sugars are known to influence wine's maturation and aging, 
and may lead to desirable or undesirable changes. Among the consequences of their presence may be malolactic fermentation and browning of the wine (Esau and Amerine 2000).

The residual sugar content of dry wine is generally less than $1.5 \mathrm{~g} /$ liter (Rivero-Pérez et al. 2002). At this concentration, sweet taste is practically undetectable and the bottled wine is not at spoilage risk. However, as the residual sugar content rises, so does the risk of microbial instability. That is particularly true for sweet wines that are low in acids and alcohol levels, and action is required to prevent undesirable yeast and bacterial activity. The perception of sweetness varies from person to person, however, the sugar content must be greater than $1 \mathrm{~g} / \mathrm{L}$ so that sweetness is perceived (Dittrich, H.H., Sponholz, W.R., Kast 1974). In addition, sweetness descendant from residual sugars are strongly influenced by tannins, acids and ethanol, as well as mitigate sourness and bitterness. Although residual sugars are of obvious importance to the sweetness of wine, they are also an important sensory and quality parameter, given their interaction with other wine constituents, and a potential precursor of wine faults, given their association with microbial spoilage.

There are several techniques of varying degree of difficulty and analytical accuracy that are used to measure the concentration of residual sugar in wine (AWRI 2017). In increasing order of accuracy, commonly used available techniques include Clinitest ${ }^{\circledR}$, Reaction and Titration as described by Iland et al. 2013, Enzymatic Essay and High Performance Liquid Chromatography (HPLC). The last two, aside from returning highly accurate results, also offer the possibility of differentiate sugars, whereas Clinitest only works with reducing sugars. Clinitest ${ }^{\circledR}$, the method used in this study, provides an 
approximate sugar content of wines in a certain range (1-20 g/L). Despite the method's lower accuracy, it is very simple, fast, and cost-effective.

\section{$2.2 \mathrm{pH}$ and Titratable Acidity}

Acid taste in wine is dependent primarily on total and titratable acidity. While titratable acidity is observational based on using a strong base, total acidity is the sum of the concentrations of all acids. Secondarily, acid taste is dependent on $\mathrm{pH}$ (Amerine et al. 1965). Nevertheless, $\mathrm{pH}$ and acidity are interrelated in complex ways. $\mathrm{pH}$ is a measure of the concentration of hydrogen ions $\left(\mathrm{H}^{+}\right)$in an aqueous solution. The higher the concentration of $\mathrm{H}^{+}$in solution, e.g. wine, the lower the $\mathrm{pH}$ will be; conversely, the lower the concentration the higher the $\mathrm{pH}$. Wines can vary significantly in $\mathrm{pH}, 2.6-4.0$, but typically, red wines have higher $\mathrm{pH}$ values than white wines (Plane et al. 1980).

While $\mathrm{pH}$ is a measure of the concentration of hydrogen ions $\left(\mathrm{H}^{+}\right)$in an aqueous solution, titratable acidity is a measure of the total amount of hydrogen ions and undissociated acids that can react with a strong base. $\mathrm{pH}$ is heavily impacted by cations; the higher the concentration of cations, the higher the concentration of undissociated acids and then the higher the $\mathrm{pH}$. Titratable acidity, however, is not actually impacted by cations. That is why it is possible to lower a wine's $\mathrm{pH}$ by removing potassium and still maintain TA levels. The $\mathrm{pH}$ is not correlated with the concentration of acids present, but is influenced by their ability to dissociate (AWRI 2016). Ultimately, TA relates to taste whereas $\mathrm{pH}$ is important from a chemical and microbial stand point, although sourness has been shown to vary independently with $\mathrm{pH}$, total acid concentration and specific anion (Sowalsky and Noble 1998). 
The acid composition and $\mathrm{pH}$ are of fundamental importance in winemaking and in bottled wine. They affect the perception of sourness and related organoleptic properties, and play essential roles in color and microbial stability, since many spoilage bacteria such as Pediococcus and Lactobacillus cannot thrive below pH values of 3.5 (Davis et al. 1986; Boban et al. 2010).

They can affect the incidence and extent of the malolactic fermentation. If the winemaker intends to allow secondary fermentation by malolactic bacteria, $\mathrm{pH}$ can influence the kinetics of the fermentation; the use of potassium metabisulfite or sulfur dioxide as an antimicrobial is dependent on $\mathrm{pH}$, and sulfur additions become less effective as $\mathrm{pH}$ rises and values approach 4 (Bousbouras and Kunkee 1971).

The solubility of potassium bitartrate and calcium tartrate, effectiveness of enzyme addition, rates of formation and hydrolysis of esters, oxidative degradation, ionization and rate of polymerization of anthocyanins in red wines, incidence of protein instabilities in white wines, and ultimately the lifespan of a wine are all correlated with $\mathrm{pH}$ and acidity (Boulton 1979; Czibulya et al. 2015). Wine pH has the potential to alter the structural characteristics of precursor compounds involved in the formation of volatile sulfur compounds (Bekker et al. 2016b).

For consumers, $\mathrm{pH}$ can impact the sensory perception of a wine, since odor activity values (OAVs) of volatile compounds in wines are highly dependent on the $\mathrm{pH}$ of the solution (Ebeler 2007). Certain pigments will also take on different conformations depending on the $\mathrm{pH}$ of a solution, again altering the perception of the depth, stability, or brightness of color in a wine (Brouillard and Dubois 1976). 
Although titratable acidity and $\mathrm{pH}$ have been routinely measured and used as quality parameters for decades, the relationship between $\mathrm{pH}$, TA and the multiple other wine characteristics described above are not well understood (Boulton 1979). In this study, the quantification of titratable acidity and $\mathrm{pH}$ was performed by titration to $\mathrm{pH}$ endpoint with $\mathrm{NaOH}$ (a strong base) and by $\mathrm{pH}$ meter, respectively. Further correlations were investigated and the results can be seen in Chapter 2 .

\subsection{Organic Acids}

Acids are known by their ionization potential and release of hydrogen ions $\left(\mathrm{H}^{+}\right)$. With organic acids, the ionization property is associated with its carboxyl group. The carboxyl group dissociates into a negatively charged carboxyl radical and a free, positively charged, hydrogen ion (Soyer et al. 2003) (see Error! Reference source not found.).

Figure 1. The ionization process of organic acids (reproduced from Jackson 2014).

Organic acids make major contributions to the composition, stability and organoleptic qualities of wines, especially white wines. Their preservative properties carry out wines' microbiological and physicochemical stability, including $\mathrm{pH}$ (P. Ribereau-Gayon, Y. Glories, A. Maujean 2006). Organic acids important to wine can be roughly divided in two groups: organic acids found in grapes (e.g. tartaric, malic, citric, succinic, gluconic, mucic, and coumaric acids), and organic acids formed during fermentation by yeast and bacterial activity (e.g. lactic, acetic, succinic, pyruvic, oxaloacetic, and fumaric acids). Organic acids formed during fermentation are classified in mono-protic, di-protic and tri-protic. A mono- 
protic acid, e.g. lactic acid, is an acid that donates only one proton or hydrogen atom per molecule to an aqueous solution. Consequentially, di- and tri-protic acids are acids that can donate two and three protons or hydrogens, respectively. It is worth it to mention that succinic acid is found in grapes, however, in minute quantities.

For the purpose of quantification, organic acids are also divided in Volatile Acidity (VA), and Fixed Acidity or Non-Volatile Acidity. The sum of the former and latter is called Total Acidity. Among fixed acids found in wine are tartaric, malic, citric and succinic; acetic makes up most of the volatile acids group, however, the carryover of other elements, such as lactic acid, may occur during the distillation process. The quantification of organic acids in must and wine is of fundamental importance for wine quality and understanding fault development.

Grape variety, climate conditions, and viticulture and vinification techniques are among the factors affecting organic acid composition of grapes and wines. Tartaric acid is one of the major grape acids, along with malic acid, and rarely found in other fleshy fruits. It is a relatively strong acid, giving wine a $\mathrm{pH}$ of 3.0-3.5. Because tartaric acid is metabolized by a few microbes only, wine remains sufficiently acidic to limit the growth of most bacteria and fungi. (P. Ribereau-Gayon, Y. Glories, A. Maujean 2006). For this reason, wines high in $\mathrm{pH}$ and/or low in titratable acidity (TA) can be treated with tartaric acid. Although bitartrate instability could become an issue, tartaric acid addition is effective (Ough 1988).

Malic acid may constitute half of the total acidity of grapes and wine. Under high temperatures, a decrease of malic acid concentration may occur, leading to the production of wine with flat taste and susceptible to microbial spoilage. Conversely, lower 
temperatures encourage high levels of malic acid throughout the maturation process yielding sour tasting wines. Malic acid can be bacterially converted to lactic acid and $\mathrm{CO}_{2}$ spontaneously or after the alcoholic fermentation when conditions favor the development of indigenous malolactic (ML) bacteria (Gockowiak and Henschke 2003). In addition, wines that have undergone malolactic fermentation often have buttery or nutty character due to microbial formation of diacetyl, 2,3-butanedione (Ebeler 2007). While not a malodorous characteristic, it might be undesirable and a fault for some wines. Therefore, malic acid concentration is a significant indicator of wine quality as well as a harvest date determinant (Jackson et al. 1993).

The third most abundant acid in grapes, citric acid, can also undergo bacterial conversion. Malolactic bacteria can transform citric acid into acetic acid or diacetyl, both of which can easily give a wine fault characteristics (Shimazu et al. 1985; Nielsen et al. 1999). In order to prevent citric acid degradation, malolactic fermentation is usually interrupted as soon as the malic acid is consumed by lowering wine temperatures below microbial tolerance, sulfur addition, and/or sterile filtration. Although citric acid is not present in all wine grapes, it has been found in concentrations as high as $1 \mathrm{~g} / \mathrm{L}$ in some hybrid wine grapes, having the potential to cause undesirable flavors and aromas if complete secondary and tertiary fermentations are allowed (Main and Morris 2004). As well as tartaric and malic acids, citric acid is a significant indicator of wine quality and potential fault precursor.

Lactic, acetic and succinic acids are the result of yeast activity during fermentation and under optimal conditions are produced in small amounts. Lactic acid a as a major constituent in wine is indicative of bacterial activity. Lactic acid bacteria (LAB; generally 
Oenococcus oeni) produce an enzyme that converts dicarboxylic malic acid directly to monocarboxylic lactic acid. The process deacidifies the wine resulting in a wine with a softer mouth feel (Nielsen et al. 1999; Moreno-Arribas and Polo 2009). Malolactic fermentation is encouraged in red wines and some white wines, and the predominance of lactic acid over malic acid in wine is the primary indicator of malolactic fermentation (Lonvaud-Funel 1999).

Acetic acid, the primary acid of volatile acidity (VA), can add complexity to wine at normal levels $(<300 \mathrm{ppm})$ with desirable fruity taste and odor. Above 300ppm, however, it becomes a fault and imparts a sour/vinegary taste. Fault associated with acetic acid can usually be related with contamination with acetic acid bacteria (Moreno-Arribas and Polo 2009; Jackson 2014). The production of acetic acid will result in the concomitant formation of other, sometimes unpleasant, aroma compounds, such as ethyl acetate and acetaldehyde. In addition to the undesirable aromas, both acetic acid and acetaldehyde are toxic to Saccharomyces cerevisiae and may lead to stuck fermentations (Waterhouse 2015a). The elimination of air during vinification accompanied with sulfur dioxide addition will limit acetic bacteria growth and prevent spoilage, as well as rejection of moldy grapes. Reverse osmosis and blending with unfaulted wines are two possible ways of treating spoilage by acetic acid.

Succinic acid is a minor by-product of yeast fermentation. It is not volatile, and like tartaric, malic and citric acids it is considered a non-volatile acid. Its resistance to microbes even under anaerobic conditions makes succinic acid a stable acid in wine. In contrast, the bitter-salty taste of succinic acid limits its use as a wine acidulant (Thoukis et al. 1965; Song and Lee 2006). 
The quantification of organic acids in must and wine is of fundamental importance for wine quality and understanding fault development because of their influence in organoleptic properties (flavor, color and aroma) and in the stability and microbiologic control of these beverages (Mato et al. 2005). Steam Distillation and Cash Still are the two main methods listed by AOAC International for measurement of acidity. However, there is vast literature exploring faster and high precision methods of analysis of organic acids. High-Performance Liquid Chromatography (HPLC) (Lopez and Gomez 1996; Pereira et al. 2010), Liquid-Chromatography (Kerem et al. 2004), Spectrophotometry (McCloskey 1976), Gas Chromatography (GC) and enzymatic methods are among it (Mato et al. 2005). For the purpose of this study, clarification and filtration of red, rosé and specialty wines and filtration of white wines followed by HPLC analysis was employed.

\subsection{Turbidity and Sediments}

Turbidity is an optical property that causes light to be scattered and absorbed rather than transmitted in straight lines through the sample, caused when suspended particles in wine interfere with light passing through (Crespo et al. 2010). A turbid wine is a wine that contains solids in suspension, and it can also be called hazed or clouded. Turbidity results from the clumping of dissolved proteins into light-dispersing colloidal particles, microbial activity, cell debris, potassium hydrogen tartrate crystals, and other insoluble material (Moreno-Arribas and Polo 2009; Jackson 2014). Visually, turbidity does to a wine what dirt does to a glass of water.

The appropriate Nephelometric Turbidity Unit (NTU) values differ in the literature. Oliveira and Clemente 2003 and Mutanen et al. 2007 reported that a finished wine is 
expected to have very low turbidity, in most of the cases, lower than 1 or 2 NTU, and that during alcoholic fermentation values can exceed 2000 NTU, establishing a very wide margin of measurement. Other authors, however, reported values ranging between 50-150 and 100-250 NTU (Sadar 2002; Mutanen et al. 2007).

Although there have been numerous investigations on grape, juice, and wine proteins in recent years, the nature of the proteins responsible for, or the factors that trigger, wine turbidity remains unclear (Ferreira et al. 2001). According to Ferreira et al. 2001, there is increasing evidence suggesting that the development of turbidity is also associated with the presence of polyphenols, polysaccharides, and wine $\mathrm{pH}$.

In the wine industry, turbidity is one of the most important parameters used to determine the quality of finished wines and serves as a control during the vinification processes. The absence of turbidity must be a permanent quality in finished wine, since the particles in suspension may interfere in the sensory experience and are often signs of quality deterioration (Sadar 2002; Crespo et al. 2010). Turbidity can be measured with a turbidity meter. The method is simple, fast, accurate and widely available to wineries.

All commercial wines can be absolutely clear. That because most sources of haziness are known and controllable. Turbidity in pre-bottled samples is of little concern since it can be removed during clarification and fining, before bottling. Although an issue for bottled wines, turbidity has limited association with modification of taste or aromas (Waters et al. 1993).

Sediment is the material that accumulates on the sides or bottom of bottled wine usually consisting of precipitated tartrate crystals and tannin complexes. While harmless, sediments can create an unpleasant, gritty drinking experience. Prevention or removal of 
sediments are crucial in high quality winemaking; they can be achieved by stabilization and clarification. Both methods involve procedures designed to produce clear wine free of flavor and visual faults. However, the procedures themselves can create problems, thus it is essential that they be used cautiously. For example, ion exchange, a stabilization method, has been said to adversely affects the quality of a high quality wine, especially one with delicate flavor (Dharmadhikari 1994).

The most common stabilization methods are cold stabilization, ion exchange and contact process. In these methods, tartrate and other crystalline salts, as well as proteins, are removed from the wine; principal clarification methods include filtration and fining. Clarification improves aesthetics and microbial stability, besides polishing the wine prior bottling. During filtration, wine is passed through a material that contain a series of pores (filters) that work as retention walls holding particles that are equal or greater than filter pores. Fining on the other hand, is the introduction of an agent to the wine that physically binds with a targeted element, usually tannins or proteins; once the reaction finishes and the agglomeration precipitates out of solution to the bottom of the vessel, the wine is racked to remove it from the sediment.

\section{Volatile Aromas}

In designing the volatile aromas part of this thesis, and based on literature review and winemaking laws we were able to divide and define thresholds into the three following categories. The term sensory threshold or odor threshold as the lowest concentration that can be detected by human perception; the fault threshold as the concentration at which a volatile aroma starts to contribute negatively to the aroma profile of the wine, and the legal 
threshold as concentrations determined by TTB or other internationally reputable regulatory organization.

\subsection{Hydrogen Sulfide - $\mathrm{H}_{2} \mathrm{~S}$}

Volatile sulfur compounds can be formed at various stages during wine production and storage, and some may impart unpleasant "reduced" aromas to wine when present at sensorially significant concentrations (Siebert et al. 2010a). These compounds are either grape derived, like 3-mercapto-hexenol, which imparts the "cat pee" aroma to Sauvignon blanc wines, or they are created as fermentation byproducts (Subileau et al. 2008). In general, these compounds are easily oxidized and have very low sensory thresholds, making them both very important to some wines sensory profiles, but exceedingly difficult to quantify analytically (Siebert et al. 2010b).

Hydrogen sulfide is the most common volatile sulfur compound found in wine. Although generally occurring in trace amounts, its high volatility, low sensory threshold (1.1 - $1.6 \mathrm{ppb})$, and distinctive odor of rotten-eggs give hydrogen sulfide great significance (Schütz and Kunkee 1977). At levels lower than the recognition threshold, on the other hand, $\mathrm{H}_{2} \mathrm{~S}$ is not perceived as a fault and may contribute to the bouquet of a young wine with yeasty odors, adding complexity to wine aroma profile (Henschke and Jiranek 1991).

Chemical and biological routes can be accounted for the formation of hydrogen sulfide. It may be produced at low concentrations by Saccharomyces cerevisiae, as the result of cysteine catabolism (sulfur is an integral component of this amino acid), reduction of elemental sulfur in higher concentrations, and as the result of nitrogen depletion, due to imbalances in sulfur metabolism; exposure to light and heat treatment have also been linked 
to the formation of $\mathrm{H}_{2} \mathrm{~S}$ (Schütz and Kunkee 1977; Giudici and Kunkee 1994; Jiranek 2002).

Methods for measuring volatile sulfur compounds in wines usually use analytical tools unavailable to most wineries (Chen et al. 2017), being mainly employed in research studies. Given their low concentrations in wine, sensitivity to oxygen, volatility, and reactivity, accurate measurements can be challenging, expensive and time consuming (López et al. 2007). Typical instrumental methods for hydrogen sulfide analysis consists of sample extraction, usually through static headspace (HS) or solid-phase microextraction (SPME), paired with gas chromatographic (GC) separation, followed by sulfur selective detectors, sulfur chemoluminescence detection (SCD) or pulsed flame photometric detection (PFPD) (Fang and Qian 2005; Bosch-Fusté et al. 2007; Siebert et al. 2010a; Ugliano et al. 2012). SPME is relatively convenient to perform despite the method's inherent fragility that includes fiber breakage and burn, post-conditioning bleeding, carry over and a certain degree of variability. Static HS sampling, on the other hand, in combination with cool-oncolumn injection addresses the disadvantages of SPME, but requires a specialized injection port and cryogenic cooling equipment, which are not commonly available in most research labs, let alone wineries labs (Grau 2017).

An alternative option for accurate, convenient $\mathrm{H}_{2} \mathrm{~S}$ measurement utilizes gas detection tubes filled with a metal salt (lead acetate or mercury chloride) and inert packing material which undergoes a colorimetric reaction with $\mathrm{H}_{2} \mathrm{~S}$ as it moves into the tube (Ugliano and Henschke 2010; Grau 2017). The stack height of color change along the tube is proportional to the quantity of $\mathrm{H}_{2} \mathrm{~S}$ present. This method has been used to quantify $\mathrm{H}_{2} \mathrm{~S}$ generated by elemental sulfur residue in grape must and grape macerate (Kwasniewski et 
al. 2011), to monitor production of $\mathrm{H}_{2} \mathrm{~S}$ during wine fermentations (Park 2008), and to detect $\mathrm{H}_{2} \mathrm{~S}$ released from copper complexes in wine (Chen et al. 2017).

Given that most methods require analytical tools that are unavailable to most wineries, and the difficulty associated with accurate, reproducible, and reliable sampling and quantification techniques for volatile sulfur compounds in wine, progress of research aimed at understanding this particular wine fault and its formation pathways during vinification and aging remain incremental.

\subsection{Sulfur Dioxide - $\mathrm{SO}_{2}$}

Sulfur dioxide is a normal constituent of wine, and has been reported to accumulate to between 12 and $64 \mathrm{mg} / \mathrm{L}$ as a result of yeast metabolism (Larue et al. 1985); nevertheless, $\mathrm{SO}_{2}$ levels above $30 \mathrm{mg} / \mathrm{L}$ usually result from addition during or after vinification (Sussi and Romano 1982). Sulfur dioxide is also the most widely used preservative in winemaking with antioxidant, antimicrobial and anti-enzymatic activities.

At wine $\mathrm{pH}(3-4)$, free $\mathrm{SO}_{2}$ is present in the form of ionized bisulfite (93-99\%, $\mathrm{HSO}_{3}$ ), molecular $\mathrm{SO}_{2}$, and at trace levels as sulfite $\left(\mathrm{SO}_{3}{ }^{2-}\right)$ (Butzke 2010). Free forms act as antioxidant and antimicrobial, with the limit of protection at concentrations around 10 mg/L (Buechsenstein and Ough 1978; Godden et al. 2001; Lopes et al. 2009), and values between 0.8 and $1.5 \mathrm{mg} / \mathrm{L}(\mathrm{ppm})$ molecular $\mathrm{SO}_{2}$ have generally been viewed as sufficient to inhibit the growth of most wild yeasts and bacteria (Moreno-Arribas and Polo 2009; Jackson 2014). The bisulfite ion can covalently bound with carbonyl groups of wine compounds, such as acetaldehyde, aldose sugars, pyruvate, and $\alpha$-ketoglutaric acid to form bisulfite compounds, or bound $\mathrm{SO}_{2}$; bisulfite can also bind with anthocyanins 
(Buechsenstein and Ough 1978; Bueno et al. 2016). Overall, acetaldehyde is recognized as the most important $\mathrm{SO}_{2}$ binder in wine (Jackowetz and Mira de Orduña 2013) (see Figure 2).

Winemakers must analyze free $\mathrm{SO}_{2}$ accurately in order to know the extent to which the wine is protected, while total $\mathrm{SO}_{2}$ analysis is performed for legal and sensory reasons. The legal limit for total $\mathrm{SO}_{2}$ in the United States is $350 \mathrm{mg} / \mathrm{L}$ (27 Code of Federal Regulations 4.22(b)(1)) regardless of wine type. Other nations, such as the EU, are more restrictive and established limits ranging from 150 - $300 \mathrm{mg} / \mathrm{L}$ based on wine type and residual sugar concentration.

At excessive concentrations, $\mathrm{SO}_{2}$ will impart a pungent sensation in the nose and odor resembling a struck match. The health risks that sulfur dioxide poses for sensitive consumers and the increasing popularity of wines with low preservative concentrations have triggered research exploring the efficacy of alternative antioxidant additives, such as glutathione, which is naturally found in grapes and formed by yeast and ascorbic acid (Chinnici et al. 2013; Jackowetz and Mira de Orduña 2013). Although the sulfite content of wine is a legitimate health concern for some individuals, the issue has been grossly exaggerated (Taylor et al. 1986). Regardless, the attention has been useful in steering research on the action, benefits, and disadvantages, of sulfur dioxide use (Jackson 2014). 


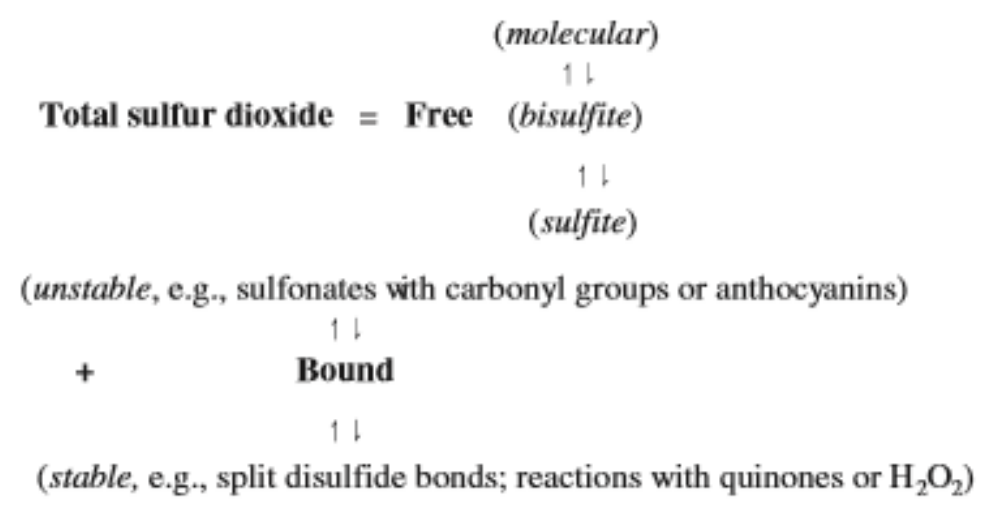

Figure 2. Forms of sulfur dioxide in wine (reproduced from Jackson 2014).

Methods for measuring $\mathrm{SO}_{2}$ in musts and wines, unlike other wine quality parameters, can be simple and the analytical tools are widely available for wineries. The OIV and the AWRI both propose two standard methods for the determination of sulfur dioxide in wine: aeration-oxidation (AO), also called Paul method and Rankine and Pocock method, and the Ripper iodometric method.

In a comparison study, Buechsenstein and Ough 1978 reported that the AO method gives more consistently accurate results than the Ripper method. Although slower than Ripper, aeration-oxidation addresses Ripper's issues, such as ambiguous results for red wines given the use of colorimetric indicators, volatilization of $\mathrm{SO}_{2}$ during titration and reduction of iodine titrant by non-sulfite compounds. On the other hand, Giménez-Gómez et al. 2017 reports the impracticalities of the AO method since it requires flushing of the sample, use large sample volumes and the precision depends on the experience of the technician.

For this study, standard aeration-oxidation (AO) method was used for the determination of free, bound and total $\mathrm{SO}_{2}$ concentration in bottled wines. In this method, a stream of air is passed through an acidified wine sample, carrying $\mathrm{SO}_{2}$ through a condenser into a 
hydrogen peroxide trapping solution containing an acid-base indicator. The trapping solution is then titrated with diluted standardized $\mathrm{NaOH}$ to a clearly visible endpoint (Buechsenstein and Ough 1978; Iland et al. 2013). Despite somewhat lengthy (approximately 30 minutes per sample), the consistently accurate results brought by AO made this method a reliable option for sulfur dioxide measurement.

Alternative methods for measuring $\mathrm{SO}_{2}$ in musts and wines have been reported that involve sophisticated analytical procedures, such as HS-GC (Aberl and Coelhan 2013), molecular absorption (Huang et al. 2008) and spectrometry (Čmelík et al. 2005). However, for the purpose of this thesis, preference was given to methods that are aligned with wineries' current capabilities, in an attempt of replicating their results.

\subsection{Volatile Phenols}

Volatile phenols are aromatic compounds and one of the key type of molecules responsible for olfactory defects in wine (Kheir et al. 2013). The potential sensory impact of these compounds is dramatic due to their low sensory thresholds of parts per billion and parts per trillion, therefore, it is essential to understand their origins and methods of mitigation (Waterhouse 2015b).

Polyphenols and phenolic compounds found in grapes can be divided in two categories, flavonoids and non-flavonoids (Ribéreau-Gayon and Glories 1986; Sacchi et al. 2005). Although flavonoids are often present in greater quantities in red wines than nonflavonoids, all polyphenols contribute significantly to wine quality and the perception of astringency, flavor, aroma, and color. Non-flavonoids consist of benzoic acids, hydrolysable tannins, stilbenes, and hydroxycinnamic acids (Cheynier 2005; Prajitna et al. 
2007). Esters of hydroxycinnamic acid derivatives, notably coumaric and ferulic acids, are particularly important for wine aromas. Hydroxycinnamates can be metabolized to volatile phenols by a variety of microbes, notably those belonging to the genus Brettanomyces (Dekkera). Their derivatives, vinylphenols (4-vinylguaiacol and 4-vinylphenol) and ethylphenols (4-ethylphenol and 4-ethylguaiacol) can donate spicy, pharmaceutical, clove like odors, and smoky, phenolic, animal, stable-like notes, respectively. Conversion initially involves decarboxylation of the hydroxycinnamate precursors to vinylphenols, possibly followed by reduction to ethylphenols (Chatonnet et al. 1992; Chatonnet et al. 1997).

The volatile phenols most often found in wine are 4-Ethylguaiacol (4- EG), 4Ethylphenol (4- EP), 4-Vinylphenol (4-VP), Guaiacol, Eugenol, and Vanillin (Chatonnet et al. 1997; Spillman et al. 1997; Kennison et al. 2008a). Volatile phenols can be present either in the berry or produced as a result of microbial activity, oak maturation, or smoke taint (Waterhouse 2015b). In high concentrations, volatile phenols can be an indicator of an oxidative off-aroma in white wines, but can provide a level of complexity in small concentrations for both red and white wines (Escudero et al. 2002).

As mentioned above, these potent aroma compounds can be traced back to microbial, oak maturation, and smoke-taint sources in wine. Vast literature on volatile phenol faults caused by microbial activity is available. Although several bacteria and yeasts are capable of metabolizing hydroxycinnamates to vinylphenols, only a few yeasts, particularly those belonging to the genus Brettanomyces (Dekkera) (specifically B. bruxellensis), can convert high quantities to ethylphenols (Chatonnet et al. 1992; Chatonnet et al. 1997; Ugarte et al. 2005). Brettanomyces bruxellensis is a yeast found on the surfaces of grapes as well as in 
barrels, but the greatest concern is its presence in wine (Wedral et al. 2010). Red wines typically show a greater proportion of ethyl- to vinyl-phenols, and a higher absolute concentration of these compounds than white wines (Romano et al. 2009). Brettanomyces (Brett) is less frequently identified in white wines largely due to the efficacy of sulfur dioxide at low $\mathrm{pH}$, and absence of precursor compounds such as oak cooperage during vinification (Wedral et al. 2010).

Brettanomyces can be isolated from the outside of grapes and from winery equipment that are difficult to clean, such as barrels (Benito et al. 2009). Oak maturation can affect the volatile phenol profile of a wine in different ways, particularly when $\mathrm{SO}_{2}$ concentration is low (molecular $\left.\mathrm{SO}_{2}<0.5 \mathrm{mg} / \mathrm{l}\right), \mathrm{pH}$ is high (>3.8), and temperature is above $15{ }^{\circ} \mathrm{C}$. The porous microstructure of (new and old) oak barrels allows the influx of small amounts of oxygen, which helps the growth of Brettanomyces. Furthermore, the use of old wooden casks can also increase the presence of these species because they are impossible to sterilize (Kheir et al. 2013). Volatile phenols can also be produced from the thermal degradation of lignin, cellulose and hemicellulose during oak wood toasting (Kennison et al. 2008a; Waterhouse 2015b). Ultimately, the extraction of volatile phenols into wine will depend on the period of time the wine is barrel-aged as well as the concentration of volatile phenols present in the barrel.

Kennison et al. 2008 and The Australian Wine Research Institute have reported that grape and grapevine exposure to smoke from forest fires has been shown to affect the chemical composition and sensory properties of wine. This represents a risk to winemakers since signs of fault from smoke would not be perceivable until after maceration. 
The mitigation of faults by volatile phenols has been investigated. Good manufacturing practices in the wineries and selection of sound grapes are crucial. Biotechnology has been reported as a natural and preventative method against Brett faults via selection of yeast strains that favor the formation of vinylphenolic pyranoanthocyanin adducts during fermentation, reducing the content of p-coumaric acid and minimizing the formation of 4ethylphenol Dekkera/Brettanomyces contamination of finished wines (Suárez-Lepe and Morata 2012). Ugarte et al. 2005 reports treatment of impaired wines via reverse osmosis followed by hydrophobic adsorptive resin; in the study, reduction of 4-Ethylphenol and 4Ethylguaiacol to acceptable levels was reported, indicating a potential method for recovery of wines contaminated by Brettanomyces.

The potent sensory impact of volatile phenols combined with their low sensory threshold turn accurate quantifications into a complex task. (López et al. 2000; López et al. 2002) have reported sensory thresholds of 7.8, 440, and $180 \mathrm{ppb}$ for 4-EG, 4-EP, and 4VP, respectively. Volatile phenols are usually analyzed by Gas Chromatography, after their extraction from the sample. However, most analytical instruments cannot handle sample matrices directly requiring several multi-step, time-consuming, sample preparations that involve the use of expensive and hazardous solvents, and produce low accuracy due to the manual handling (Monje et al. 2002; Fariña et al. 2007).

Traditionally, liquid-liquid extraction methods were employed, but now simpler and more selective extraction methods are applied, such as solid-phase extraction (SPE), solidphase microextraction (SPME) or stir bar sorptive extraction (SBSA) (López et al. 2002; Fariña et al. 2007). Research into new adsorbent materials for SPE and SPME has made these techniques more selective towards the compound studied, resulting in cleaner and 
more concentrated extracts. This allows a more selective analysis of compounds in complex samples, such as wine, since clearer chromatograms and lower detection limits are obtained (Martorell et al. 2002; Monje et al. 2002; Fariña et al. 2007).

The selection of Headspace - Solid-phase microextraction - Gas Chromatography Mass Spectrometry (HS-SPME-GC-MS) for the quantification of volatile phenols in this thesis is explored in detail on section 4.5.

\subsection{Trichloroanisole - TCA}

The organic compound 2,4,6-Trichloroanisole (TCA) is a chlorinated derivative of anisole. TCA is the main compound responsible for cork taint in wine and is the best known example of a processing-associated cork taint (Pollnitz et al. 1996). TCA produces a musty or moldy odor perceptible at very low thresholds (a few parts per trillion). Interestingly, TCA threshold increases with alcohol content, and perception becomes very unlikely.

The recognition threshold and the limit of quantitation (LOQ) of TCA in wine is 2ng/L. The limit of detection (LOD) was reported as 0.1ng/L (Soleas et al. 2002). Various authors have estimated that up to $2-6 \%$ of all bottled wine may be affected by musty (corky) offodors to some extent. If true, wine producers and retailers are fortunate that the majority of consumers seem unable to detect, recognize, or object to the presence of TCA. Nonetheless, whether bottles are returned or not, tainted wine may result in significant source of financial loss to the wine trade (Pollnitz et al. 1996). Luckily, TCA does not pose a health risk to consumers, and there are no government regulations regarding TCA levels in wine (Wine Institute 2017). 
TCA was first found in the corks drawn from tainted wines. Buser et al. 1982 suggested that TCA originated from chlorination of lignin-related substances during bleaching of the cork, the product(s) subsequently being leached into the wine during storage, resulting in a chemical (chlorination) and microbiological (methylation) mechanism. In other words, chloride present in the cork could react with phenolic compounds also present in the cork, producing chlorophenols, and subsequent methylation by microbes in or on the cork could produce TCA and contaminate the bottled wine (see Figure 3). As a result, this taint has come to be known as "corkiness" and is attributed to the interaction of bacteria and fungi with constituents of the cork (Soleas et al. 2002). This discovery resulted in the almost elimination of hypochlorite treatment in cork processing and wineries. Oak cooperage and the use of pentachlorophenol (PCP) as a fungicide at wineries are additional sources of TCA formation. Soleas et al. 2002 highlights the formation of TCA from coumaric acid, via its decomposition to phenols followed by methylation to anisole and chlorination to TCA, what would suggest that Vinyl-/ethyl-phenols faults and TCA share a fault precursor naturally found in grapes, however, no competitive relationship or association between the formation of volatile phenols and TCA was found. Although contamination by TCA is known by the term "cork taint", it is important to emphasize that it can be formed in the absence of corks and what it actually needs is a phenol precursor and the presence of a chlorinated compound. In fact, corks have absorbent properties and can remove varietal and age-derived aromatic compounds from wine, thus, uncontaminated cork can absorb TCA from affected wine, removing its corked odor. 


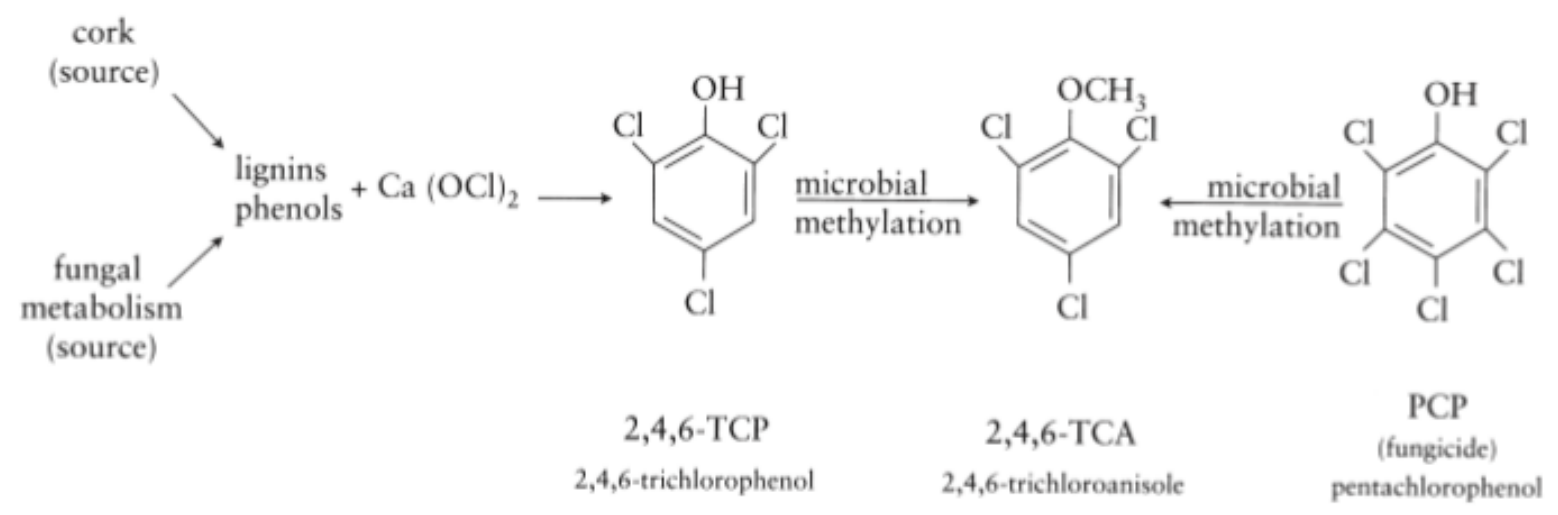

Figure 3. Formation of TCA in wine.

The mitigation of faults by TCA has been investigated. There is no shortage of methods to remove, limit or prevent development and diffusion of cork taint. The elimination of chloride in cork processing and wineries is imperative. The use of closure types other than natural cork, such as synthetic corks and metal screw cap, could be beneficial; however, caution is advised. Alternative bottle closures will introduce an entirely new dynamic on permeability, absorption, adsorption and oxidation rates, and can potentially alter the wines' organoleptic profile while not eliminating risk factors for fault development. A common alternative bleaching agent for the cork industry is peroxide. Peroxide compounds may induce polymerization of surface phenols, reducing their potential involvement in the production of TCA (Frommberger 1991). Vasserot et al. 2001 reported that a slice of silicone attached to the inner surface of a champagne cork tempered at $200^{\circ} \mathrm{C}$ for several hours could prevent the diffusion of TCA into the wine for at least 1 year. Alternative cork treatment with autoclaving, pressurized steam, ozone, carbon dioxide, microwaving, and coating with special membranes has also been reported (Rocha et al. 2000). 
Similar to volatile phenols, the potent sensory impact of TCA combined with its low sensory threshold turn accurate quantifications into a complex task. Traditionally, analytical procedures to detect cork taint compounds, especially the presence of $2,4,6$ trichloroanisole, include liquid-liquid extraction or solid phase extraction with a C18 cartridge followed by a reconcentration of the extract and direct injection into the standard GC-system, Soxhlet, or solid phase extraction and subsequent concentration. However, these techniques often produce more artefact compounds than the trace level analytes that are to be determined (Zalacain et al. 2004). Several studies include solid phase microextraction (SPME) as a viable alternative. Arthur and Pawliszyn 1990 and Fischer and Fischer 1997 report Solid Phase Microextraction (SPME) as an advantageous alternative method, since it not only eliminates the use of solvents, but also is highly selective and can be automated.

\subsection{1-octen-3-ol}

The so-called mushroom alcohol, 1-octen-3-ol is an aromatic alcohol produced by many filamentous fungi, and it possesses a mushroom-like, metallic fragrance. 1-octen-3ol is one of the few higher alcohols that can survive fermentation. The sensory threshold of 1 -octen-3-ol is $20-40 \mu \mathrm{g} / \mathrm{L}$ while the limit of quantitation is $10 \mu \mathrm{g} / \mathrm{L}$ (Lancard and Arriet 2006).

In Botrytized wine, Botrytis cinerea is responsible for producing this pleasant-smelling higher alcohol. Contamination by fungi, including Penicillium, Aspergillus, and Mucor, is likely to generate most of the moldy off-odors and tastes associated with bunch rot. For 
instance, $P$. frequentans produces moldy off-odors, via the synthesis of 1-octen-3-ol (Kaminski et al. 1974).

\subsection{The "good" Volatile Aromas - $\beta$-damascenone}

A lot more is known about the chemical nature of wine faults than about the positive fragrant attributes of wine (San-Juan et al. 2011). Many studies have been carried out to determine the volatile compounds responsible for the most important aromatic nuances of each wine, such as linalool in Moscatel and Chardonnay wines, with advances seemingly imminent (de Pinho et al. 2007; Preston et al. 2008; Pons et al. 2008).

Despite referring here to some volatile aromas as "good" aromas, the good/bad classification of volatile aromas does not apply. Although certain volatile compounds clearly and pleasantly contribute to most wines, some of them produce off-odors at high concentrations that are often desirable at low concentrations, because they may donate complexity and interesting nuances to a wine. Similarly, faults in one wine may be desirable in another, e.g., the oxidized bouquet of Sherries or the fusel odor of Porto; some faults, like the barnyard odor, generated by ethylphenols, maybe be considered rustic, or be part of a wine's terroir (Escudero et al. 2002). Ultimately, one cannot standardize or generalize factors that give a wine a good aroma profile.

López et al. 2000 reported ethyl octanoate, ethyl hexanoate, isoamyl acetate, and $\beta$ dascenone to be the "good" aromas mostly always present in red wines. With the exception of $\beta$-damascenone, all of them are by-products of yeast or bacteria metabolism. $\beta$ damascenone was the only "good" volatile aroma quantified in this study. 
$\beta$-damascenone is a norisoprenoid ketone found in grapes. It is one of the few ketones found in grapes (several other ketones are of fungal derivation) and is characterized by an intense rose-like aroma, low thresholds (white wines $0.05 \mu \mathrm{g} / \mathrm{L}$, and red wines $1.8 \mu \mathrm{g} / \mathrm{L}$ ), and the ability to survive fermentation (Simpson and Miller 1984; Guth 1997; López et al. 2000).

The detection threshold of $\beta$-damascenone is associated with other wine constituents. For example, it is around 1000 times higher in red wine than in a hydroalcoholic solution, suggesting limited sensory significance in wine (Jackson 2014). It is estimated that an inversely proportional relationship exists between carotenoid degradation and norisoprenoid aromatics synthesis, including $\beta$-damascenone. Furthermore, previous research has shown that this compound forms by hydrolysis of certain hydroxylated precursors and their glycoconjugates (Lloyd et al. 2011).

For the purpose of this study, $\beta$-damascenone was treated as a quality factor rather than a wine fault, that is, wines with $\beta$-damascenone concentration above sensory threshold were not considered faulted.

\subsection{Measurement of Trace Volatile Compounds}

As stated previously, many chemicals important to wine quality and in particular wine aroma are very potent, with the ability to be perceived at very low concentrations. Quantifying chemicals at such low levels necessitates very sensitive and selective analytical equipment, but even then, it can be difficult due to the complex matrix of wines and grapes. Often it is necessary to pre concentrate and/or separate classes of compounds, to allow strong signal of the analytes of interest with minimal noise. Solid-phase 
microextraction (SPME) is a technique for chromatographic analysis of solutions diluted in complex matrices, both liquid and gaseous, invented in the early nineties by Prof. Janusz Pawliszyn from the University of Waterloo in Ontario, Canada (University of Waterloo 2017). It is faster, cheaper, and simpler than other sample extraction techniques, such as headspace GC and thermal desorption, with the added benefit of not requiring a solvent (Arthur and Pawliszyn 1990; Zhang et al. 1994). In SPME, a fused fiber coated with a polymer is exposed in the headspace area above a given sample. Under certain temperature, time and agitation, analytes establish equilibria among the sample matrix, the headspace above the sample, and the fiber, then are desorbed from the fiber to a chromatography column (Hinshaw 2003; Sigma Aldrich 2017). In other words, SPME integrates sampling, extraction, concentration and sample introduction into a single step (University of Waterloo 2017). Canuti et al. 2009 talk about it being highly reproducible and sensitive, and therefore suitable for the analyses of low sensory thresholds compounds, such as volatile aromas found in wine.

In wine chemistry, SPME coupled with GC-MS can be efficiently employed to analyze volatile compounds found in grapes, grape juice and wine. Before the introduction of SPME method in the nineties, other techniques had been, and still are, successfully employed in the analysis of volatile compounds: simultaneous distillation-extraction (SDE), closed-loop stripping analysis (CLSA), liquid-liquid extraction (LLE), solid-phase extraction (SPE), and purge and trap/dynamic headspace system (Buchholz and Pawliszyn 1993; Mamede et al. 2005; Riu-Aumatell et al. 2006). Despite their effectivess, they are also solvent-based, time-consuming and generally require large amounts of sample (Sánchez-Palomo et al. 2005). SPME on the other hand offers a simple, rapid, solvent-free 
and inexpensive method for extracting volatile and semi-volatile compounds that requires small amounts of sample instead (Bosch-Fusté et al. 2007).

Nevertheless, no technique is without drawback (Jackson et al. 1993). SPME fibers are fragile and can be easily broken or burnt if exposed to high temperatures inside the GC column for long periods. As of any other precision product, the quality of the fibers is subject to manufacturers, and variability between batches of samples can occur. Postconditioning bleeding of the coating material may occur regardless of strictly following manufacturers' instructions (Alpendurada 2000). The carry-over of the fiber has been reported to be a problem that in some cases is difficult to eliminate, even at high temperatures, thus, runs of blank GC with the fiber in between samples should be performed (Alpendurada 2000; Mamede and Pastore 2006). Dissimilarly, Yang and Peppard 1994 state that bleedings mostly contain silicon and are easily recognized by their distinctive mass spectra. The sensitivity of the fiber varies according to the volume of the stationary phase; as the sample volume increases, so does the amount of analytes extracted, until the volume of the sample becomes significantly larger than the volume of the coating material. At this point, the sensitivity of the SPME method will not improve with further increases in sample volume. On the other hand, in LLE or SPE the sample volume can be manipulated to increase sensitivity (Arthur and Pawliszyn 1990; Alpendurada 2000).

For the scope of this thesis and given the nature, availability, and limit of detection of the compounds of interest, we conclude that the benefits offered by SPME method outnumbered its limitations being, therefore, the best fir for our study. 


\section{The Wine Industry}

Worldwide production of wine has steadily risen over recent years while consumption has not kept pace with this increase, explaining many countries surpluses of wine and subsequent problems in international trade (Jackson et al. 1993; Charters 2003; The International Organisation of Vine and Wine 2015).

The Wine Institute reported a world wine production increase of $6.4 \%$ in 2014 compared with 2011, reaching 7.45 billion of gallons. The United States, the fourth largest wine producer in the world holding a share of $10.7 \%$, showed a production increase of $12.2 \%$ with over 798 millions of gallons produced in 2014 versus 711 millions of gallons in 2011. Reiterating the stated decrease in wine consumption, the World Wine Consumption Report also from The Wine Institute showed cutbacks for several countries in Europe and in the South Hemisphere. Leading producers France and Italy respectively consumed $4.85 \%$ and $11.5 \%$ less wine in 2014 versus 2011 . Germany showed negative 0.49\% consumption from 2013 to 2014 . Argentinian consumption contracted $4.23 \%$ from 2013 to 2014 . United States, however, managed a shy growth of $1.71 \%$ in between 2011 and 2014, and 3.2\% growth from 2013 to 2014.

\subsection{Missouri Wine Industry}

Missouri wine industry dates back to 1837 , when German immigrants established the town of Hermann alongside Missouri River. Hermann soils, although too rocky for many crops, seemed to be appropriate for wine grapes. Concurrently with the German settlement, around 1830, French Canadian immigrants began to produce wine in St. Genevieve. French settlers had been planting grapes on the banks of the Mississippi River since late 1700s. 
Around 1847 Hermann's wineries were producing over 10,000 gallons of wine every year, and by 1880s impressive two million gallons per year of Missouri wines were being consumed across America and Europe (Jeremy Nulik 2013; Missouri Wines 2015).

Missouri gained international attention in 1870 when early European explorers seemingly took grapevines carrying phylloxera back to European countries. This threatening vineyard pest once in contact with vinifera rootstock triggered a widespread devastation of French vineyards at an alarming rate. It was when Charles Valentine Riley, a British-born American entomologist sent millions of phylloxera-immune American rootstocks to France, so they could be grafted to European viniferas. His endeavors helped save the French wine industry. The effort was generously reciprocated with a statue honoring the Missourians for saving the French winemaking industry (Herman Vintners 2013).

The attention and respect associated with the provision of immune American rootstocks following the French vineyard devastation leveraged the Missouri wine industry. The number of wineries significantly increased as well as the level of wine production. By 1880s Missouri was the leading producer of grapes in the U.S and by 1900s it was home for the second largest winery in the United Sates and third largest in the world, Stone Hill in Hermann (Country 2016).

With the $20^{\text {th }}$ century came Prohibition. It not only stopped Missouri wine production but also meant severe economic setback. With the Great Depression and World War II that followed, Missouri wine industry did not recover until 1960s. 
In 1980 Augusta became the first American Viticultural Area (AVA) in the country, ahead of Napa Valley by almost three years. In 1986 and 1987 Ozark Mountain, Hermann and Ozark Highlands would become AVAs (Missouri Wines 2015).

Powered by AVAs and an encouraging consumer demand, oenophiles as well as retirees, entrepreneurs and romantics began to open new wineries in Missouri. According to the Missouri Wine and Grape Board (Wines 2014a; Wines 2014b), in 2004 there were 52 wineries in the state. In only 12 years, this number grew 150\% and in 2016, Missouri was counting 130 wineries. In 2014, the Missouri landscape included 1,700 acres of grapevine planted and sold over 910,000 gallons of wine generating \$268 million in revenues. Although presenting significant and definitely important numbers for the economy of the state, these indicators actually reveal how much Missourian wine industry still is in its early hours. For the same year, Wine Institute statistics showed that California had 615,000 acres of grapes, over 638 Million gallons sold and \$31.9 Billion in revenues. As a reference, wine sales in the U.S were $\$ 55.8$ Billion.

It is worth mentioning that the state of California is home for $41 \%$ of the wineries in U.S, with 4,285 wineries, while Missouri hosts only $1.25 \%$, with 130 wineries. Despite of being significantly smaller, per capita profits seem much more attractive in Missouri where on average a winery makes $\$ 2$ Million in revenues/year whereas in California, revenues run at $\$ 745,000 /$ year.

\section{Summary}

If a dictionary definition is taken into account, fault is "a condition of something that shows that it is not working perfectly". By this definition, a wine exhibiting such 
"conditions" that make it not "work perfectly" would be considered faulted. Although such formal definition is not the most appropriate way to explain the wine jargon, fundamentally, a "perfect" wine is a quality wine, which in turn, is fault free. In wine chemistry, these conditions are called quality parameters or faults, and the reasons causing faults are called risk factors. Quality parameters/faults include, but are not limited to, hydrogen sulfide $\left(\mathrm{H}_{2} \mathrm{~S}\right)$, sulfur dioxide $\left(\mathrm{SO}_{2}\right)$, $\mathrm{pH}$, titratable acidity (TA), turbidity, residual sugars, organic acids, and volatile aroma compounds. All of them affect wine quality. This Chapter attempted to explain the origins of these compounds, how to measure them and touched on the complex relationship between and among different quality parameters. As most wine research is conducted in a laboratory with tightly controlled experiments we can draw some conclusions about the relationship between different faults and risk factors, however we do not know how often these relationships are the driving reasons for a problem in the industry. For instance, we know low levels of $\mathrm{SO}_{2}$ can increase the risk of high acetic acid in a wine, due to $\mathrm{SO}_{2}$ inhibiting acetobacter and other spoilage microorganism growth, however, there are many other potential factors that can impact acetic acid including unsound fruit, high citric acid being converted to acetic acid by malolactic bacteria, yeast strain and stress and many other factors. Typically, enologists and winemakers treat all faults and risk factors as equal, trying to do what they can to minimize problems, based only off the idea of what could happen in an experiment, not what is happening in their winery. As time and resources are limited, especially in small wineries, the first question that needs to be answered is "how often does a certain fault arise?" Not, "what should be done to prevent it?" Unfortunately, very little information is available about the incidence of faults in commercial, and even less looking across different 
fault and risk factor categories. After knowing what are the primary problems facing wine quality it is then appropriate to look to lab work for what risk factors maybe driving this problem. If a high proportion of wines have unexpectable levels of acetic acid, do they also have low levels of $\mathrm{SO}_{2}$ ? High $\mathrm{pH}$ ? Did the all go through malolactic fermentation? If some or all of those risk factors hold true it could be an easy fix, if not it could point to other areas that need to be researched.

A high concentration of volatile acidity will indicate low levels of the antimicrobial $\mathrm{SO}_{2}$. Acetic acid is related to citric acid, since the metabolism of the latter during malolactic fermentation produces the former; acetic acid is also a product of the metabolism of tartaric and malic acids e pentoses. The relationship between sulfur dioxide and $\mathrm{pH}$ is widely known; the requirements for free $\mathrm{SO}_{2}$ concentrations in wine increase exponentially with $\mathrm{pH}$, and the higher the $\mathrm{pH}$, the less effective the $\mathrm{SO}_{2}$. Coumaric acid, an ester of hydroxycinnamic derivatives, can be metabolized by microbes into vinyl- and ethylphenols, or decomposed into phenols and methylated and chlorinated into TCA. The preservative and antimicrobial properties of organic acids are associated with $\mathrm{pH}$ stability. Malic and lactic acids share another well-known relationship via malolactic fermentation, where malolactic bacteria converts the former into the latter. Vinyl-phenols can be reduce to ethyl-phenols during the decarboxylation of the hydroxycinnamate precursors. Low levels of $\mathrm{SO}_{2}$ summed to high $\mathrm{pH}$ favor the development of 4-vynilphenol and 4ethylphenol. As one would expect of any fermentative process, these relationships are complex and far from being binary or causal. One of the aims of this study was to validate these relationships when applied to Missouri wines, as well as search for new ones. 


\section{References}

Aberl a, Coelhan M (2013) Determination of sulfur dioxide in wine using headspace gas chromatography and electron capture detection. Food Addit Contam Part A Chem Anal Control Expo Risk Assess 30:226-33. doi: 10.1080/19440049.2012.743191

Alpendurada MF (2000) Solid-phase microextraction: A promising technique for sample preparation in environmental analysis. In: Journal of Chromatography A. pp 3-14

Amerine M, Roessler EB, Ough CS (1965) Acids and the Acid Taste I: The Effect of pH and Titratable Acidity. Am J Enol Vitic 16:29-37.

Arthur CL, Pawliszyn J (1990) Solid phase microextraction with thermal desorption using fused silica optical fibers. Anal Chem 62:2145-2148. doi: $10.1021 / \mathrm{ac} 00218 \mathrm{a} 019$

AWRI (2017) Measurement of residual sugar in wine - The Australian Wine Research Institute. https://www.awri.com.au/industry_support/winemaking_resources/laboratory_meth ods/chemical/rs/. Accessed 14 Jul 2017

AWRI (2016) Acidity and pH - The Australian Wine Research Institute. In: Aust. Wine Res. Inst. http://www.awri.com.au/industry_support/winemaking_resources/frequently_asked_ questions/acidity_and_ph/. Accessed 17 Oct 2016

Batista L, Monteiro S, Loureiro V (2009) The complexity of protein haze formation in wines. Food Chem 112:169-177. doi: 10.1016/j.foodchem.2008.05.070

Bekker M, Day M, Holt H, Wilkes E (2016a) Effect of oxygen exposure during fermentation on volatile sulfur compounds in Shiraz wine and a comparison of strategies for remediation of reductive character.

Bekker MZ, Mierczynska-Vasilev A, Smith PA, Wilkes EN (2016b) The effects of pH and copper on the formation of volatile sulfur compounds in Chardonnay and Shiraz wines post-bottling. Food Chem 207:148-156. doi: 10.1016/j.foodchem.2016.03.060

Benito S, Palomero F, Morata A, et al (2009) A method for estimating Dekkera/Brettanomyces populations in wines. J Appl Microbiol 106:1743-1751. doi: 10.1111/j.1365-2672.2008.04137.x

Boban N, Tonkic M, Budimir D, et al (2010) Antimicrobial effects of wine: Separating the role of polyphenols, pH, Ethanol, and other wine components. J Food Sci. doi: 10.1111/j.1750-3841.2010.01622.x

Bosch-Fusté J, Riu-Aumatell M, Guadayol JM, et al (2007) Volatile profiles of sparkling wines obtained by three extraction methods and gas chromatography-mass spectrometry (GC-MS) analysis. Food Chem 105:428-435. doi: 10.1016/j.foodchem.2006.12.053

Boulton R (1979) The Relationshipsbetween Total Acidity, Titratable Acidity and pH in Wine. Am J Enol Vitic 31:76-80.

Boulton R (1980) The General Relationship between Potassium, Sodium and pH in Grape Juice and Wine. 31:2-6.

Bousbouras G, Kunkee R (1971) Effect of $\mathrm{pH}$ on malo-lactic fermentation in wine. Am J Enol ... 22:121-126.

Brouillard R, Dubois J-E (1976) Mechanism of the Structural Transformations of 
Anthocyanins in Acid Media. J Am Chem Soc 99:1359-1364. doi:

10.1021/ja00447a012

Buchholz KD, Pawliszyn J (1993) Determination of Phenols by Solid-Phase

Microextraction and Gas Chromatographic Analysis. Environ Sci Technol 27:28442848. doi: $10.1021 / \mathrm{es} 00049 \mathrm{a} 026$

Buechsenstein J, Ough C (1978) SO2 determination by aeration-oxidation: a comparison with Ripper. Am J ... 29:161-164.

Bueno M, Carrascon V, Ferreira V (2016) Release and Formation of Oxidation-Related Aldehydes during Wine Oxidation. J Agric Food Chem 64:608-617. doi: 10.1021/acs.jafc.5b04634

Buser HR, Zanier C, Tanner H (1982) Identification of 2,4,6-trichloroanisole as a potent compound causing cork taint in wine. J Agric Food Chem 30:359-362. doi: $10.1021 / \mathrm{jf00110a037}$

Butzke C (2010) Use of SO2 in High-pH Wines - Sulfur dioxide dosage. Purdue Ext. 13.

Canuti V, Conversano M, Calzi ML, et al (2009) Headspace solid-phase microextractiongas chromatography-mass spectrometry for profiling free volatile compounds in Cabernet Sauvignon grapes and wines. J Chromatogr A 1216:3012-3022. doi: 10.1016/j.chroma.2009.01.104

Charters SJ (2003) Perceptions of wine quality. Edith Cowan University

Chatonnet P, Dubourdie D, Boidron J ???n, Pons M (1992) The origin of ethylphenols in wines. J Sci Food Agric 60:165-178. doi: 10.1002/jsfa.2740600205

Chatonnet P, Viala C, Dubourdieu D (1997) Influence of polyphenolic components of red wines on the microbial synthesis of volatile phenols. Am J Enol Vitic 48:443-448.

Chen Y, Jastrzembski JA, Sacks GL (2017) Copper-complexed hydrogen sulfide in wine: Measurement by gas detection tubes and comparison of release approaches. Am J Enol Vitic 68:91-99. doi: 10.5344/ajev.2016.16024

Cheynier V (2005) Polyphenols in food are more complex then often thought. Am J Clin Nutr 81:223-229.

Chinnici F, Sonni F, Natali N, Riponi C (2013) Oxidative evolution of (+)-catechin in model white wine solutions containing sulfur dioxide, ascorbic acid or gallotannins. Food Res Int 51:59-65. doi: 10.1016/j.foodres.2012.11.013

Čmelík J, MacHát J, Niedobová E, et al (2005) Determination of free and total sulfur dioxide in wine samples by vapour-generation inductively coupled plasma-opticalemission spectrometry. Anal Bioanal Chem 383:483-488. doi: 10.1007/s00216-005$3382-2$

Country MW (2016) The History of Missouri Wine. http://www.missouriwinecountry.com/articles/history/. Accessed 12 Aug 2016

Crespo R, Carcel LM, Perez MA, et al (2010) Suitable at-line turbidity sensor for wine fermentation supervision. In: Food Innova - International Conference on Food Innovation. Valencia,

Czibulya Z, Horváth I, Kollár L, et al (2015) The effect of temperature, pH, and ionic strength on color stability of red wine. Tetrahedron 71:3027-3031. doi:

10.1016/j.tet.2015.01.036

Davis CR, Wibowo DJ, Lee TH, Fleet GH (1986) Growth and Metabolism of Lactic Acid Bacteria during and after Malolactic Fermentation of Wines at Different pH. Appl 
Env Microbiol 51:539-545.

De Fátima Alpendurada M (2000) Solid-phase microextraction: A promising technique for sample preparation in environmental analysis. In: Journal of Chromatography A. pp 3-14

De Mets G, Goos P, Hertog M, et al (2017) Sensory quality of wine: Quality assessment by merging ranks of an expert-consumer panel. Aust J Grape Wine Res 1-11. doi: 10.1111/ajgw.12287

de Pinho PG, Falqué E, Castro M, et al (2007) Further Insights into the Floral Character of Touriga Nacional Wines. J Food Sci 72:S396-S401. doi: 10.1111/j.17503841.2007.00405.x

Dharmadhikari M (1994) Methods for Tartrate Stabilization of Wine. In: Midwest Grape Wine Ind. Inst. https://www.extension.iastate.edu/wine/methods-tartratestabilization-wine. Accessed 21 Aug 2017

Dittrich, H.H., Sponholz, W.R., Kast W (1974) Vergleichende Untersuchungen von Mosten und Weinen aus gesunden und aus Botrytis-infizierten Traubenbeeren, I. Säurestoffwechsel, Zuckerstoffwechselprodukte. Leucoanthocyangehalte. Vitis - J Grapevine Res 13:36-49.

Dufrechou M, Sauvage F-X, Bach B, Vernhet A (2010) Protein Aggregation in White Wines: Influence of the Temperature on Aggregation Kinetics and Mechanisms. J Agric Food Chem 58:10209-10218. doi: 10.1021/jf1017687

Ebeler SE (2007) Analytical Chemistry: Unlocking the Secrets of Wine Flavor. Food Rev Int 17:45-64. doi: 10.1081/

Esau P, Amerine MA (2000) Residual Sugars in Wine. Am J Enol Vitic 187-189.

Escudero A, Asensio E, Cacho J, Ferreira V (2002) Sensory and chemical changes of young white wines stored under oxygen. An assessment of the role played by aldehydes and some other important odorants. Food Chem 77:325-331. doi: 10.1016/S0308-8146(01)00355-7

Fang Y, Qian MC (2005) Sensitive quantification of sulfur compounds in wine by headspace solid-phase microextraction technique. J Chromatogr A 1080:177-185. doi: 10.1016/j.chroma.2005.05.024

Fariña L, Boido E, Carrau F, Dellacassa E (2007) Determination of volatile phenols in red wines by dispersive liquid-liquid microextraction and gas chromatography-mass spectrometry detection. J Chromatogr A 1157:46-50. doi: 10.1016/j.chroma.2007.05.006

Ferreira RB, Piçarra-Pereira MA, Monteiro S, et al (2001) The wine proteins. Trends Food Sci Technol 12:230-239. doi: 10.1016/S0924-2244(01)00080-2

Fischer C, Fischer U (1997) Analysis of Cork Taint in Wine and Cork Material at Olfactory Subthreshold Levels by Solid Phase Microextraction. J Agric Food Chem 45:1995-1997. doi: 10.1021/jf970121r

Frommberger R (1991) Cork products: a potential source of polychlorinated dibenzo-pdioxins and polychlorinated dibenzofurans. Chemosphere 23:133-139. doi: 10.1016/0045-6535(91)90102-J

Giménez-Gómez P, Gutiérrez-Capitán M, Puig-Pujol A, et al (2017) Analysis of free and total sulfur dioxide in wine by using a gas-diffusion analytical system with $\mathrm{pH}$ detection. Food Chem 228:518-525. doi: 10.1016/j.foodchem.2017.02.026

Giudici P, Kunkee RE (1994) The effect of nitrogen deficiency and sulfur-containing 
amino-acids on the reduction of sulfate to hydrogen-sulfide by wine yeasts. Am J Enol Vitic 45:107-112.

Gockowiak H, Henschke PA (2003) Interaction of $\mathrm{pH}$, ethanol concentration and wine matrix on induction of malolactic fermentation with commercial "direct inoculation" starter cultures. Aust J Grape Wine Res 9:200-209. doi: 10.1111/j.17550238.2003.tb00271.x

Godden P, Francis IL, Field J, et al (2001) Wine bottle closures: physical characteristics and effect on composition and sensory properties of a Semillon wine. I. Performance up to 20 months post-bottling. Aust J Grape Wine Res 7:64-105. doi: 10.1111/j.1755-0238.2001.tb00196.x

Grau S (2017) Impacts of Bottle Storage on Wine Flavor and Underlying Chemistry. University of Missouri

Guth H (1997) Quantitation and Sensory Studies of Character Impact Odorants of Different White Wine Varieties. J Agric Food Chem 45:3027-3032. doi: 10.1021/jf970280a

Hampel D, Robinson AL, Johnson AJ, Ebeler SE (2014) Direct hydrolysis and analysis of glycosidically bound aroma compounds in grapes and wines: Comparison of hydrolysis conditions and sample preparation methods. Aust J Grape Wine Res 20:361-377. doi: 10.1111/ajgw.12087

Henschke PA, Jiranek V (1991) Hydrogen sulfide formation during fermentation: effect of nitrogen composition in model grape must. Int Symp Nitrogen Grapes Wine Seattle, Washington, Usa 172-184.

Herman Vintners A (2013) About Missouri Wine - Our Roots go Deep. http://hermannwinetrail.com/about-missouri-wine/. Accessed 12 Aug 2016

Hinshaw J V. (2003) Soli-Phase Microextraction. GC Connect. - LC-GC Eur. 2-5.

Hoemmen GA (2013) Regional Wine Quality Reputation: the perceptions and Possibilities in the Shawnee Hills AVA. Southern Illinois University Carbondale

Hsu J-C, Heatherbell DA, Riesling W (1987) Heat-Unstable Proteins in Wine. I. Characterization and Removal by Bentonite Fining and Heat Treatment. Am J Enol Vitic 38:11-16.

Huang MD, Becker-Ross H, Florek S, et al (2008) Determination of sulfur forms in wine including free and total sulfur dioxide based on molecular absorption of carbon monosulfide in the air-acetylene flame. Anal Bioanal Chem 390:361-367. doi: 10.1007/s00216-007-1669-1

Iland P, Bruer N, Edwards G, et al (2013) Chemical analysis of grapes and wine: techniques and concepts, 2nd edn. Patrick Iland Wine Promotions

Jackowetz JN, Mira de Orduña R (2013) Survey of SO2 binding carbonyls in 237 red and white table wines. Food Control 32:687-692. doi: 10.1016/j.foodcont.2013.02.001

Jackson DI, Lombard PB, Kabinett LQ (1993) Environmental and Management Practices Affecting Grape Composition and Wine Quality - A Review. Am J Enol Vitic 44:409-430.

Jackson RS (2014) Wine science: Principles and applications, 4th edn. Academic Press

Jeremy Nulik (2013) A History of Missouri Wine. In: Feast Mag. http://www.feastmagazine.com/dine-out/features/article_e23ee424-acef-11e2-83d6001a4bcf6878.html. Accessed 12 Aug 2016

Jiranek V (2002) Causes of Hydrogen Sulfide in Winemaking. Wine Internet Tech J 3:1- 
10.

Jiranek V, Henschke P (1991) Assimilable nitrogen: regulator of hydrogen sulfide production during fermentation.

Kaminski E, Stawicki S, Wasowicz E (1974) Volatile Flavor Compounds Produced by Molds of Aspergillus, Penicillium, and Fungi imperfecti. Appl Microbiol 27:10011004.

Kennard D (2014) A Year in Burgundy - Film.

Kennison KR, Gibberd MR, Pollnitz AP, Wilkinson KL (2008a) Smoke-derived taint in wine: The release of smoke-derived volatile phenols during fermentation of Merlot juice following grapevine exposure to smoke. J Agric Food Chem 56:7379-7383. doi: 10.1021/jf800927e

Kennison KR, Gibberd MR, Pollnitz AP, Wilkinson KL (2008b) Smoke-derived taint in wine: The release of smoke-derived volatile phenols during fermentation of Merlot juice following grapevine exposure to smoke. J Agric Food Chem 56:7379-7383. doi: 10.1021/jf800927e

Kerem Z, Bravdo BA, Shoseyov O, Tugendhaft Y (2004) Rapid liquid chromatographyultraviolet determination of organic acids and phenolic compounds in red wine and must. J Chromatogr A 1052:211-215. doi: 10.1016/j.chroma.2004.08.105

Kheir J, Salameh D, Strehaiano P, et al (2013) Impact of volatile phenols and their precursors on wine quality and control measures of Brettanomyces/Dekkera yeasts. Eur Food Res Technol 237:655-671. doi: 10.1007/s00217-013-2036-4

Kunkee RE (1991) Some roles of malic acid in the malolactic fermentation in wine making. FEMS Microbiol Lett 88:55-71. doi: 10.1016/0378-1097(91)90696-8

Kwasniewski MT, Allison RB, Wilcox WF, Sacks GL (2011) Convenient, inexpensive quantification of elemental sulfur by simultaneous in situ reduction and colorimetric detection. Anal Chim Acta 703:52-57. doi: 10.1016/j.aca.2011.07.010

Kwiatkowski MJ, Skouroumounis GK, Lattey KA, Waters EJ (2007) The impact of closures, including screw cap with three different headspace volumes, on the composition, colour and sensory properties of a Cabernet Sauvignon wine during two years' storage. Aust J Grape Wine Res 13:81-94. doi: 10.1111/j.17550238.2007.tb00238.x

Lancard DOB, Arriet PHD (2006) Characterization of Some Mushroom and Earthy OffOdors Microbially Induced by the Development of Rot on Grapes. J Agric Food Chem 54:9193-9200.

Larue F, Park MK, Caruana C (1985) Quelques observations sur les conditions de la formation d'anhydride sulfureux en vinification. Connaiss la Vigne du Vin 19:241248.

Lloyd NDR, Capone DL, Ugliano M, et al (2011) Formation of damascenone under both commercial and model fermentation conditions. J Agric Food Chem 59:1338-1343. doi: $10.1021 /$ jf103741n

Lonvaud-Funel A (1999) Lactic acid bacteria in the quality improvement and depreciation of wine. In: Lactic Acid Bacteria: Genetics, Metabolism and Applications. Springer Netherlands, Dordrecht, pp 317-331

Lopes P, Silva MA, Pons A, et al (2009) Impact of oxygen dissolved at bottling and transmitted through closures on the composition and sensory properties of a sauvlgnon blanc wine during bottle storage. J Agric Food Chem 57:10261-10270. 
doi: $10.1021 / \mathrm{jf} 9023257$

Lopez EF, Gomez EF (1996) Simultaneous Determination of the Major Organic Acids, Sugars, Glycerol, and Ethanol by HPLC in Grape Musts and White Wines. J Chromatogr Sci 34:254-257. doi: 10.1093/chromsci/34.5.254

López R, Aznar M, Cacho J, Ferreira V (2002) Determination of minor and trace volatile compounds in wine by solid-phase extraction and gas chromatography with mass spectrometric detection. J Chromatogr A 966:167-177. doi: 10.1016/S00219673(02)00696-9

López R, Ferreira V, Cacho JF (2000) Quantitative determination of the odorants of young red wines from different grape varieties. J Sci Food Agric

López R, Lapeña AC, Cacho J, Ferreira V (2007) Quantitative determination of wine highly volatile sulfur compounds by using automated headspace solid-phase microextraction and gas chromatography-pulsed flame photometric detection. J Chromatogr A 1143:8-15. doi: 10.1016/j.chroma.2006.12.053

Main GL, Morris JR (2004) Leaf-Removal Effects on Cynthiana Yield, Juice Composition, and Wine Composition.

Mamede MEO, Cardello HMAB, Pastore GM (2005) Evaluation of an aroma similar to that of sparkling wine: Sensory and gas chromatography analyses of fermented grape musts. Food Chem 89:63-68. doi: 10.1016/j.foodchem.2004.02.012

Mamede MEO, Pastore GM (2006) Study of methods for the extraction of volatile compounds from fermented grape must. Food Chem 96:586-590. doi: 10.1016/j.foodchem.2005.03.013

Martorell N, Martí MP, Mestres M, et al (2002) Determination of 4-ethylguaiacol and 4ethylphenol in red wines using headspace-solid-phase microextraction-gas chromatography. J Chromatogr A 975:349-354. doi: 10.1016/S00219673(02)01277-3

Mato I, Suárez-Luque S, Huidobro JF (2005) A review of the analytical methods to determine organic acids in grape juices and wines. Food Res Int 38:1175-1188. doi: 10.1016/j.foodres.2005.04.007

McCloskey LP (1976) An Acetic Acid Assay for Wine Using Enzymes.

Miller M (2013) Monitoring Acids and $\mathrm{pH}$ in Winemaking. 1-14.

Missouri Wines (2015) History \& AVAs. https://missouriwine.org/about-us/history-andavas. Accessed 12 Aug 2016

Monje MC, Privat C, Gastine V, Nepveu F (2002) Determination of ethylphenol compounds in wine by headspace solid-phase microextraction in conjunction with gas chromatography and flame ionization detection. Anal Chim Acta 458:111-117. doi: 10.1016/S0003-2670(01)01528-8

Moreno-Arribas VM, Polo CM (eds) (2009) Wine Chemistry and Biochemistry. Springer, New York

Mutanen J, Räty J, Gornov E, et al (2007) Measurement of color, refractive index, and turbidity of red wines. Am J Enol Vitic 58:387-392.

Nielsen JC, Richelieu M, Nielsen J a NC, et al (1999) Control of Flavor Development in Wine during and after Malolactic Fermentation by Oenococcus oeni Control of Flavor Development in Wine during and after Malolactic Fermentation by Oenococcus oeni. Appl Environ Microbiol 65:740-745.

Oliveira CM, Ferreira ACS, De Freitas V, Silva AMS (2011) Oxidation mechanisms 
occurring in wines. Food Res. Int. 44:1115-1126.

Oliveira LMC, Clemente MACP (2003) Port wine spectronephelometry. Opt Laser

Technol 35:491-496. doi: 10.1016/S0030-3992(03)00067-7

Ough CS (1988) Acids and Amino Acids in Grapes and Wines. Springer Berlin Heidelberg, pp 92-146

P. Ribereau-Gayon, Y. Glories, A. Maujean DD (2006) Handbook of Enology Volume 2 The Chemistry of Wine Stabilization and Treatments 2nd Edition, 2nd edn. John Wiley \& Sons, Ltd

Park S-K (2008) Development of a method to measure hydrogen sulfide in wine fermentation. J Microbiol Biotechnol 18:1550-4.

Pereira V, Câmara JS, Cacho J, Marques JC (2010) HPLC-DAD methodology for the quantification of organic acids, furans and polyphenols by direct injection of wine samples. J Sep Sci 33:NA-NA. doi: 10.1002/jssc.200900784

Plane RA, Mattick LR, Weirs LD (1980) An acicity index for the taste of wines. Am J Enol Vitic 31:265-268.

Pocock KF, Waters EJ (2007) Protein haze in bottled white wines: How well do stability tests and bentonite fining trials predict haze formation during storage and transport? Aust J Grape Wine Res 12:212-220. doi: 10.1111/j.1755-0238.2006.tb00061.x

Pollnitz AP, Pardon KH, Liacopoulos D, et al (1996) The analysis of 2,4,6trichloroanisole and other chloroanisoles in tainted wines and corks. Aust J Grape Wine Res 2:184-190. doi: 10.1111/j.1755-0238.1996.tb00107.x

Pons A, Lavigne V, Eric F, et al (2008) Identification of Volatile Compounds Responsible for Prune Aroma in Prematurely Aged Red Wines. J Agric Food Chem 56:5285-5290. doi: 10.1021/jf073513z

Prajitna A, Dami IE, Steiner TE, et al (2007) Influence of cluster thinning on phenolic composition, resveratrol, and antioxidant capacity in chambourcin wine. Am J Enol Vitic 58:346-350.

Preston LD, Block DE, Heymann H, et al (2008) Defining Vegetal Aromas in Cabernet Sauvignon Using Sensory and Chemical Evaluations.

Ribereau-Gayon P, Dubourdieu D, Doneche B, Lonvaud A (2006) Handbook of Enology Volume 1 The Microbiology of Wine and Vinifications, 2nd edn. John Wiley \& Sons, Ltd

Ribéreau-Gayon P, Glories Y (1986) Phenolics in grapes and wines.

Riu-Aumatell M, Bosch-Fusté J, López-Tamames E, Buxaderas S (2006) Development of volatile compounds of cava (Spanish sparkling wine) during long ageing time in contact with lees. Food Chem 95:237-242. doi: 10.1016/j.foodchem.2005.01.029

Rivero-Pérez MD, Pérez-Magariño S, González-San José ML (2002) Role of melanoidins in sweet wines. Anal Chim Acta 458:169-175. doi: 10.1016/S0003-2670(01)015914

Rocha SM, Coimbra MA, Delgadillo I (2000) Demonstration of pectic polysaccharides in cork cell wall from Quercus suber L. J Agric Food Chem 48:2003-2007. doi: 10.1021/jf991147g

Romano A, Perello MC, Lonvaud-Funel A, et al (2009) Sensory and analytical reevaluation of "Brett character." Food Chem 114:15-19. doi: 10.1016/j.foodchem.2008.09.006

Sacchi KL, Bisson LF, Adams DO (2005) A review of the effect of winemaking 
techniques on phenolic extraction in red wines. Am J Enol Vitic 56:197-206. doi: 10.1002/JSFA. 2740670416

Sadar M (2002) Turbidity Instrumentation - An Overview of Today's Available Technology.

San-Juan F, Ferreira V, Cacho J, Escudero A (2011) Quality and aromatic sensory descriptors (mainly fresh and dry fruit character) of spanish red wines can be predicted from their aroma-active chemical composition. In: Journal of Agricultural and Food Chemistry. pp 7916-7924

Sánchez-Palomo E, Díaz-Maroto MC, Pérez-Coello MS (2005) Rapid determination of volatile compounds in grapes by HS-SPME coupled with GC-MS. Talanta 66:11521157. doi: 10.1016/j.talanta.2005.01.015

Schütz M, Kunkee RE (1977) Formation of Hydrogen Sulfide from Elemental Sulfur During Fermentation by Wine Yeast.

Shimazu Y, Uehara M, Watanabe M (1985) Transformation of Citric Acid to Acetic Acid, Acetoin and Diacetyl by Wine Making Lactic Acid Bacteria. Agric Biol Chem 49:2147-2157. doi: 10.1080/00021369.1985.10867041

Siebert TE, Solomon MR, Pollnitz AP, Jeffery DW (2010a) Selective determination of volatile sulfur compounds in wine by gas chromatography with sulfur chemiluminescence detection. J Agric Food Chem 58:9454-9462. doi: 10.1021/jf102008r

Siebert TE, Solomon MR, Pollnitz AP, Jeffery DW (2010b) Selective determination of volatile sulfur compounds in wine by gas chromatography with sulfur chemiluminescence detection. J Agric Food Chem 58:9454-9462. doi: 10.1021/jf102008r

Sigma A (2017) Solid Phase Micro-extraction ( SPME ) Modern Sample Preparation.

Simpson RF, Miller GC (1984) Aroma composition of Chardonnay wine. Aust Wine Res Inst 23:143-158.

Slegers A, Angers P, Ouellet É, et al (2015) Volatile compounds from grape skin, juice and wine from five interspecific hybrid grape cultivars grown in Qu??bec (Canada) for wine production. Molecules 20:10980-11016. doi:

10.3390/molecules200610980

Soleas GJ, Yan J, Seaver T, Goldberg DM (2002) Method for the gas chromatographic assay with mass selective detection of trichloro compounds in corks and wines applied to elucidate the potential cause of cork taint. J Agric Food Chem 50:10321039. doi: 10.1021/jf011149c

Song H, Lee SY (2006) Production of succinic acid by bacterial fermentation. Enzyme Microb. Technol. 39:352-361.

Sowalsky RA, Noble AC (1998) Comparison of the effects of concentration, $\mathrm{pH}$ and anion species on astringency and sourness of organic acids. Chem Senses 23:343349. doi: 10.1093/chemse/23.3.343

Soyer Y, Koca N, Karadeniz F (2003) Organic acid profile of Turkish white grapes and grape juices. J Food Compos Anal 16:629-636. doi: 10.1016/S08891575(03)00065-6

Spillman PJ, Pollnitz AP, Liacopoulos D, et al (1997) Accumulation of Vanillin during Barrel-Aging of White, Red, and Model Wines. J Agric Food Chem 45:2584-2589. doi: 10.1021/jf970034z 
Suárez-Lepe JA, Morata A (2012) New trends in yeast selection for winemaking. Trends Food Sci Technol 23:39-50. doi: 10.1016/j.tifs.2011.08.005

Subileau M, Schneider R, Salmon JM, Degryse E (2008) New insights on 3mercaptohexanol (3MH) biogenesis in Sauvignon Blanc wines: Cys-3MH and (E)hexen-2-al are not the major precursors. J Agric Food Chem 56:9230-9235. doi: $10.1021 / \mathrm{jf} 801626 \mathrm{f}$

Sussi G, Romano P (1982) Induced changes by SO2 on the population of Saccharomyces as agents of the natural fermentation of musts.

Swiegers JH, Bartowsky EJ, Henschke P a., Pretorius IS (2005) Yeast and bacterial modulation of wine aroma and flavour. Aust J Grape Wine Res 11:139-173. doi: 10.1111/j.1755-0238.2005.tb00285.x

Taylor SL, Higley NA, Bush RK (1986) Sulfites in Foods: Uses, Analytical Methods, Residues, Fate, Exposure Assessment, Metabolism, Toxicity, and Hypersensitivity. pp 1-76

The Australian Wine Research Institute Wine flavour, faults and taints. https://www.awri.com.au/industry_support/winemaking_resources/sensory_assessm ent/recognition-of-wine-faults-and-taints/wine_faults/. Accessed 22 Jul 2017

The Australian Wine Research Institute (2017) Smoke Taint. https://www.awri.com.au/industry_support/winemaking_resources/smoke-taint/. Accessed 24 Jul 2017

The International Organisation of Vine and Wine (2015) OIV - 2015 OIV report on the world vitivinicultural situation. http://www.oiv.int/en/oiv-life/2015-oiv-report-onthe-world-vitivinicultural-situationnbsp. Accessed 8 Oct 2016

Thoukis G, Ueda M, Wright D (1965) The Formation of Succinic Acid during Alcoholic Fermentation.

Ugarte P, Agosin E, Bordeu E, Villalobos JI (2005) Reduction of 4-Ethylpheol and 4Ethylguaiacol Concentration in RedWines Using Reverse Osmosis and Adsorption. Am J Enol Vitic 56:30-36.

Ugliano M, Dieval JB, Siebert TE, et al (2012) Oxygen consumption and development of volatile sulfur compounds during bottle aging of two Shiraz wines. influence of preand postbottling controlled oxygen exposure. J Agric Food Chem 60:8561-8570. doi: $10.1021 / \mathrm{jf} 3014348$

Ugliano M, Henschke PA (2010) Comparison of three methods for accurate quantification of hydrogen sulfide during fermentation. Anal Chim Acta 660:87-91. doi: 10.1016/j.aca.2009.09.049

University of Waterloo (2017) SPME. In: Pawliszyn Res. Gr. https://uwaterloo.ca/pawliszyn-group/research/spme. Accessed 1 Jan 2017

Vannier A, Brun OX, Feinberg MH (1999) Application of Sensory Analysis to Champagne Wine Characterisation and Discrimination. Food Qual Prefer 10:101107. doi: 10.1016/S0950-3293(98)00047-0

Vasserot Y, Pitois C, Jeandet P (2001) Protective effect of a composite cork stopper on champagne wine pollution with 2,4,6-trichloroanisole. Am J Enol Vitic 52:280-281.

Volschenk H, Van Vuuren HJJ (2006) Malic Acid in Wine : Origin, Function and Metabolism during Vinification. S Afr J Enol Vitic 27:123-136.

Waterhouse AL (2015a) Volatile Acidity. http://waterhouse.ucdavis.edu/whats-inwine/volatile-acidity. Accessed 10 Jul 2017 
Waterhouse AL (2015b) Volatile Phenols. In: Waterhouse Lab. http://waterhouse.ucdavis.edu/whats-in-wine/volatile-phenols. Accessed 11 Jul 2017

Waters EJ, Wallace W, T ME, Williams PJ (1993) Isolation and Partial Characterization of a Natural Haze Protective Factor from Wine. Food Chem 41:724-730. doi: 10.1021/jf00029a009

Wedral D, Shewfelt R, Frank J (2010) The challenge of Brettanomyces in wine. LWT Food Sci Technol 43:1474-1479. doi: 10.1016/j.lwt.2010.06.010

Wine Institute (2017) Trichloroanisole (TCA) Fact Sheet - The Wine Institute. https://www.wineinstitute.org/initiatives/issuesandpolicy/tca. Accessed 14 Jul 2017

Wine Institute Statistics - The Wine Institute. http://www.wineinstitute.org/resources/statistics. Accessed 10 Oct 2016

Wines M (2014a) Missouri Grape Facts.

Wines M (2014b) Missouri Grape \& Wine Industry Fact Sheet.

Wu BH, Liu HF, Guan L, et al (2011) Carbohydrate metabolism in grape cultivars that differ in sucrose accumulation. Vitis - J Grapevine Res 50:51-57.

Yang X, Peppard T (1994) Solid-Phase Microextraction for Flavor Analysis. J Agric Food Chem 42:1925-1930. doi: 10.1021/jf00045a018

Zalacain A, Alonso GL, Lorenzo C, et al (2004) Stir bar sorptive extraction for the analysis of wine cork taint. J Chromatogr A 1033:173-178. doi: 10.1016/j.chroma.2003.12.059

Zhang Z, Yang MJ, Pawliszyn J (1994) Solid-phase Microextraction: Solid-phase microextraction integrates sampling, extraction, concentration, and sample introduction into a single step. Anal Chem 66:844A-853A.

Zotou A, Loukou Z, Karava O (2004) Method Development for the Determination of Seven Organic Acids in Wines by Reversed-Phase High Performance Liquid Chromatography. Chromatographia 60:39-44. doi: 10.1365/s10337-004-0330-9 


\section{CHAPTER 2 - WINE FAULTS AND RISK FACTORS CHEMISRY IN MISSOURI WINES}

\section{Introduction}

In wine making, one of the most crucial considerations for quality is the presence or absence of faults. Fundamentally, a quality wine is fault free. Beyond the many factors that need to come into balance to make a great wine, what constitutes a great wine is also more about personal preference than what makes a bad wine. Numerous faults have been identified in wine, chemical or physical characteristics that if recognized in a wine most people would find a wine to be of poor quality. In some cases, such as with Brettanomyces $s p$., low but recognizable levels may not be enough to make a wine faulted, but higher levels will make a wine unenjoyable or undrinkable. While many contributing factors to fault development have been studied in lab settings little work has been done to prove that lab observation relate to what is observed in commercial wines. Many wine faults are also potentially related in such complex ways that limiting our understanding to what experiments can be conducted in a controlled laboratory setting may overlook some of the important variables between commercially produced wines.

For all the potential economic impact of wine faults, they are left relatively unstudied "in the wild." In a 1996 survey of Australian wine approximately $4.8 \%$ of wines were considered faulted by at least $20 \%$ of the participants in a wine assessment course (Pollnitz et al. 1996). This has the potential to turn a large number of potential consumers to other products that may have a lower incidence of problems. However, in comparison to the other aspects of wine and consumer perception our understanding of the incidence of faults 
is much less then something like consumer preference in wine style, or buying habits which are exhaustively monitored at local through international levels.

Wine faults can generally be divided into several different subcategories. There are those that are purely chemically derived, such as potassium bitartrate instability as well as those that are microbially derived such as the aromas associated with Brettanomyces $s p$. infection. Both of those two categories can be further divided into faults that are physical in nature such as hazes and sediments, or those that are causing a fault due to their chemistry such as unwanted aroma compounds or unwanted changes in wine organic acid content. The type and origin of a fault often dictate what can be done to inhibit its formation, or if there are options for removing it, assuming the wine has not already been bottled.

Wine hazes and sediments can originate from a number of factors including microbial contamination, poor solubility of polysaccharides or acid salts, denatured proteins or other factors. In most cases, wineries take several steps to stabilize a wine prior to bottling to ensure that both a wine does not go into the bottle with a haze or sediment problem and that it is stable in the bottle. Filtration, fining and cold stabilization are all used as ways to remove problems and preventing them from appearing in bottle. Additionally haze and sediment issues can happen when microbial growth initiates in bottle. With a properly sterilized bottling line and sterile filtered wine the risk of microbial growth should be minimal but some small producers may be using systems that do not allow for complete sterility. In these cases, it is likely that they rely on the antimicrobial activity of sulfur dioxide and some use sorbic acid to inhibit yeast growth. Many of the measures, however, have some risk of failure. For instance if a wine is not made heat stable, a winemaker 
decides between the trade-offs of greater heat stability, or the potentially deleterious impacts of bentonite fining (Hsu et al. 1987; Pocock and Waters 2007). If a wine will never exceed a cellar temperature of around $15^{\circ} \mathrm{C}$ no fining may be needed, whereas if there is risk that many consumers will leave a wine in a $35^{\circ} \mathrm{C}$ car considerable fining may be needed to avoid consumer rejection. In many cases, once a wine is bottled a winemaker has little information on how that wine was treated through transport, storage and sale, forcing them to guess at the appropriate preventative measure to take.

A wide range of undesirable aromas can also cause faulted wines. Some, such as acetic acid or Brettanomyces sp. derived aromas, are considered tolerable, or even beneficial to wine aroma at low levels. Others, such as mouse taint (2-acetyl-3,4,5,6-tetrahydropyridine and others), geranium taint (2-ethoxyhexa-3,5-diene) or many sulfur off aromas (methanethiol, dimethyl sulfide and others), will result in a wine being undrinkable once they exceed their recognition threshold, and may lower quality even below that concentration. There are a number of risk factors known for all of the faults, for instance in general those faults that are microbially derived are generally believed to be more likely at higher $\mathrm{pH}$. Many of the microbes such as Lactobacillus sp. and Brettanomyces sp. that can cause the off aromas are both inhibited by low wine $\mathrm{pH}$, as well as are sensitive to $\mathrm{SO}_{2}$ which is more microbially active at low pH (Davis et al. 1986; Butzke 2010). Other off aromas may be more likely to exist depending on the redox potential of a wine, with $\mathrm{H}_{2} \mathrm{~S}$ both being created and retained from a number of different mechanisms in a reductive environment and acetaldehyde being a problem in more oxidized wine (Fang and Qian 2005; Oliveira et al. 2011). 
The difficulty of measuring wine faults, either analytically or sensorially, has been a limiting factor in understanding their prevalence and risk factors in commercial wines. Many of the faults can have an impact on a wine below their recognition threshold, making it impossible even for a trained panelist to identify a fault at a concentration that by definition is below the concentration they can recognize it. It is also common that when a wine has one fault, it may in fact have several off-aromas above threshold, leading to conflicting observations as to what is wrong with the wine. Analytically it can be very challenging to quantify these compounds given both their odor activity at extremely low concentrations, below $1 \mathrm{ng} / \mathrm{L}$ in some cases. Additionally, compounds like $\mathrm{H}_{2} \mathrm{~S}$ are also incredibly reactive, existing in a relatively stable state in the reductive environment of a wine bottle, but are instantly oxidized when coming in contact with air.

Despite those challenges, methods have been developed to quantify the compounds responsible for off-aromas. Most rely on separation by gas chromatography with some preconcentration and an isolation step. The preparation step, depending on the compound, may be done through liquid extraction, solid phase extraction, headspace trapping, or solid phase microextraction. For most compounds, mass-spectrometry is used for detection, however in some cases those compounds that are at incredibly low concentrations and are not just hydrocarbons, can be better detected using an elemental selective detector (De Fátima Alpendurada 2000; Soleas et al. 2002). All of the methods described, however, have the limiting factor of requiring expensive and complicated equipment. In previous years there have been efforts made to develop methods that can be carried out with labs with limited resources, including small winery labs. Enzymatic methods for many trace compounds of interest now exist, including acetaldehyde or diacetyl. Compound selective 
methods are also being borrowed from other industries to use existing detectors, such as gas detection tubes, to quantify compounds of interest in wine (Ebeler 2007; Kwasniewski et al. 2011).

Ultimately, one of the most critical aspects to ensuring a given region or the wine industry is considered to be creating high quality products, is to minimize any products reaching consumers that are bad. Unfortunately, little information is known about how often bad wines are produced and sold, or what of the theoretical risk factors has actually contributed to bad wines being produced. With knowledge of what faults exist in the wines that get to consumers it is possible for the industry to focus on what steps they should focus on to eliminate their problems.

\section{Materials and Methods}

\subsection{Sampling}

To evaluate the incidence of wine faults and their relationship to known risk factors, 100 wines produced by Missouri-owned wineries and sold in Missouri were randomly selected from 125 wineries and the approximately 2500 wines available for sale in 20152016. Wines were either donated or purchased through tasting rooms or retail stores. The "Randbetween" function in Excel was used to randomly select wineries; if, when wineries were selected multiple times, those selections remained in the population. The same process was used for randomly selected wines, but any duplicate wines were removed from the population and a new wine was selected. Summarily, repetition among wineries was allowed, whereas repetition among wines was not. Only grape wines and flavored grape wines were considered and no distinction between varietal, sugar content, vintage, or wine 
style was imposed. Wines were kept at $65^{\circ} \mathrm{F}$ until the sampling process was completed and the analyses started.

\subsection{General and Visual Assessment}

Once collected, wines were categorized according to their style in red, white, rosé and specialty/dessert, followed by their sweetness scale when the information was available.

Prior to basic wine chemistry and volatile compound analyses, wine bottles were submitted to visual inspection. During this checkup, the following features were noted: type and condition of closure, neck volume, presence/absence of sediments, particles in suspension, haze, tartrates, apparent turbidity and any other visual abnormalities were registered, vintage, varietal, and type of blend when available. Finally, an informal sensory analysis was conducted to act as a check on analytical methods, either to confirm analytical findings, or, if some clear fault was missed to allow the re-evaluation of analytical methods. Panelists where trained with authentic standards of wine faults and rated wines for these faults on a 5-point hedonic scale.

\subsection{Chemical Analyses}

\subsubsection{Hydrogen Sulfide $-\mathrm{H}_{2} \mathrm{~S}$}

Hydrogen sulfide measurement was performed according to Kwasniewski et al. 2011. A sample of $40 \mathrm{~mL}$ of wine was poured into a $120 \mathrm{~mL}$ glass screw-top flask. One tablet of Alka-Seltzer was added to the wine for $\mathrm{CO}_{2}$ generation, and consequential aid in $\mathrm{H}_{2} \mathrm{~S}$ release. The flask was immediately closed. Once a reduction in effervescence was 
observed, a second tablet was quickly added to the wine. Any $\mathrm{H}_{2} \mathrm{~S}$ released passed through a silicone tubing connected to the flask and detected by Gastec no. 4LT colorimetric $\mathrm{H}_{2} \mathrm{~S}$ detection tubes. The detection tube turns pink if $\mathrm{H}_{2} \mathrm{~S}$ is present. The stack height of the pink pigment was measured in millimeters and used as a variable in the linear equation proposed in the method.

\subsubsection{Sulfur dioxide}

The quantification of free, bound and total $\mathrm{SO}_{2}$ was performed with analytical replicates via aeration-oxidation method describe by Iland et al. 2013 .

\subsubsection{Turbidity and residual sugar}

Turbidity (in Formazine Turbidity Unit, FTU, equivalent to Nephelometric Turbidity Unit, NTU) was quantified via a turbidity meter (HANNA Instruments 93703 Microprocessor, Woonsocket, R.I.). All wine samples were tested in duplicates. Residual sugar was determined by Clinitest tablets which have a limit of detection of $0.025 \mathrm{~g} / \mathrm{L}$ glucose (Bayer Corporation, West Haven, CT).

\subsection{4. pH and Titratable Acidity}

Using an auto-titrator (Model G20, Mettler Toledo, Greifensee, Switzerland), the titratable acidity (TA) in $\mathrm{g} / \mathrm{L}$ tartaric acid was measured with duplicate analytical replicates. A $2 \mathrm{~mL}$ wine sample was diluted in $48 \mathrm{~mL}$ of deionized and degassed water and titrated with a $0.1 \mathrm{~N} \mathrm{NaOH}$ solution to an endpoint of $\mathrm{pH} 8.2 \mathrm{pH}$ measurements were taken with Thermo Scientific Orion 5-Star, Waltham, Mass. pH meter.

\subsubsection{Organic Acids}

For the organic acids analysis, red, specialty, and rosé wines were previously prepared as follows: $5 \mathrm{~mL}$ of wine sample were mixed with PVPP 
(Polyvinylpolypyrrolidone) for color removal until homogeneous. The mixture was transferred to three bullet tubes, and the tubes centrifuged at 18,407 G-force (Model 5424, Eppendorf, Hamburg, Germany; Zotou et al. 2004) for 5 minutes. The supernatant was filtered and transferred to secondary bullet tubes, then finally filtered again $(0.22 \mu \mathrm{m}$ pore size filters) into HPLC vials. White wines were straight filtered ( $0.22 \mu \mathrm{m}$ pore size filters) into HPLC vials, since the clarification step is not needed. Wine samples were run in triplicates, with each triplicate injected twice. Sample injection volume was $10 \mu \mathrm{L}$.

The separation and quantitative analyses of tartaric, malic, lactic, citric, succinic, and acetic acids were performed with High-Performance Liquid Chromatography (VARIAN, Inc. ProStar, Palo Alto, CA) with a 410 Autosampler, 210 pump with in-line degasser, $335 \mathrm{LC}$ dual path diode array UV-Visible detector, and attached to two Agilent Zorbax SB-Aq columns connected in series (first column 4.6x250mm and second column $4.6 \times 150 \mathrm{~mm}$, both with $5 \mu \mathrm{m}$ pore size) operating at $35^{\circ} \mathrm{C}$. The HPLC was managed by Galaxie chromatography software (Version 1.9.302.530, Agilent Technologies, Santa Clara, CA). For the mobile phase, $20 \mathrm{mM}$ of $\mathrm{NaH}_{2} \mathrm{PO}_{4}$ (Sodium Phosphate Dibasic) solution was prepared and brought to $\mathrm{pH} 2.0$ via titration with $\mathrm{H}_{3} \mathrm{PO}_{4}$ (Phosphoric Acid). The solution was then mixed with LCMS grade Acetonitrile in a 99:1 ratio.

The flow rate was $1 \mathrm{~mL} / \mathrm{min}$, and run time 12 minutes. UV-Visible light at $210 \mathrm{~nm}$ was used as the detector.

Acids were identified by reference standard from Sigma Aldrich, and quantified via a 5-point calibration curve (peak area mAU.min vs concentration $\mathrm{g} / \mathrm{L}$ ) ranging from 0.25 $\mathrm{g} / \mathrm{L}$ to $10 \mathrm{~g} / \mathrm{L}$. Acid concentration in $\mathrm{g} / \mathrm{L}$ was determined by inserting the peak area (mAU.min) into the calibration curve. 


\subsubsection{Volatile Aromas Analysis}

Volatile aroma analysis was performed according to Hampel et al. 2014. Wine samples were tested for High Molecular Weight (HMW) and Low Molecular Weight (LMW) both in duplicate analytical replicates.

\section{HMW (High Molecular Weight) HS-SPME-GC-MS analysis}

For the extraction of volatile compounds of HMW 10mm SPME fibers, 24 gauge, coated with Polydimethylsiloxane-divinylbenzene-carboxen (PDMS/DVB $65 \mu \mathrm{m}$; Supelco) were used. Fibers were conditioned prior to use according to the manufacturer's recommendations. Various $20 \mathrm{~mL}$ sample vials were labeled, and pre-weighted portions of $1.9 \mathrm{~g}$ each of $\mathrm{NaCl}$ were added to them to enhance SPME adsorption. Next, $5 \mathrm{~mL}$ of wine sample were pipetted into designated and tared vials. Wine weights were recorded. A series of three Internal Standards was added to the wine samples (3-octanone 0.15ppm, 2-octanol 0.01ppm, and 4-methyl-2-pentanol 1ppm), and the final weight was recorded. Samples were pre-incubated for 15 minutes at $45^{\circ} \mathrm{C}$. SPME fiber was exposed in the headspace above the salt/wine/IS solution for $45 \mathrm{~min}$ at $45^{\circ} \mathrm{C}$ prior to GC-MS analysis, with constant agitation during the extraction.

\section{GC-MS analysis}

GC-MS analysis of HMW and LMW compounds was carried out on an Agilent 7890B gas chromatograph (Santa Clara, CA, USA) coupled with a PAL autosampler (Varian) and an Agilent 5977A mass selective detector (MSD). SPME fiber desorption in the inlet was carried at $250^{\circ} \mathrm{C}$ for $2 \mathrm{~min}$ in splitless mode (inlet glass liner/SPME direct, $0.75 \mathrm{~mm}$ I.D., Supelco). After that, the split flow was turned on at $50 \mathrm{~mL}$ for the rest of the run. The SPME fiber was conditioned for $14.7 \mathrm{~min}$ in the inlet in between runs. Helium as 
the carrier gas (flow rate: $1.2 \mathrm{~mL} / \mathrm{min}$ ) and a DB-Wax column (30 $\mathrm{m} \times 0.25 \mathrm{~mm}$ I.D., $0.25 \mu \mathrm{m}$ film thickness were used for all runs. Oven temperatures for the GC was set as follows: initial temperature was $40^{\circ} \mathrm{C}$ for $1.0 \mathrm{~min}$, then was increased to $200^{\circ} \mathrm{C}$ at $5^{\circ} \mathrm{C} / \mathrm{min}$, followed by a second increase at $12^{\circ} \mathrm{C} / \mathrm{min}$ to the final temperature of $240^{\circ} \mathrm{C}$. The final temperature was held for $10 \mathrm{~min}$. The mass selective detector was operated in SIM/Scan mode $(121 \mathrm{~m} / \mathrm{z} ; 190 \mathrm{~m} / \mathrm{z}$, range $40-250 \mathrm{~m} / \mathrm{z} ; 6.4 \mathrm{scans} / \mathrm{s})$, and the MS transfer line was maintained at $240^{\circ} \mathrm{C}$.

\subsection{Statistical Analysis and Data Treatment}

All chemical data was statistically analyzed to determine correlations, interactions and significance between parameters. Significance p-values were obtained by 1-way ANOVAs and 1-way MANOVAs using XLSTAT (Addinsoft, Ver. 2017.02.43674) in Excel (Microsoft Office Home and Student 2013) that were run on all parameters measured using wine type, residual sugar, fill volume, closure type, occurrence of Brett aromas, and occurrence of malolactic fermentation as possible sources of variance in the data. Welch Statistic was employed given the differences in population sizes. Significant variances were determined using Tukey's HSD for p-value $<0.05$.

Microsoft Excel (Microsoft Office Home and Student 2013) was used for basic statistical analyses including means, standard deviations, linear regressions, basic graphs and tables. 


\section{Results}

\subsection{Overview and Overall Fault Incidence and Categorical Data}

The incidence of wine faults were surveyed in Missouri wines by collecting 100 wines produced by Missouri producers. To be included, a wine must have been produced by a winery bonded in Missouri, though no effort was made to control for fruit, juice or wine being imported by that winery to the state. Wines also need to be grape based and for sale in the 2015-2016 sampling period, either through a tasting room or a $3^{\text {rd }}$ party seller such as a liquor store. During this period, there were 125 wineries in the state, with approximately 2500 different wines for sale, for a mean of 20 different wines on sale per winery. If on sale, concurrently multiple vintages of the same wine would be considered different wines. As no frequently updated master list of all 2500 wines on sale exists, but currently bonded and active wineries are public information, random choice of wine was made by winery, followed by wines they currently had for sale. For example, for wine 1, a random winery out of the 125 was selected, then a list generated of their current offerings, and a wine was randomly selected out of however many wines they were currently selling, that winery was replaced into the pool of potential wineries, but that specific wine was not.

Ultimately, this sampling methodology means that, each winery, regardless of size, market share or number of wines produced were equally able to influence results. Thus, smaller wineries had greater influence on results than they would have if adjusted by market share.

Out of the 100 sampled wines, 46 were white, 40 red, 9 where rosé, and five were specialty wines (e.g. Port style, or Dessert wines) ( 
Table 1). Given sample size and mean, the margin of error for all categorical variables was calculated and included in 


\section{Table 1.}

According to their labeling, 52 of the wines were labeled as interspecific-hybrid varietals, 7 were vinifera varietals, 7 were blends of some sort and 34 wines used only a proprietary name which did not clearly designate what grape varieties contributed to the wine.

An assortment of different closure types were found in the sampling. This included cork-based closures (i.e. natural cork, and technical corks made from agglomerated cork) and closure made from synthetic material (i.e. synthetic "corks", Stelvin ${ }^{\circledR}$ closures and Zork® closures). The natural cork constituted the largest portion of the sample with 30, Twin-top® a proprietary product made from agglomerated cork with intact cork disks at the end had 23 represented in the sample. The other closures found in order of incidence were synthetic with 17, Stelvin ${ }^{\circledR}$ 14, agglomerated 13, Zork® 2 and 1 T-cork closure. In total 67 of the closures where cork based.

An assortment of vintages were included in the sample, though all wines were purchased between 2015 and 2016. Of the 100 wines sampled, 77 had no vintage information available; of the remaining 23, 1 was from 2002, 1 from 2007, 2 from 2008, 2 from 2010, 1 from 2011, 6 from 2012, 2 from 2013, and 8 were from 2014.

The wines collected went under a battery of tests for selected wine faults, flaws and known risk factors for problem development. The physical assessments included in this study where visual faults such as haze, sediment, excess turbidity and fill height from top of the bottle. Volatile compounds related to Brettanomyces sp. infection and cork taint were quantified as well as the undesirable aromas compounds $\mathrm{H}_{2} \mathrm{~S}$ and 1-octen-3-ol, and acetic acid. Additional risk factors for fault development such as low free $\mathrm{SO}_{2}$, high $\mathrm{pH}$ (above 
$\mathrm{pH}$ 3.7) and residual sugar were also assessed. General statistical measurements with means, standard deviations, p-values and errors can be found on

Table 2.

Overall, of the 100 wines analyzed, 20 wines were free of any potential flaw indicator and 80 wines had at least one fault (Supplemental Table J). On average, a single wine had $1.25 \pm 0.9$ faults, and no more than four faults were found in one wine sample. In terms of risk factors, 84 wines had at least one, while 16 wines were not associated with any risk factors. On average, a single wine was associated with $1.31 \pm 0.9$ risk factors. Out of the 20 fault free wines, 18 were at risk of being faulted, being associated with at least one risk factor. Out of the 80 faulted wines, 65 had at least one risk factor, 15 were not associated with any risk factor, and none was tested positive for more than three risk factors. Since an association with risk factors does not explain 15 faulted wines, further investigation is needed in regards to fault development in these cases. Supplemental Tables $\mathrm{J}$ and $\mathrm{K}$ contain detailed information on incidence of faults and risk factors. More in-depth findings for the various faults and risk factors are included below.

\subsection{Wine TA and Organic Acid Content}

A great range of wine $\mathrm{pH}$ was observed in the sample ranging from a low of $\mathrm{pH} 2.97$ to a high of $\mathrm{pH} 4.11$ with a mean of $\mathrm{pH} 3.54 \pm 0.25$ (Table 5). While an ANOVA indicated a significant impact of $\mathrm{pH}$ by wine style $(\mathrm{p}=0.002)$, no significant separation of means was

found by Tukey HSD. Wines with a $\mathrm{pH}>3.7$ were considered at risk of being faulted, and $31 \%$ fit the criteria. Titratable acidity ranged from $4.52-12.32 \mathrm{~g} / \mathrm{L}$ as tartaric, with a mean 
of $7.57 \mathrm{~g} / \mathrm{L} \pm 1.7$. No significant differences were found between styles. In order to be considered faulted, a wine had to present tartaric acid $>10 \mathrm{~g} / \mathrm{L}$.

The organic acids were analyzed by HPLC, with tartaric, malic, lactic, acetic, citric and succinic present at detectable levels (above $0.1 \mathrm{~g} / \mathrm{L}$ ) in at least some of the wines (Table 3). Tartaric acid ranged from $0.48-9.04 \mathrm{~g} / \mathrm{L}$ with a mean of $2.32 \mathrm{~g} / \mathrm{L} \pm 1.37$. Rosé wines had significantly higher levels of tartaric compared to other styles (Figure 2). Malic acid content ranged from not detectable (below $0.1 \mathrm{~g} / \mathrm{L}$ ) to $9.64 \mathrm{~g} / \mathrm{L}$ with a mean of 2.04 $\mathrm{g} / \mathrm{L} \pm 2.08$. Red wines had a significantly lower amount of malic acid then white or rosé wines (Table 3 and Figure 5). Lactic acid ranged from not detectable (below $0.1 \mathrm{~g} / \mathrm{L}$ ) to $11.70 \mathrm{~g} / \mathrm{L}$ with a mean of $1.80 \mathrm{~g} / \mathrm{L} \pm 2.16$. No significant differences were found between different wine styles. Citric acid ranged from not detectable (below 0.1g/L) to $5.05 \mathrm{~g} / \mathrm{L}$ with a mean of $0.36 \mathrm{~g} / \mathrm{L} \pm 0.64$ and no significant differences between styles. Succinic acid ranged from not detectable (below $0.1 \mathrm{~g} / \mathrm{L}$ ) to $3.65 \mathrm{~g} / \mathrm{L}$ with a mean of $0.76 \mathrm{~g} / \mathrm{L} \pm 0.66$ and no significant differences between styles. Acetic acid ranged from not detectable (below $0.1 \mathrm{~g} / \mathrm{L}$ ) to $5.09 \mathrm{~g} / \mathrm{L}$ with a mean of $0.87 \mathrm{~g} / \mathrm{L} \pm 1.23$ and no significant differences between styles. Figure 4 shows the distribution of the concentration of tartaric, malic, lactic and citric acids for all wine samples.

In addition to contributing to the acid profile of a wine, acetic can also be considered a fault both because of its pungent vinegar like aroma and because there are legal regulations for how much is allowed in a wine. With 47 wines above $0.8 \mathrm{~g} / \mathrm{L}$, which could be considered faulted, we found $47 \%$ incidence of wines above the sensory threshold. Acetic acid was found above the legal threshold of $1.4 \mathrm{~g} / \mathrm{L}$ in $18 \%$ of the wines $( \pm 7.5 \%$ 
margin of error), and above the sensory threshold of $0.2 \mathrm{~g} / \mathrm{L}$ in $72 \%$ of the wines $( \pm 8.8 \%$ margin of error).

The incidence of malolactic fermentation (MLF) was measured by the presence of lactic acid above $0.03 \mathrm{~g} / \mathrm{L} ; 65 \%$ ( $\pm 9.3 \%$ margin of error) of the wines were considered to have gone through MLF (29 red wines, 27 white wines, 5 rosé wines, and 4 specialty wines). Conversely, out of the $35 \%( \pm 9.3 \%$ margin of error $)$ of wine samples that seemingly did not go through MLF, 11 were red, 19 white, 4 rosé, and one was specialty.

\subsection{Hazes and other Visual Faults}

Sediment and hazes where noted by visual inspection of the wine prior to opening. Additionally, turbidity was measured and compared to haze by visual inspection with haze free wine ranging from 0-10 NTUs for red, rosé and specialty wines, and 0-5 NTUs for white wines, and wine with hazes ranging from 10-40, and 5-40 NTUs, respectively. A wide range of turbidity values was observed during analyses (0-39.25 NTU). At 5\% level of significance, there was no significant differences in turbidity for red and specialty wines. The same was valid for white and rosé wines. Thus, specialty wines differed significantly from white and rosé wines (Supplemental Figure C). Similarly, no significant differences in haze were found for different wines at $5 \%$ level of significance.

A wide range of residual sugars was observed $(0-50 \mathrm{~g} / \mathrm{L})$. White wines range from 0-50 g/L, red 2.5-50 g/L, rosé 10-50 g/L and specialty wines 30-50 g/L. At 5\% level of significance, there was no significant differences in residual sugar for red and white wines. The same was observed for rosé and specialty, thus the former two differed significantly from the latter two wines (Supplemental Figure A). 


\subsection{Aroma Related Faults}

Trace volatile aromas such as cork taint was found in only $3 \%( \pm 3.3 \%$ margin of error) of the wines, while Brett aromas were absent at fault threshold concentrations. For sensory thresholds, Brett was observed in 4 wines (1 white wine with 4-EG, 1 red wine with 4-EP and 2 white wines with 4-VP). No significant differences were found in different wines for 4-Ethylguaiacol (4-EG) and 4-Ethylphenol (4-EP). However, a wide concentration range of 2.26 - 150.11 and 5.12 - $376.72 \mathrm{ppb}$, respectively, was observed. The guaiacol content of specialty, red and rosé wines were determined to be significantly different, while no differences were observed between rosé and white wines. For 4vinylphenol, white and red wines were determined to be significantly different, whereas no differences were noted between any other wine style. The concentration of $\beta$-damascenone was determined to be significantly different among rosé and specialty wines, however no differences were observed between other wine styles (Table 4).

For the volatile sulfur aroma hydrogen sulfide $\left(\mathrm{H}_{2} \mathrm{~S}\right)$ a fault recognition threshold of $10 \mathrm{ppb}$ was established according to (Kwasniewski et al. 2011); 23\% ( $\pm 8.4 \%$ margin of error) of the sample was found above this threshold; similarly, a detection limit of $1.25 \mathrm{ppb}$ $\mathrm{H}_{2} \mathrm{~S}$ was established with $63 \%$ ( $\pm 9.5 \%$ margin of error) of the wines above it (Table 4$)$.

\subsection{Residual Sugar, $\mathrm{SO}_{2}$ content and Other Risk Factors}

The incidence of residual sugars was measured by the presence of reducing sugars. At 5\% level of significance, there was no significant differences in residual sugar for rosé and specialty wines. The same was valid for white and red wines. Thus, rosé and specialty wines differed significantly from white and reds (Supplemental Table A). 
Components legally regulated, such as sulfur dioxide, were at fault for $84 \%$ of the wines, since they did not meet the free $\mathrm{SO}_{2}$ requirement of $0.8 \mathrm{ppm}$ based upon $\mathrm{pH}$. All wines were compliant with U.S. regulations for total $\mathrm{SO}_{2}$ addition, meaning no wines had $>350 \mathrm{mg} / \mathrm{L}$ of total $\mathrm{SO}_{2}$, however, if E.U. regulations were considered, $6 \%$ of the wines would have exceeded the limit, and $3 \%$ would be at the legal limit.

Significant differences in Free $\mathrm{SO}_{2}$ were observed for different wine styles at $5 \%$ level of significance. Running Tukey HSD test, we found that rosé and specialty wines were significantly different from each other in Free $\mathrm{SO}_{2}$, whereas no difference was observed in Free $\mathrm{SO}_{2}$ in white and red wines. Similarly, significant differences in Total $\mathrm{SO}_{2}$ were found in different wines at $5 \%$ level of significance. The Tukey HSD test showed that white wines were significantly different in Total $\mathrm{SO}_{2}$ from red and specialty wines, whereas no difference was observed in Total $\mathrm{SO}_{2}$ in rosé and other wine styles (Figure 6).

\section{Overall Fault Incidence and Categorical Data}

When it comes to comprehensive comparison analyses of wine faults, risk factors and their complex relationship, a limited number of publications can be found. For all the potential economic impact of wine faults, they are left relatively unstudied. Many precursor factors to fault development have been individually studied. Because they are usually performed in lab settings and most disregard interactions with other risk factors and faults, there is still a gap between lab observations and what actually happens in commercial wineries.

In this study, categories with different population sizes (n) were analyzed. It is worth mentioning that we were aware of the loss of power that comes from using categories with 
different $n$, especially when some are so low, such as rosé $(n=9)$ and specialty wines $(n=$ 5). However, oversampling with the intention of building same size populations for all wine categories was not the aim of this thesis. We instead acknowledged that the risk of rejecting $\mu_{0}$ when it was true would be compensated by low p-values.

\subsection{Wine TA and Organic Acid Content}

Tartaric and malic acids are the most abundant organic acids found in grapes; they account for more than $90 \%$ of grape acid content. Tartaric acid is usually present in grapes at average concentrations of 5 to $10 \mathrm{~g} / \mathrm{L}$, while mature grapes contain between 2 and 6.5 g/L malic acid (Volschenk and Van Vuuren 2006). In this study, tartaric acid concentration ranged from $0.48-9.04 \mathrm{~g} / \mathrm{L}$ with a mean of $2.32 \mathrm{~g} / \mathrm{L} \pm 1.37$, showing large variation from literature ranges. The low end of this range could be explained by the removal of tartaric acid during vinification, either intentionally through deacidification or through microbial degradation, which would be rare, given that only a few microbes are capable of such metabolization. The high end, on the other hand, could be explained by the addition of large amounts of tartrates, potentially for the correction of high $\mathrm{pH}$ and/or low TA, even for cultivars inherently high in acid, such as Frontenac (Slegers et al. 2015). It is worth it to mention that our sample contained one Frontenac wine with tartaric acid concentration of $1.5 \mathrm{~g} / \mathrm{L}$. Malic acid ranged from not detectable (below $0.1 \mathrm{~g} / \mathrm{L}$ ) to $9.64 \mathrm{~g} / \mathrm{L}$ with a mean of $2.04 \mathrm{~g} / \mathrm{L} \pm 2.08$. It is known that high concentrations of malic acid could be explained by grapes harvested during cold summers in cool-climate regions, however, the state of Missouri does not fit in this category. It is a common practice for winemakers to purchase grapes or grape juice from elsewhere, which was validated during the sampling phase of 
this study, and could explain the high concentration of malic acid $(>6.5 \mathrm{~g} / \mathrm{L})$ in $6 \%$ of the sample.

In general, levels of titratable acidity (TA, as tartaric acid) below 10g/L were considered acceptable. Only $9 \%$ of the wines were above this level. While tartaric acid ranged from $0.48-9.04 \mathrm{~g} / \mathrm{L}$ with a mean of $2.32 \mathrm{~g} / \mathrm{L} \pm 1.37$, TA varied from $4.52-12.32 \mathrm{~g} / \mathrm{L}$ with a mean of $7.57 \pm 1.7$. The relationship of TA to tartaric acid was investigated; a linear regression showed that only $23 \%$ of the variability in TA is explained by tartaric acid at $5 \%$ level of significance.

Lactic acid ranged from not detectable (below $0.1 \mathrm{~g} / \mathrm{L}$ ) to $11.70 \mathrm{~g} / \mathrm{L}$ with a mean of $1.80 \mathrm{~g} / \mathrm{L} \pm 2.1$. Unless winemakers were starting with grapes excessively high in malic acid, so sourcing raw material from out of state, these numbers could be explained by two odd alternatives: the addition of malic acid to an already high acid wine, or the addition of lactic acid.

Citric acid ranged from not detectable (below $0.1 \mathrm{~g} / \mathrm{L}$ ) to $5.05 \mathrm{~g} / \mathrm{L}$ with a mean of $0.36 \mathrm{~g} / \mathrm{L} \pm 0.64$ and no significant differences between styles. Usually, grapes are low in citric acid. Some hybrids can have $1 \mathrm{~g} / \mathrm{L}$ (Boulton 1980), however, no grapes produce $5 \mathrm{~g} / \mathrm{L}$, meaning that it must have been added. It makes sense to add citric acid rather than tartaric acid to wines in need of acidification, such as high in $\mathrm{pH}$, and/or wines at risk of tartrate instability. The problem with this practice is that citric acid is susceptible to microbial degradation by lactic acid bacteria, and if malolactic fermentation starts, that can lead to unwanted high concentrations of diacetyl (Miller 2013).

Succinic acid ranged from not detectable (below $0.1 \mathrm{~g} / \mathrm{L}$ ) to $3.65 \mathrm{~g} / \mathrm{L}$ with a mean of $0.76 \mathrm{~g} / \mathrm{L} \pm 0.66$ and no significant differences between styles. Concentrations of $3.0 \mathrm{~g} / \mathrm{L}$ 
succinic acid have been reported (Swiegers et al. 2005). However, the $3.65 \mathrm{~g} / \mathrm{L}$ found in this study is unusually high for this salty/bitter taste acid, and could be traced back to high oxidation and microbial infection.

The incidence of malolactic fermentation (MLF) was measured by the presence of lactic acid above $0.03 \mathrm{~g} / \mathrm{L} .65 \%( \pm 9.3 \%$ margin of error $)$ of the wines were considered to have gone through MLF (29 red wines, 27 white wines, 5 rosé wines, and 4 specialty wines). Conversely, out of the $35 \%$ ( $\pm 9.3 \%$ margin of error) of wine samples that seemingly did not go through MLF, 11 were red, 19 white, 4 rosé, and one was a specialty wine. It is interesting to note such a high number of white wines going through MLF, since the secondary fermentation is commonly encouraged in red wines more than it is in other wine styles, however, this high number may have been slightly inflated by lactic acid resulted from yeast cells activity during fermentation (Kunkee 1991). Given that wines with $\mathrm{pH}$ below 3.5 are not hospitable to MLF, it would be reasonable to not expect many of them to have gone through MLF; however, out of the 51 wines with $\mathrm{pH} \leq 3.5,33$ wines seemed to have gone through malolactic fermentation.

Contrary to what would be expected, not all of the wines with $\mathrm{pH}$ above 3.5 went through MLF. Out of 66 wines with $\mathrm{pH}>3.5,21$ wines had zero or non-detectable concentrations of lactic acid, indicating no malolactic fermentation.

The establishment of thresholds for acetic acid was a complex task. Besides the legal limit imposed by the TTB, literature diverges in regards to sensory and recognition thresholds. Not only is the nomenclature not standardized, threshold values are affected by a number of parameters and threshold studies are often based on sensory evaluations, known for their inherent subjectivity. Based on literature review and winemaking laws we 
were able to establish the sensory threshold, or odor threshold $(0.2 \mathrm{~g} / \mathrm{L})$ as the lowest concentration that can detected by human perception, a recognition, or fault threshold $(0.8 \mathrm{~g} / \mathrm{L})$ as the concentration at which acetic acid starts to contribute negatively to the aroma profile of the wine, and the legal threshold $(1.4 \mathrm{~g} / \mathrm{L})$, determined by TTB (The Australian Wine Research Institute; Soleas et al. 2002; Lancard and Arriet 2006; Kwasniewski et al. 2011).

We found $47 \%$ ( $\pm 9.8 \%$ margin of error) incidence of wine above the sensory threshold, with 47 wines above $0.8 \mathrm{~g} / \mathrm{L}$, which could be considered faulted. Acetic acid was found above the legal threshold of $1.4 \mathrm{~g} / \mathrm{L}$ in $18 \%$ of the wines $( \pm 7.5 \%$ margin of error), and above the sensory threshold of $0.2 \mathrm{~g} / \mathrm{L}$ in $72 \%$ of the wines $( \pm 8.8 \%$ margin of error).

\subsection{Hazes and other Visual Faults}

Haze, also called turbidity or clouding, results from the clumping of dissolved proteins into light-dispersing, colloidal particles. Haze can happen at standard temperatures, but is accelerated by heat exposure. The heat causes proteins to denature in the presence of polyphenolics, metals, and/or sulfates (Pocock and Waters 2007). A complete understanding of the causes of haze development remains elusive, possibly due to variation in secondary factors involved in different wines (Batista et al. 2009). Haze formation is a primary concern with white wines, occasionally affecting rosé wines. It is rarely a problem with red wines, probably due to the precipitation of the precursor proteins with tannins, and removal before bottling (Dufrechou et al. 2010). From visual assessment of the bottles, we classified as hazed wines, wines with particles in suspension and/or that were visibly cloudy, and $33 \%$ of wines were determined to be hazed. From analysis with a 
turbidity meter, 19 the wines tested positive; 9 white, 6 red, 2 rosé and 2 specialty wines. The sediment content of the sample varied largely, but regardless of amount, 20 wines had sediments to some degree. It is likely that many factors contributed to hazes, since wines with low titratable acidity (TA) and low tartaric acid content also had hazes.

Excessive headspace (ullage or the volume of air inside a wine bottle) in bottled wine can be considered a risk factor to fault development since it increases the risk of oxidation, $\mathrm{SO}_{2}$ loss, appropriate environment to acid bacteria growth, and for legal reasons (it is illegal to sell less volume than advertised on the label). The composition of the headspace (ullage) in a bottle of wine has been implicated in the development of reduced characters but there is a lack of robust data (Kwiatkowski et al. 2007). Excessive headspace was determined to be a problem in $31 \%$ of the wines. Manual bottling processes, potentially less consistent than automated processes, could explain that.

\subsection{Aroma Related Faults}

1-octen-3-ol is synthesized by many filamentous fungi, such as Botrytis cinerea, Penicillium, Aspergillus, and Mucor at sensory thresholds as low as 20ppb, giving wines a mushroom, metallic aroma (Kaminski et al. 1974; Lancard and Arriet 2006). No wines in this study was botrytized. In addition, the absence of 1-octen3-ol in $100 \%$ of the sample indicates that no wine was affected by fungal contamination.

Volatile sulfur compounds are formed during various stages of wine production and storage. Some compounds may impart unpleasant aromas to wine when present at or above sensory thresholds, and their analysis is not a trivial undertaking (Siebert et al. 2010a). Hydrogen sulfide $\left(\mathrm{H}_{2} \mathrm{~S}\right)$ is the most common volatile sulfur compound found in wine used 
by yeasts to make sulfur-containing amino acids and small peptides (e.g., cysteine, cystine, methionine, glutathione) that are important in yeast cell metabolism and growth (Jiranek and Henschke 1991). In this study, a recognition threshold of 10ppb for $\mathrm{H}_{2} \mathrm{~S}$ was established (Kwasniewski et al. 2011) and $23 \%$ of the wines were at or above it, being considered faulted.

The organic compound 2,4,6-Trichloroanisole (TCA) is a chlorinated derivative of anisole. TCA is the main compound responsible for cork taint in wine and is the best known example of a processing-associated cork taint (Pollnitz et al. 1996). TCA produces a musty or moldy odor perceptible at thresholds as low as 1ppt. According to the Wine Institute 2017 , it has been estimated that up to $2-6 \%$ of all bottled wine may be affected by musty (corky) off-odors to some extent. In our data set, we found $3 \%$ of the wines were contaminated with TCA; which is a small percentage even if we consider that with our margin of error it could be higher. The small incidence could be indicative that the efforts to diminish faulted corks have worked. All three contaminated wines came from cork products; not from traditional high quality corks, but T-cork and twin top cork instead. Although contamination by TCA is known by cork taint, it is important to emphasize that it can be formed in the absence of corks, and what it actually needs is a phenol precursor and the presence of a chlorinated compound. Given the extremely low thresholds of TCA, its quantification is challenging. While we could only measure TCA down to 1ppt, it was enough to identify faulted wines.

Guaiacol is the volatile phenol present in smoke commonly associated with smoke taint in wine. When grapes are exposed to smoke (e.g. from forest fires), guaiacol can bind with sugars forming glycosides that can later on break apart releasing the smoke character 
to wines (The Australian Wine Research Institute 2017). It is also associated with oak barrel maturation, derived predominantly from the thermal degradation of oak lignin during the toasting process of cooperage (Kennison et al. 2008b). The guaiacol content of specialty, red and rosé wines were determined to be significantly different, while no differences were observed between rosé and white wines. In this study, although guaiacol ranged from $2.21-15.19 \mathrm{ppb}$ with a mean of $3.39 \mathrm{ppb} \pm 2.05( \pm 0.4$ error at $95 \%)$, no incidence was found for neither sensory (20ppb) or recognition (70ppb) thresholds (The Australian Wine Research Institute). This could mean that no grapes in our sample were exposed to smoke prior vinification. It could also be that the little concentration was due to natural occurrence in the berry, or that wines were not barrel aged, were aged in previously used barrels, and therefore withdrawn from most of its aroma compounds, or were aged in barrels for short periods of time.

Brett aromas are phenolic compounds that originate from the metabolism of hydroxycinnamates to vinylphenols by microbes of the genus Brettanomyces (Dekkera). They can also can be present in the berry or produced as a result of oak maturation and smoke taint (Waterhouse 2015b). In high concentrations, volatile phenols can be an indicator of an oxidative off-aroma in white wines, but can provide a level of complexity in small concentrations for both red and white wines (Escudero et al. 2002). Based on the sensory and recognition thresholds found in literature (Table 4) no wines in this study were found faulted by Brett aromas. According to the HSD Tukey test, at 5\% level of significance, no differences were found in 4-Ethylguaiacol (4-EG) and 4-Ethylphenol (4EP) among different wine styles. 4-EG ranged from 2.26-150.11ppb, while 4-EP ranged from 5.12-376.72ppb. The 4-Vinylphenol content of white and red wines were determined 
to be significantly different, while no differences were observed between rosé and specialty, rosé and white, rosé and red, specialty and white, and specialty and red wines. The occurrence of volatile phenols below recognition threshold by Brett aromas could be explained by a non-contamination with Brettanomyces; these volatile phenols could have come from sound berries.

\subsection{Residual Sugar, $\mathrm{SO}_{2}$ content and Other Risk Factors}

Residual sugars are considered a risk factor to fault development due to increasing spoilage risk by microbial growth. According to the Commission Regulation (EC) No. $753 / 2002$ we considered wines with $>10 \mathrm{~g} / \mathrm{L}$ high in residual sugar; $61 \%$ of the wines were determined to be high in residual sugar, indicating that most wines produced in Missouri are sweet.

Sulfur dioxide is the most widely used preservative in winemaking with antioxidant, antimicrobial and anti-enzymatic activities. Winemakers must analyze free $\mathrm{SO}_{2}$ accurately in order to know the extent to which the wine is protected, while total $\mathrm{SO}_{2}$ analysis is performed for legal and sensory reasons. At excessive concentrations, $\mathrm{SO}_{2}$ will impart a pungent sensation in the nose and odor resembling struck match. The legal limit for total $\mathrm{SO}_{2}$ in the United States is $350 \mathrm{mg} / \mathrm{L}$ (27 Code of Federal Regulations 4.22(b)(1)) regardless of wine type. All wines analyzed in this study were compliant with U.S. regulations, however, $84 \%$ of the wines did not meet the free $\mathrm{SO}_{2}$ concentration requirement given their $\mathrm{pH}$ to obtain $0.8 \mathrm{mg} / \mathrm{L}$ of molecular $\mathrm{SO}_{2}$, indicating that 84 wines were unprotected from microbial spoilage and oxidation. That could indicate uneducated additions or lack of when it comes sulfur dioxide. 


\section{Conclusions}

This study demonstrates that there are numerous areas where Missouri winemakers are having problems as well as possible risk factors such as low free $\mathrm{SO}_{2}$ and high $\mathrm{pH}$ that maybe to blame. This was not an exhaustive study of all faults and risk factors, and looking to additional metrics may help in understanding wine quality issues and prioritizing what to do to improve them. In addition, this is only one small sub-set of one region; to best understand how this data fits in with the wine industry as a whole, additional surveys are warranted. However, there is no reason to believe that this region is any different than would be found elsewhere. 


\section{References}

Aberl a, Coelhan M (2013) Determination of sulfur dioxide in wine using headspace gas chromatography and electron capture detection. Food Addit Contam Part A Chem Anal Control Expo Risk Assess 30:226-33. doi: 10.1080/19440049.2012.743191

Alpendurada MF (2000) Solid-phase microextraction: A promising technique for sample preparation in environmental analysis. In: Journal of Chromatography A. pp 3-14

Amerine M, Roessler EB, Ough CS (1965) Acids and the Acid Taste I: The Effect of pH and Titratable Acidity. Am J Enol Vitic 16:29-37.

Arthur CL, Pawliszyn J (1990) Solid phase microextraction with thermal desorption using fused silica optical fibers. Anal Chem 62:2145-2148. doi: $10.1021 / \mathrm{ac} 00218 \mathrm{a} 019$

AWRI (2017) Measurement of residual sugar in wine - The Australian Wine Research Institute. https://www.awri.com.au/industry_support/winemaking_resources/laboratory_meth ods/chemical/rs/. Accessed 14 Jul 2017

AWRI (2016) Acidity and pH - The Australian Wine Research Institute. In: Aust. Wine Res. Inst. http://www.awri.com.au/industry_support/winemaking_resources/frequently_asked_ questions/acidity_and_ph/. Accessed 17 Oct 2016

Batista L, Monteiro S, Loureiro V (2009) The complexity of protein haze formation in wines. Food Chem 112:169-177. doi: 10.1016/j.foodchem.2008.05.070

Bekker M, Day M, Holt H, Wilkes E (2016a) Effect of oxygen exposure during fermentation on volatile sulfur compounds in Shiraz wine and a comparison of strategies for remediation of reductive character.

Bekker MZ, Mierczynska-Vasilev A, Smith PA, Wilkes EN (2016b) The effects of pH and copper on the formation of volatile sulfur compounds in Chardonnay and Shiraz wines post-bottling. Food Chem 207:148-156. doi: 10.1016/j.foodchem.2016.03.060

Benito S, Palomero F, Morata A, et al (2009) A method for estimating Dekkera/Brettanomyces populations in wines. J Appl Microbiol 106:1743-1751. doi: 10.1111/j.1365-2672.2008.04137.x

Boban N, Tonkic M, Budimir D, et al (2010) Antimicrobial effects of wine: Separating the role of polyphenols, pH, Ethanol, and other wine components. J Food Sci. doi: 10.1111/j.1750-3841.2010.01622.x

Bosch-Fusté J, Riu-Aumatell M, Guadayol JM, et al (2007) Volatile profiles of sparkling wines obtained by three extraction methods and gas chromatography-mass spectrometry (GC-MS) analysis. Food Chem 105:428-435. doi: 10.1016/j.foodchem.2006.12.053

Boulton R (1979) The Relationshipsbetween Total Acidity, Titratable Acidity and pH in Wine. Am J Enol Vitic 31:76-80.

Boulton R (1980) The General Relationship between Potassium, Sodium and pH in Grape Juice and Wine. 31:2-6.

Bousbouras G, Kunkee R (1971) Effect of $\mathrm{pH}$ on malo-lactic fermentation in wine. Am J Enol ... 22:121-126.

Brouillard R, Dubois J-E (1976) Mechanism of the Structural Transformations of 
Anthocyanins in Acid Media. J Am Chem Soc 99:1359-1364. doi:

10.1021/ja00447a012

Buchholz KD, Pawliszyn J (1993) Determination of Phenols by Solid-Phase

Microextraction and Gas Chromatographic Analysis. Environ Sci Technol 27:28442848. doi: 10.1021/es00049a026

Buechsenstein J, Ough C (1978) SO2 determination by aeration-oxidation: a comparison with Ripper. Am J ... 29:161-164.

Bueno M, Carrascon V, Ferreira V (2016) Release and Formation of Oxidation-Related Aldehydes during Wine Oxidation. J Agric Food Chem 64:608-617. doi: 10.1021/acs.jafc.5b04634

Buser HR, Zanier C, Tanner H (1982) Identification of 2,4,6-trichloroanisole as a potent compound causing cork taint in wine. J Agric Food Chem 30:359-362. doi: $10.1021 / \mathrm{jf00110a037}$

Butzke C (2010) Use of SO2 in High-pH Wines - Sulfur dioxide dosage. Purdue Ext. 13.

Canuti V, Conversano M, Calzi ML, et al (2009) Headspace solid-phase microextractiongas chromatography-mass spectrometry for profiling free volatile compounds in Cabernet Sauvignon grapes and wines. J Chromatogr A 1216:3012-3022. doi: 10.1016/j.chroma.2009.01.104

Charters SJ (2003) Perceptions of wine quality. Edith Cowan University

Chatonnet P, Dubourdie D, Boidron J ???n, Pons M (1992) The origin of ethylphenols in wines. J Sci Food Agric 60:165-178. doi: 10.1002/jsfa.2740600205

Chatonnet P, Viala C, Dubourdieu D (1997) Influence of polyphenolic components of red wines on the microbial synthesis of volatile phenols. Am J Enol Vitic 48:443-448.

Chen Y, Jastrzembski JA, Sacks GL (2017) Copper-complexed hydrogen sulfide in wine: Measurement by gas detection tubes and comparison of release approaches. Am J Enol Vitic 68:91-99. doi: 10.5344/ajev.2016.16024

Cheynier V (2005) Polyphenols in food are more complex then often thought. Am J Clin Nutr 81:223-229.

Chinnici F, Sonni F, Natali N, Riponi C (2013) Oxidative evolution of (+)-catechin in model white wine solutions containing sulfur dioxide, ascorbic acid or gallotannins. Food Res Int 51:59-65. doi: 10.1016/j.foodres.2012.11.013

Čmelík J, MacHát J, Niedobová E, et al (2005) Determination of free and total sulfur dioxide in wine samples by vapour-generation inductively coupled plasma-opticalemission spectrometry. Anal Bioanal Chem 383:483-488. doi: 10.1007/s00216-0053382-2

Country MW (2016) The History of Missouri Wine. http://www.missouriwinecountry.com/articles/history/. Accessed 12 Aug 2016

Crespo R, Carcel LM, Perez MA, et al (2010) Suitable at-line turbidity sensor for wine fermentation supervision. In: Food Innova - International Conference on Food Innovation. Valencia,

Czibulya Z, Horváth I, Kollár L, et al (2015) The effect of temperature, pH, and ionic strength on color stability of red wine. Tetrahedron 71:3027-3031. doi:

10.1016/j.tet.2015.01.036

Davis CR, Wibowo DJ, Lee TH, Fleet GH (1986) Growth and Metabolism of Lactic Acid Bacteria during and after Malolactic Fermentation of Wines at Different pH. Appl 
Env Microbiol 51:539-545.

De Fátima Alpendurada M (2000) Solid-phase microextraction: A promising technique for sample preparation in environmental analysis. In: Journal of Chromatography A. pp 3-14

De Mets G, Goos P, Hertog M, et al (2017) Sensory quality of wine: Quality assessment by merging ranks of an expert-consumer panel. Aust J Grape Wine Res 1-11. doi: 10.1111/ajgw.12287

de Pinho PG, Falqué E, Castro M, et al (2007) Further Insights into the Floral Character of Touriga Nacional Wines. J Food Sci 72:S396-S401. doi: 10.1111/j.17503841.2007.00405.x

Dharmadhikari M (1994) Methods for Tartrate Stabilization of Wine. In: Midwest Grape Wine Ind. Inst. https://www.extension.iastate.edu/wine/methods-tartratestabilization-wine. Accessed 21 Aug 2017

Dittrich, H.H., Sponholz, W.R., Kast W (1974) Vergleichende Untersuchungen von Mosten und Weinen aus gesunden und aus Botrytis-infizierten Traubenbeeren, I. Säurestoffwechsel, Zuckerstoffwechselprodukte. Leucoanthocyangehalte. Vitis - J Grapevine Res 13:36-49.

Dufrechou M, Sauvage F-X, Bach B, Vernhet A (2010) Protein Aggregation in White Wines: Influence of the Temperature on Aggregation Kinetics and Mechanisms. J Agric Food Chem 58:10209-10218. doi: 10.1021/jf1017687

Ebeler SE (2007) Analytical Chemistry: Unlocking the Secrets of Wine Flavor. Food Rev Int 17:45-64. doi: 10.1081/

Esau P, Amerine MA (2000) Residual Sugars in Wine. Am J Enol Vitic 187-189.

Escudero A, Asensio E, Cacho J, Ferreira V (2002) Sensory and chemical changes of young white wines stored under oxygen. An assessment of the role played by aldehydes and some other important odorants. Food Chem 77:325-331. doi: 10.1016/S0308-8146(01)00355-7

Fang Y, Qian MC (2005) Sensitive quantification of sulfur compounds in wine by headspace solid-phase microextraction technique. J Chromatogr A 1080:177-185. doi: 10.1016/j.chroma.2005.05.024

Fariña L, Boido E, Carrau F, Dellacassa E (2007) Determination of volatile phenols in red wines by dispersive liquid-liquid microextraction and gas chromatography-mass spectrometry detection. J Chromatogr A 1157:46-50. doi: 10.1016/j.chroma.2007.05.006

Ferreira RB, Piçarra-Pereira MA, Monteiro S, et al (2001) The wine proteins. Trends Food Sci Technol 12:230-239. doi: 10.1016/S0924-2244(01)00080-2

Fischer C, Fischer U (1997) Analysis of Cork Taint in Wine and Cork Material at Olfactory Subthreshold Levels by Solid Phase Microextraction. J Agric Food Chem 45:1995-1997. doi: 10.1021/jf970121r

Frommberger R (1991) Cork products: a potential source of polychlorinated dibenzo-pdioxins and polychlorinated dibenzofurans. Chemosphere 23:133-139. doi: 10.1016/0045-6535(91)90102-J

Giménez-Gómez P, Gutiérrez-Capitán M, Puig-Pujol A, et al (2017) Analysis of free and total sulfur dioxide in wine by using a gas-diffusion analytical system with $\mathrm{pH}$ detection. Food Chem 228:518-525. doi: 10.1016/j.foodchem.2017.02.026

Giudici P, Kunkee RE (1994) The effect of nitrogen deficiency and sulfur-containing 
amino-acids on the reduction of sulfate to hydrogen-sulfide by wine yeasts. Am J Enol Vitic 45:107-112.

Gockowiak H, Henschke PA (2003) Interaction of $\mathrm{pH}$, ethanol concentration and wine matrix on induction of malolactic fermentation with commercial "direct inoculation" starter cultures. Aust J Grape Wine Res 9:200-209. doi: 10.1111/j.17550238.2003.tb00271.x

Godden P, Francis IL, Field J, et al (2001) Wine bottle closures: physical characteristics and effect on composition and sensory properties of a Semillon wine. I. Performance up to 20 months post-bottling. Aust J Grape Wine Res 7:64-105. doi: 10.1111/j.1755-0238.2001.tb00196.x

Grau S (2017) Impacts of Bottle Storage on Wine Flavor and Underlying Chemistry. University of Missouri

Guth H (1997) Quantitation and Sensory Studies of Character Impact Odorants of Different White Wine Varieties. J Agric Food Chem 45:3027-3032. doi: 10.1021/jf970280a

Hampel D, Robinson AL, Johnson AJ, Ebeler SE (2014) Direct hydrolysis and analysis of glycosidically bound aroma compounds in grapes and wines: Comparison of hydrolysis conditions and sample preparation methods. Aust J Grape Wine Res 20:361-377. doi: 10.1111/ajgw.12087

Henschke PA, Jiranek V (1991) Hydrogen sulfide formation during fermentation: effect of nitrogen composition in model grape must. Int Symp Nitrogen Grapes Wine Seattle, Washington, Usa 172-184.

Herman Vintners A (2013) About Missouri Wine - Our Roots go Deep. http://hermannwinetrail.com/about-missouri-wine/. Accessed 12 Aug 2016

Hinshaw J V. (2003) Soli-Phase Microextraction. GC Connect. - LC-GC Eur. 2-5.

Hoemmen GA (2013) Regional Wine Quality Reputation: the perceptions and Possibilities in the Shawnee Hills AVA. Southern Illinois University Carbondale

Hsu J-C, Heatherbell DA, Riesling W (1987) Heat-Unstable Proteins in Wine. I. Characterization and Removal by Bentonite Fining and Heat Treatment. Am J Enol Vitic 38:11-16.

Huang MD, Becker-Ross H, Florek S, et al (2008) Determination of sulfur forms in wine including free and total sulfur dioxide based on molecular absorption of carbon monosulfide in the air-acetylene flame. Anal Bioanal Chem 390:361-367. doi: 10.1007/s00216-007-1669-1

Iland P, Bruer N, Edwards G, et al (2013) Chemical analysis of grapes and wine: techniques and concepts, 2nd edn. Patrick Iland Wine Promotions

Jackowetz JN, Mira de Orduña R (2013) Survey of SO2 binding carbonyls in 237 red and white table wines. Food Control 32:687-692. doi: 10.1016/j.foodcont.2013.02.001

Jackson DI, Lombard PB, Kabinett LQ (1993) Environmental and Management Practices Affecting Grape Composition and Wine Quality - A Review. Am J Enol Vitic 44:409-430.

Jackson RS (2014) Wine science: Principles and applications, 4th edn. Academic Press Jeremy Nulik (2013) A History of Missouri Wine. In: Feast Mag. http://www.feastmagazine.com/dine-out/features/article_e23ee424-acef-11e2-83d6001a4bcf6878.html. Accessed 12 Aug 2016

Jiranek V (2002) Causes of Hydrogen Sulfide in Winemaking. Wine Internet Tech J 3:1- 
10.

Jiranek V, Henschke P (1991) Assimilable nitrogen: regulator of hydrogen sulfide production during fermentation.

Kaminski E, Stawicki S, Wasowicz E (1974) Volatile Flavor Compounds Produced by Molds of Aspergillus, Penicillium, and Fungi imperfecti. Appl Microbiol 27:10011004.

Kennard D (2014) A Year in Burgundy - Film.

Kennison KR, Gibberd MR, Pollnitz AP, Wilkinson KL (2008a) Smoke-derived taint in wine: The release of smoke-derived volatile phenols during fermentation of Merlot juice following grapevine exposure to smoke. J Agric Food Chem 56:7379-7383. doi: 10.1021/jf800927e

Kennison KR, Gibberd MR, Pollnitz AP, Wilkinson KL (2008b) Smoke-derived taint in wine: The release of smoke-derived volatile phenols during fermentation of Merlot juice following grapevine exposure to smoke. J Agric Food Chem 56:7379-7383. doi: 10.1021/jf800927e

Kerem Z, Bravdo BA, Shoseyov O, Tugendhaft Y (2004) Rapid liquid chromatographyultraviolet determination of organic acids and phenolic compounds in red wine and must. J Chromatogr A 1052:211-215. doi: 10.1016/j.chroma.2004.08.105

Kheir J, Salameh D, Strehaiano P, et al (2013) Impact of volatile phenols and their precursors on wine quality and control measures of Brettanomyces/Dekkera yeasts. Eur Food Res Technol 237:655-671. doi: 10.1007/s00217-013-2036-4

Kunkee RE (1991) Some roles of malic acid in the malolactic fermentation in wine making. FEMS Microbiol Lett 88:55-71. doi: 10.1016/0378-1097(91)90696-8

Kwasniewski MT, Allison RB, Wilcox WF, Sacks GL (2011) Convenient, inexpensive quantification of elemental sulfur by simultaneous in situ reduction and colorimetric detection. Anal Chim Acta 703:52-57. doi: 10.1016/j.aca.2011.07.010

Kwiatkowski MJ, Skouroumounis GK, Lattey KA, Waters EJ (2007) The impact of closures, including screw cap with three different headspace volumes, on the composition, colour and sensory properties of a Cabernet Sauvignon wine during two years' storage. Aust J Grape Wine Res 13:81-94. doi: 10.1111/j.17550238.2007.tb00238.x

Lancard DOB, Arriet PHD (2006) Characterization of Some Mushroom and Earthy OffOdors Microbially Induced by the Development of Rot on Grapes. J Agric Food Chem 54:9193-9200.

Larue F, Park MK, Caruana C (1985) Quelques observations sur les conditions de la formation d'anhydride sulfureux en vinification. Connaiss la Vigne du Vin 19:241248.

Lloyd NDR, Capone DL, Ugliano M, et al (2011) Formation of damascenone under both commercial and model fermentation conditions. J Agric Food Chem 59:1338-1343. doi: $10.1021 /$ jf103741n

Lonvaud-Funel A (1999) Lactic acid bacteria in the quality improvement and depreciation of wine. In: Lactic Acid Bacteria: Genetics, Metabolism and Applications. Springer Netherlands, Dordrecht, pp 317-331

Lopes P, Silva MA, Pons A, et al (2009) Impact of oxygen dissolved at bottling and transmitted through closures on the composition and sensory properties of a sauvlgnon blanc wine during bottle storage. J Agric Food Chem 57:10261-10270. 
doi: $10.1021 / \mathrm{jf} 9023257$

Lopez EF, Gomez EF (1996) Simultaneous Determination of the Major Organic Acids, Sugars, Glycerol, and Ethanol by HPLC in Grape Musts and White Wines. J Chromatogr Sci 34:254-257. doi: 10.1093/chromsci/34.5.254

López R, Aznar M, Cacho J, Ferreira V (2002) Determination of minor and trace volatile compounds in wine by solid-phase extraction and gas chromatography with mass spectrometric detection. J Chromatogr A 966:167-177. doi: 10.1016/S00219673(02)00696-9

López R, Ferreira V, Cacho JF (2000) Quantitative determination of the odorants of young red wines from different grape varieties. J Sci Food Agric

López R, Lapeña AC, Cacho J, Ferreira V (2007) Quantitative determination of wine highly volatile sulfur compounds by using automated headspace solid-phase microextraction and gas chromatography-pulsed flame photometric detection. J Chromatogr A 1143:8-15. doi: 10.1016/j.chroma.2006.12.053

Main GL, Morris JR (2004) Leaf-Removal Effects on Cynthiana Yield, Juice Composition, and Wine Composition.

Mamede MEO, Cardello HMAB, Pastore GM (2005) Evaluation of an aroma similar to that of sparkling wine: Sensory and gas chromatography analyses of fermented grape musts. Food Chem 89:63-68. doi: 10.1016/j.foodchem.2004.02.012

Mamede MEO, Pastore GM (2006) Study of methods for the extraction of volatile compounds from fermented grape must. Food Chem 96:586-590. doi: 10.1016/j.foodchem.2005.03.013

Martorell N, Martí MP, Mestres M, et al (2002) Determination of 4-ethylguaiacol and 4ethylphenol in red wines using headspace-solid-phase microextraction-gas chromatography. J Chromatogr A 975:349-354. doi: 10.1016/S00219673(02)01277-3

Mato I, Suárez-Luque S, Huidobro JF (2005) A review of the analytical methods to determine organic acids in grape juices and wines. Food Res Int 38:1175-1188. doi: 10.1016/j.foodres.2005.04.007

McCloskey LP (1976) An Acetic Acid Assay for Wine Using Enzymes.

Miller M (2013) Monitoring Acids and pH in Winemaking. 1-14.

Missouri Wines (2015) History \& AVAs. https://missouriwine.org/about-us/history-andavas. Accessed 12 Aug 2016

Monje MC, Privat C, Gastine V, Nepveu F (2002) Determination of ethylphenol compounds in wine by headspace solid-phase microextraction in conjunction with gas chromatography and flame ionization detection. Anal Chim Acta 458:111-117. doi: 10.1016/S0003-2670(01)01528-8

Moreno-Arribas VM, Polo CM (eds) (2009) Wine Chemistry and Biochemistry. Springer, New York

Mutanen J, Räty J, Gornov E, et al (2007) Measurement of color, refractive index, and turbidity of red wines. Am J Enol Vitic 58:387-392.

Nielsen JC, Richelieu M, Nielsen J a NC, et al (1999) Control of Flavor Development in Wine during and after Malolactic Fermentation by Oenococcus oeni Control of Flavor Development in Wine during and after Malolactic Fermentation by Oenococcus oeni. Appl Environ Microbiol 65:740-745.

Oliveira CM, Ferreira ACS, De Freitas V, Silva AMS (2011) Oxidation mechanisms 
occurring in wines. Food Res. Int. 44:1115-1126.

Oliveira LMC, Clemente MACP (2003) Port wine spectronephelometry. Opt Laser

Technol 35:491-496. doi: 10.1016/S0030-3992(03)00067-7

Ough CS (1988) Acids and Amino Acids in Grapes and Wines. Springer Berlin Heidelberg, pp 92-146

P. Ribereau-Gayon, Y. Glories, A. Maujean DD (2006) Handbook of Enology Volume 2 The Chemistry of Wine Stabilization and Treatments 2nd Edition, 2nd edn. John Wiley \& Sons, Ltd

Park S-K (2008) Development of a method to measure hydrogen sulfide in wine fermentation. J Microbiol Biotechnol 18:1550-4.

Pereira V, Câmara JS, Cacho J, Marques JC (2010) HPLC-DAD methodology for the quantification of organic acids, furans and polyphenols by direct injection of wine samples. J Sep Sci 33:NA-NA. doi: 10.1002/jssc.200900784

Plane RA, Mattick LR, Weirs LD (1980) An acicity index for the taste of wines. Am J Enol Vitic 31:265-268.

Pocock KF, Waters EJ (2007) Protein haze in bottled white wines: How well do stability tests and bentonite fining trials predict haze formation during storage and transport? Aust J Grape Wine Res 12:212-220. doi: 10.1111/j.1755-0238.2006.tb00061.x

Pollnitz AP, Pardon KH, Liacopoulos D, et al (1996) The analysis of 2,4,6trichloroanisole and other chloroanisoles in tainted wines and corks. Aust J Grape Wine Res 2:184-190. doi: 10.1111/j.1755-0238.1996.tb00107.x

Pons A, Lavigne V, Eric F, et al (2008) Identification of Volatile Compounds Responsible for Prune Aroma in Prematurely Aged Red Wines. J Agric Food Chem 56:5285-5290. doi: 10.1021/jf073513z

Prajitna A, Dami IE, Steiner TE, et al (2007) Influence of cluster thinning on phenolic composition, resveratrol, and antioxidant capacity in chambourcin wine. Am J Enol Vitic 58:346-350.

Preston LD, Block DE, Heymann H, et al (2008) Defining Vegetal Aromas in Cabernet Sauvignon Using Sensory and Chemical Evaluations.

Ribereau-Gayon P, Dubourdieu D, Doneche B, Lonvaud A (2006) Handbook of Enology Volume 1 The Microbiology of Wine and Vinifications, 2nd edn. John Wiley \& Sons, Ltd

Ribéreau-Gayon P, Glories Y (1986) Phenolics in grapes and wines.

Riu-Aumatell M, Bosch-Fusté J, López-Tamames E, Buxaderas S (2006) Development of volatile compounds of cava (Spanish sparkling wine) during long ageing time in contact with lees. Food Chem 95:237-242. doi: 10.1016/j.foodchem.2005.01.029

Rivero-Pérez MD, Pérez-Magariño S, González-San José ML (2002) Role of melanoidins in sweet wines. Anal Chim Acta 458:169-175. doi: 10.1016/S0003-2670(01)015914

Rocha SM, Coimbra MA, Delgadillo I (2000) Demonstration of pectic polysaccharides in cork cell wall from Quercus suber L. J Agric Food Chem 48:2003-2007. doi: 10.1021/jf991147g

Romano A, Perello MC, Lonvaud-Funel A, et al (2009) Sensory and analytical reevaluation of "Brett character." Food Chem 114:15-19. doi: 10.1016/j.foodchem.2008.09.006

Sacchi KL, Bisson LF, Adams DO (2005) A review of the effect of winemaking 
techniques on phenolic extraction in red wines. Am J Enol Vitic 56:197-206. doi: 10.1002/JSFA.2740670416

Sadar M (2002) Turbidity Instrumentation - An Overview of Today's Available Technology.

San-Juan F, Ferreira V, Cacho J, Escudero A (2011) Quality and aromatic sensory descriptors (mainly fresh and dry fruit character) of spanish red wines can be predicted from their aroma-active chemical composition. In: Journal of Agricultural and Food Chemistry. pp 7916-7924

Sánchez-Palomo E, Díaz-Maroto MC, Pérez-Coello MS (2005) Rapid determination of volatile compounds in grapes by HS-SPME coupled with GC-MS. Talanta 66:11521157. doi: 10.1016/j.talanta.2005.01.015

Schütz M, Kunkee RE (1977) Formation of Hydrogen Sulfide from Elemental Sulfur During Fermentation by Wine Yeast.

Shimazu Y, Uehara M, Watanabe M (1985) Transformation of Citric Acid to Acetic Acid, Acetoin and Diacetyl by Wine Making Lactic Acid Bacteria. Agric Biol Chem 49:2147-2157. doi: 10.1080/00021369.1985.10867041

Siebert TE, Solomon MR, Pollnitz AP, Jeffery DW (2010a) Selective determination of volatile sulfur compounds in wine by gas chromatography with sulfur chemiluminescence detection. J Agric Food Chem 58:9454-9462. doi: 10.1021/jf102008r

Siebert TE, Solomon MR, Pollnitz AP, Jeffery DW (2010b) Selective determination of volatile sulfur compounds in wine by gas chromatography with sulfur chemiluminescence detection. J Agric Food Chem 58:9454-9462. doi: 10.1021/jf102008r

Sigma A (2017) Solid Phase Micro-extraction ( SPME ) Modern Sample Preparation.

Simpson RF, Miller GC (1984) Aroma composition of Chardonnay wine. Aust Wine Res Inst 23:143-158.

Slegers A, Angers P, Ouellet É, et al (2015) Volatile compounds from grape skin, juice and wine from five interspecific hybrid grape cultivars grown in Qu??bec (Canada) for wine production. Molecules 20:10980-11016. doi:

10.3390/molecules200610980

Soleas GJ, Yan J, Seaver T, Goldberg DM (2002) Method for the gas chromatographic assay with mass selective detection of trichloro compounds in corks and wines applied to elucidate the potential cause of cork taint. J Agric Food Chem 50:10321039. doi: 10.1021/jf011149c

Song H, Lee SY (2006) Production of succinic acid by bacterial fermentation. Enzyme Microb. Technol. 39:352-361.

Sowalsky RA, Noble AC (1998) Comparison of the effects of concentration, $\mathrm{pH}$ and anion species on astringency and sourness of organic acids. Chem Senses 23:343349. doi: 10.1093/chemse/23.3.343

Soyer Y, Koca N, Karadeniz F (2003) Organic acid profile of Turkish white grapes and grape juices. J Food Compos Anal 16:629-636. doi: 10.1016/S08891575(03)00065-6

Spillman PJ, Pollnitz AP, Liacopoulos D, et al (1997) Accumulation of Vanillin during Barrel-Aging of White, Red, and Model Wines. J Agric Food Chem 45:2584-2589. doi: 10.1021/jf970034z 
Suárez-Lepe JA, Morata A (2012) New trends in yeast selection for winemaking. Trends Food Sci Technol 23:39-50. doi: 10.1016/j.tifs.2011.08.005

Subileau M, Schneider R, Salmon JM, Degryse E (2008) New insights on 3mercaptohexanol (3MH) biogenesis in Sauvignon Blanc wines: Cys-3MH and (E)hexen-2-al are not the major precursors. J Agric Food Chem 56:9230-9235. doi: $10.1021 / \mathrm{jf} 801626 \mathrm{f}$

Sussi G, Romano P (1982) Induced changes by SO2 on the population of Saccharomyces as agents of the natural fermentation of musts.

Swiegers JH, Bartowsky EJ, Henschke P a., Pretorius IS (2005) Yeast and bacterial modulation of wine aroma and flavour. Aust J Grape Wine Res 11:139-173. doi: 10.1111/j.1755-0238.2005.tb00285.x

Taylor SL, Higley NA, Bush RK (1986) Sulfites in Foods: Uses, Analytical Methods, Residues, Fate, Exposure Assessment, Metabolism, Toxicity, and Hypersensitivity. pp 1-76

The Australian Wine Research Institute Wine flavour, faults and taints. https://www.awri.com.au/industry_support/winemaking_resources/sensory_assessm ent/recognition-of-wine-faults-and-taints/wine_faults/. Accessed 22 Jul 2017

The Australian Wine Research Institute (2017) Smoke Taint. https://www.awri.com.au/industry_support/winemaking_resources/smoke-taint/. Accessed 24 Jul 2017

The International Organisation of Vine and Wine (2015) OIV - 2015 OIV report on the world vitivinicultural situation. http://www.oiv.int/en/oiv-life/2015-oiv-report-onthe-world-vitivinicultural-situationnbsp. Accessed 8 Oct 2016

Thoukis G, Ueda M, Wright D (1965) The Formation of Succinic Acid during Alcoholic Fermentation.

Ugarte P, Agosin E, Bordeu E, Villalobos JI (2005) Reduction of 4-Ethylpheol and 4Ethylguaiacol Concentration in RedWines Using Reverse Osmosis and Adsorption. Am J Enol Vitic 56:30-36.

Ugliano M, Dieval JB, Siebert TE, et al (2012) Oxygen consumption and development of volatile sulfur compounds during bottle aging of two Shiraz wines. influence of preand postbottling controlled oxygen exposure. J Agric Food Chem 60:8561-8570. doi: $10.1021 / \mathrm{jf} 3014348$

Ugliano M, Henschke PA (2010) Comparison of three methods for accurate quantification of hydrogen sulfide during fermentation. Anal Chim Acta 660:87-91. doi: 10.1016/j.aca.2009.09.049

University of Waterloo (2017) SPME. In: Pawliszyn Res. Gr. https://uwaterloo.ca/pawliszyn-group/research/spme. Accessed 1 Jan 2017

Vannier A, Brun OX, Feinberg MH (1999) Application of Sensory Analysis to Champagne Wine Characterisation and Discrimination. Food Qual Prefer 10:101107. doi: 10.1016/S0950-3293(98)00047-0

Vasserot Y, Pitois C, Jeandet P (2001) Protective effect of a composite cork stopper on champagne wine pollution with 2,4,6-trichloroanisole. Am J Enol Vitic 52:280-281.

Volschenk H, Van Vuuren HJJ (2006) Malic Acid in Wine : Origin, Function and Metabolism during Vinification. S Afr J Enol Vitic 27:123-136.

Waterhouse AL (2015a) Volatile Acidity. http://waterhouse.ucdavis.edu/whats-inwine/volatile-acidity. Accessed 10 Jul 2017 
Waterhouse AL (2015b) Volatile Phenols. In: Waterhouse Lab. http://waterhouse.ucdavis.edu/whats-in-wine/volatile-phenols. Accessed 11 Jul 2017

Waters EJ, Wallace W, T ME, Williams PJ (1993) Isolation and Partial Characterization of a Natural Haze Protective Factor from Wine. Food Chem 41:724-730. doi: 10.1021/jf00029a009

Wedral D, Shewfelt R, Frank J (2010) The challenge of Brettanomyces in wine. LWT Food Sci Technol 43:1474-1479. doi: 10.1016/j.lwt.2010.06.010

Wine Institute (2017) Trichloroanisole (TCA) Fact Sheet - The Wine Institute. https://www.wineinstitute.org/initiatives/issuesandpolicy/tca. Accessed 14 Jul 2017

Wine Institute Statistics - The Wine Institute. http://www.wineinstitute.org/resources/statistics. Accessed 10 Oct 2016

Wines M (2014a) Missouri Grape Facts.

Wines M (2014b) Missouri Grape \& Wine Industry Fact Sheet.

Wu BH, Liu HF, Guan L, et al (2011) Carbohydrate metabolism in grape cultivars that differ in sucrose accumulation. Vitis - J Grapevine Res 50:51-57.

Yang X, Peppard T (1994) Solid-Phase Microextraction for Flavor Analysis. J Agric Food Chem 42:1925-1930. doi: 10.1021/jf00045a018

Zalacain A, Alonso GL, Lorenzo C, et al (2004) Stir bar sorptive extraction for the analysis of wine cork taint. J Chromatogr A 1033:173-178. doi: 10.1016/j.chroma.2003.12.059

Zhang Z, Yang MJ, Pawliszyn J (1994) Solid-phase Microextraction: Solid-phase microextraction integrates sampling, extraction, concentration, and sample introduction into a single step. Anal Chem 66:844A-853A.

Zotou A, Loukou Z, Karava O (2004) Method Development for the Determination of Seven Organic Acids in Wines by Reversed-Phase High Performance Liquid Chromatography. Chromatographia 60:39-44. doi: 10.1365/s10337-004-0330-9

7. Tables and Figures 
Table 1. Incidence of categorical variables of assessment.

\begin{tabular}{|c|c|c|c|}
\hline & & Number of wines & $\%$ Margin of error \pm \\
\hline \multirow{5}{*}{ 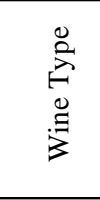 } & All wines & 100 & \\
\hline & White & 46 & 9.8 \\
\hline & Red & 40 & 9.6 \\
\hline & Rose & 9 & 5.6 \\
\hline & Specialty & 5 & 4.3 \\
\hline \multirow{7}{*}{ 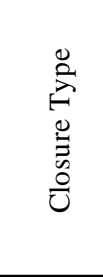 } & Natural cork & 30 & 9.0 \\
\hline & Twin top & 23 & 8.2 \\
\hline & Stelvin & 14 & 6.8 \\
\hline & Synthetic & 17 & 7.4 \\
\hline & Agglomerated & 13 & 6.6 \\
\hline & Zork & 2 & 2.7 \\
\hline & T-cork & 1 & 2.0 \\
\hline \multirow{4}{*}{ 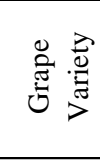 } & Hybrid & 52 & 9.8 \\
\hline & Vinifera & 7 & 5.0 \\
\hline & Known blend & 7 & 5.0 \\
\hline & Unknown blend & 34 & 9.3 \\
\hline \multirow{15}{*}{ 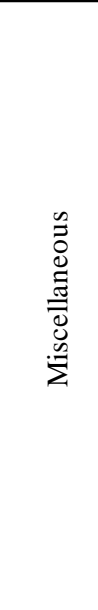 } & Turbidity & 19 & 7.7 \\
\hline & Haze & 33 & 9.2 \\
\hline & $\mathrm{H}_{2} \mathrm{~S}$ & 23 & 8.4 \\
\hline & Acetic acid & 47 & 9.8 \\
\hline & Free $\mathrm{SO}_{2}<$ recommended $*$ & 84 & 7.2 \\
\hline & Total $\mathrm{SO}_{2}>$ U.S. limit $* *$ & 0 & 0.0 \\
\hline & Total SO2 > E.U. limit*** & 9 & 5.6 \\
\hline & $\mathrm{pH}>3.7$ & 31 & 9.1 \\
\hline & Excessive headspace & 31 & 9.1 \\
\hline & Malo-lactic fermentation & 65 & 9.3 \\
\hline & No Malo-lactic fermentation & 35 & 9.3 \\
\hline & 1-octen-3-ol & 0 & 0.0 \\
\hline & TCA & 3 & 3.3 \\
\hline & Brett aromas & 0 & 0.0 \\
\hline & No Brett aromas & 100 & 0.0 \\
\hline \multicolumn{4}{|c|}{ Turbid wine: NTU > 10 for red, rosé and specalty wines, NTU > 5 for w } \\
\hline \multicolumn{4}{|c|}{ Faulted by hydrogen sulfide if $\mathrm{H}_{2} \mathrm{~S}>10 \mathrm{ppb}$ (Kwasniewski et al 2011) } \\
\hline \multicolumn{4}{|c|}{ Faulted by acetic acid if $>0.8 \mathrm{~g} / \mathrm{L}$ acetic acid (AWRI 2017) } \\
\hline \multicolumn{4}{|c|}{ *Free $\mathrm{SO}_{2}$ concentration requirement given their $\mathrm{pH}$ to obtain $0.8 \mathrm{mg} / \mathrm{L}$ of molecular $\mathrm{SO} 2$. } \\
\hline \multicolumn{4}{|c|}{$* * 350 \mathrm{mg} / \mathrm{L}$ for all wines $(27 \mathrm{CFR} 4.22(\mathrm{~b})(1))$} \\
\hline \multicolumn{4}{|c|}{$\begin{array}{l}* * * 200 \mathrm{mg} / \mathrm{L} \text { for white/rosé }<5 \mathrm{~g} / \mathrm{L} \text { sugars, } 250 \mathrm{mg} / \mathrm{L} \text { for white/rosé }>5 \mathrm{~g} / \mathrm{L} \text { sugars, } 150 \mathrm{mg} / \mathrm{L} \\
\text { for red }<5 \mathrm{~g} / \mathrm{L} \text { sugars, } 200 \mathrm{mg} / \mathrm{L} \text { for red }>5 \mathrm{~g} / \mathrm{L}, 300-400 \mathrm{mg} / \mathrm{L} \text { for specific wines (EC No } \\
606 / 2009 \text {, Annex I B). }\end{array}$} \\
\hline \multicolumn{4}{|c|}{ At risk of fault if $\mathrm{pH}>3.7$. } \\
\hline \multicolumn{4}{|c|}{ Excessive headspace: bottle necks that were filled with less than $25 \%$ their capacity. } \\
\hline \multicolumn{4}{|c|}{ Malo-lactic fermentation: presence of lactic acid. } \\
\hline \multicolumn{4}{|c|}{ No Malo-latic fermentation: absence of malic acid. } \\
\hline \multicolumn{4}{|c|}{ Faulted by 1 -octen-3-ol if $>20-40$ ppb 1 -octen-3-ol. } \\
\hline \multicolumn{4}{|c|}{ Faulted by TCA if $>2$ ppt TCA. } \\
\hline Margin 0 & r with known proportion interv & ased of $n=100$. & \\
\hline
\end{tabular}


Table 2. General statistical measurements

\begin{tabular}{lccccc} 
& \multicolumn{5}{c}{ All wines } \\
\cline { 2 - 6 } & Mean \pm std & Min & Max & p-value & Error (at 95\%) \\
\hline Basic Fruit Chemis try & $5.16 \pm 5.91$ & 0 & 25 & 0.66 & \pm 1.2 \\
$\mathrm{H}_{2} \mathrm{~S}(\mathrm{ppb})$ & $18.51 \pm 20.46$ & 0 & 118 & 0.039 & \pm 4 \\
$\mathrm{SO}_{2}$ free $(\mathrm{mg} / \mathrm{L})$ & $99.9 \pm 68.35$ & 3.6 & 324.4 & 0.001 & \pm 12.8 \\
$\mathrm{SO}_{2}$ total $(\mathrm{mg} / \mathrm{L})$ & $3.54 \pm 0.25$ & 2.97 & 4.11 & 0.002 & \pm 0.2 \\
$\mathrm{pH}$ & $21.33 \pm 17.9$ & 0 & 50 & $<0.0001$ & \pm 3.5 \\
Residual sugar & $5.74 \pm 10.91$ & 0 & 39.25 & 0.001 & \pm 2.1 \\
Turbidity (FTU) & $7.57 \pm 1.7$ & 4.52 & 12.32 & 0.443 & \pm 1.1 \\
TA (g/L as H2T) & & & & & \\
& & & & & \\
Organic Acids & $2.32 \pm 1.37$ & 0.48 & 9.04 & 0.001 & \pm 0.3 \\
Tartaric g/L & $2.04 \pm 2.08$ & 0 & 9.64 & $<0.0001$ & \pm 0.4 \\
Malic g/L & $1.80 \pm 2.16$ & 0.03 & 11.7 & 0.034 & \pm 0.4 \\
Lactic g/L & $0.87 \pm 1.23$ & 0 & 5.09 & 0.566 & \pm 0.2 \\
Acetic g/L & $0.36 \pm 0.64$ & 0 & 5.05 & 0.376 & \pm 0.1 \\
Citric g/L & $0.76 \pm 0.66$ & 0 & 3.65 & 0.858 & \pm 0.1 \\
Succinic g/L & & & & & \\
& & & & & \\
Volatile phenols & $3.39 \pm 2.05$ & 2.21 & 15.19 & $<0.0001$ & \pm 0.4 \\
Guaiacol & $8.56 \pm 21.29$ & 2.26 & 150.11 & 0.771 & \pm 4.2 \\
4EG & $22.72 \pm 54.34$ & 5.12 & 376.72 & 0.112 & \pm 10.6 \\
4EP & $4.50 \pm 13.16$ & 0 & 125.82 & 0.038 & \pm 2.6 \\
4VP & & & & & \\
$\beta$-Damascenone & $10.61 \pm 9.20$ & 0.37 & 48.61 & 0.039 & \pm 1.8 \\
\hline
\end{tabular}

$\mathrm{H} 2 \mathrm{~S}$ (ppb) measured by colorimetric tube (Kwasniewski et al 2011)

$\mathrm{SO} 2$ (mg/L) free, bound and total, measured by aeration-oxidation (Iland et al 2013)

$\mathrm{pH}$ measured with a $\mathrm{pH}$ meter

Residual sugar measured with Clinitest tablets

Turbidity (FTU) measured with turbidity meter

TA $\left(\mathrm{g} / \mathrm{L}\right.$ as $\left.\mathrm{H}_{2} \mathrm{~T}\right)$ measured by titration to end point using $\mathrm{pH}$ meter

Oganic acids measured via HPLC

Volatile aromas of HMW measured via SPME-GC-MS

All wines $n=100$, White $n=46$, Red $n=40$, Rosé $n=9$, Specialty $n=5$, Dry wines $n=39$, Not Dry wines $n=61$, High Headspace $n=31$, Low Headspace $n=69$, Natural cork $n=30$, Twin-top $n=23$, Stelvin $n=14$, Other closures $n=33$

Significance p-values were obtained by 1-way ANOVAs using XLSTAT (Addinsoft, Ver. 2017.02.43674)

Significant differences were noted with $95 \%$ confidence at a $\mathrm{p}$-value $<0.05$ 
Table 3. Organic acids concentration per wine style.

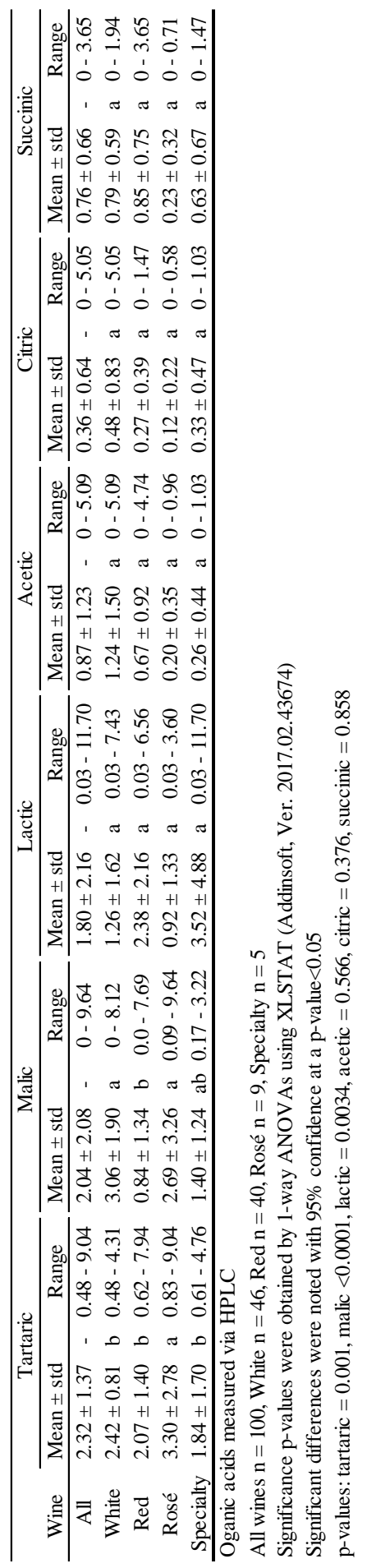


Table 4. Trace volatile aroma threshold and incidence in all sampled wines.

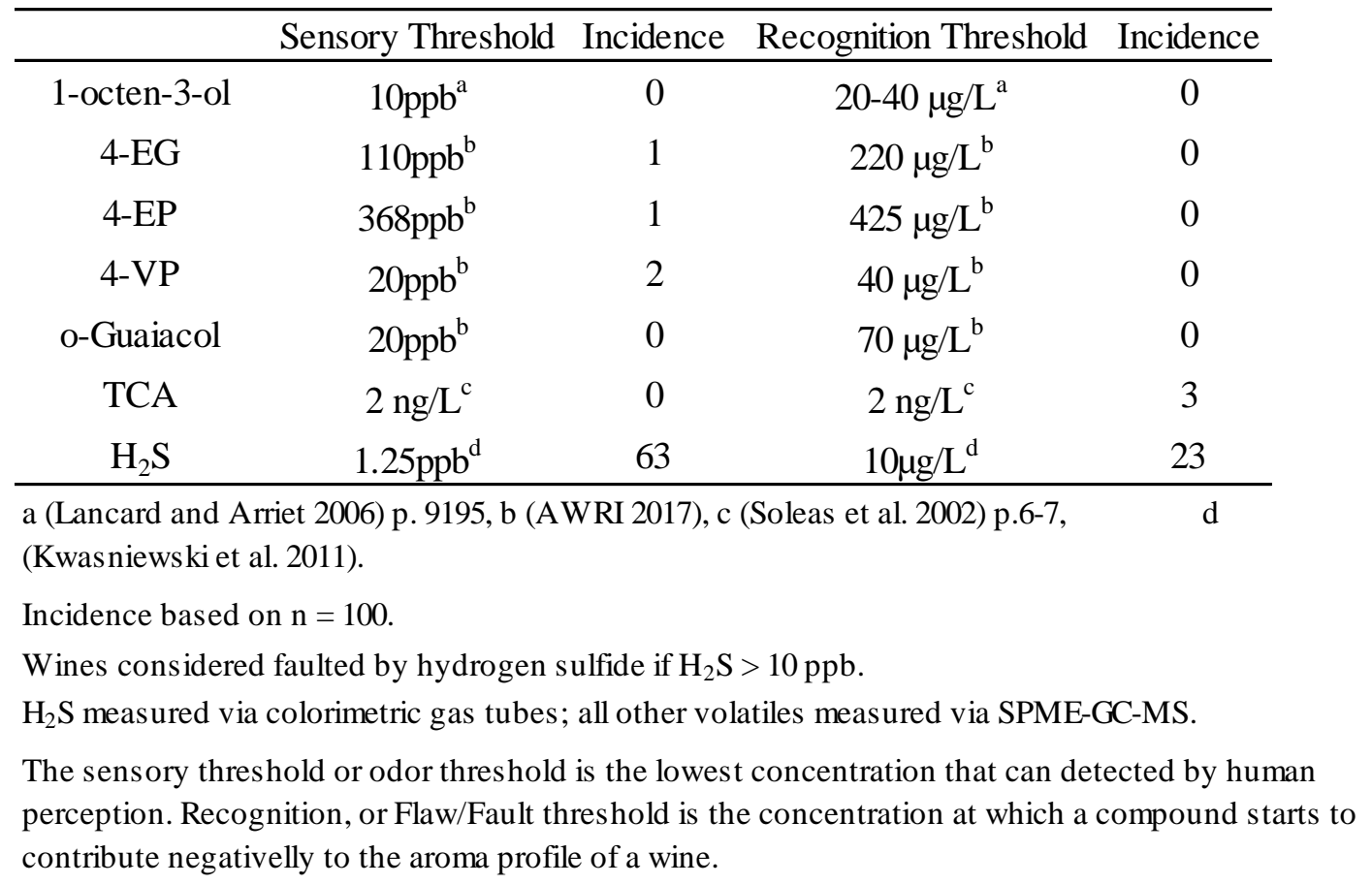

Table 5. $\mathrm{pH}$ and titratable acidity (TA) per wine style.

\begin{tabular}{|c|c|c|c|c|c|c|c|c|}
\hline & \multicolumn{4}{|c|}{$\mathrm{pH}$} & \multicolumn{4}{|c|}{ TA } \\
\hline Wine & Mean \pm std & & Lowest & Highest & Mean \pm std & & Lowest & Highest \\
\hline General & $3.54 \pm 0.25$ & - & 2.97 & 4.11 & $7.57 \pm 1.7$ & - & 4.52 & 12.32 \\
\hline White & $3.45 \pm 0.23$ & $\mathrm{a}$ & 2.97 & 3.86 & $7.44 \pm 1.62$ & $\mathrm{a}$ & 4.79 & 11.28 \\
\hline Red & $3.64 \pm 0.24$ & $\mathrm{a}$ & 3.02 & 4.11 & $7.84 \pm 1.68$ & $\mathrm{a}$ & 5.05 & 11.35 \\
\hline Rosé & $3.45 \pm 0.28$ & $\mathrm{a}$ & 3.17 & 4.00 & $7.59 \pm 2.4$ & $\mathrm{a}$ & 5.52 & 12.32 \\
\hline Specialty & $3.68 \pm 0.22$ & $\mathrm{a}$ & 3.44 & 4.01 & $6.62 \pm 1.34$ & $\mathrm{a}$ & 4.52 & 8.24 \\
\hline
\end{tabular}

$\mathrm{pH}$ measured with a $\mathrm{pH}$ meter

TA ( $\mathrm{g} / \mathrm{L}$ as $\mathrm{H}_{2} \mathrm{~T}$ ) measured by titration to end point using $\mathrm{pH}$ meter

All wines $n=100$, White $n=46$, Red $n=40$, Rosé $n=9$, Specialty $n=5$

Significance p-values were obtained by 1-way ANOVAs using XLSTAT (Addinsoft, Ver. 2017.02.43674)

Significant differences were noted with $95 \%$ confidence at a p-value $<0.05$

p-values: $\mathrm{pH}=0.002, \mathrm{TA}=0.443$ 
Figure 4. Concentration of (1) Tartaric, (2) Malic, (3) Lactic, and (4) Citric acids in all wine samples $(n=100)$. All organic acids were measured with HPLC. Mean concentration for each acid, in $\mathrm{g} / \mathrm{L}:$ tartaric $=2.32$, malic $=2.04$, lactic $=1.80$, acetic $=$ 0.87 , citric $=0.36$, and succinic $=0.76$.

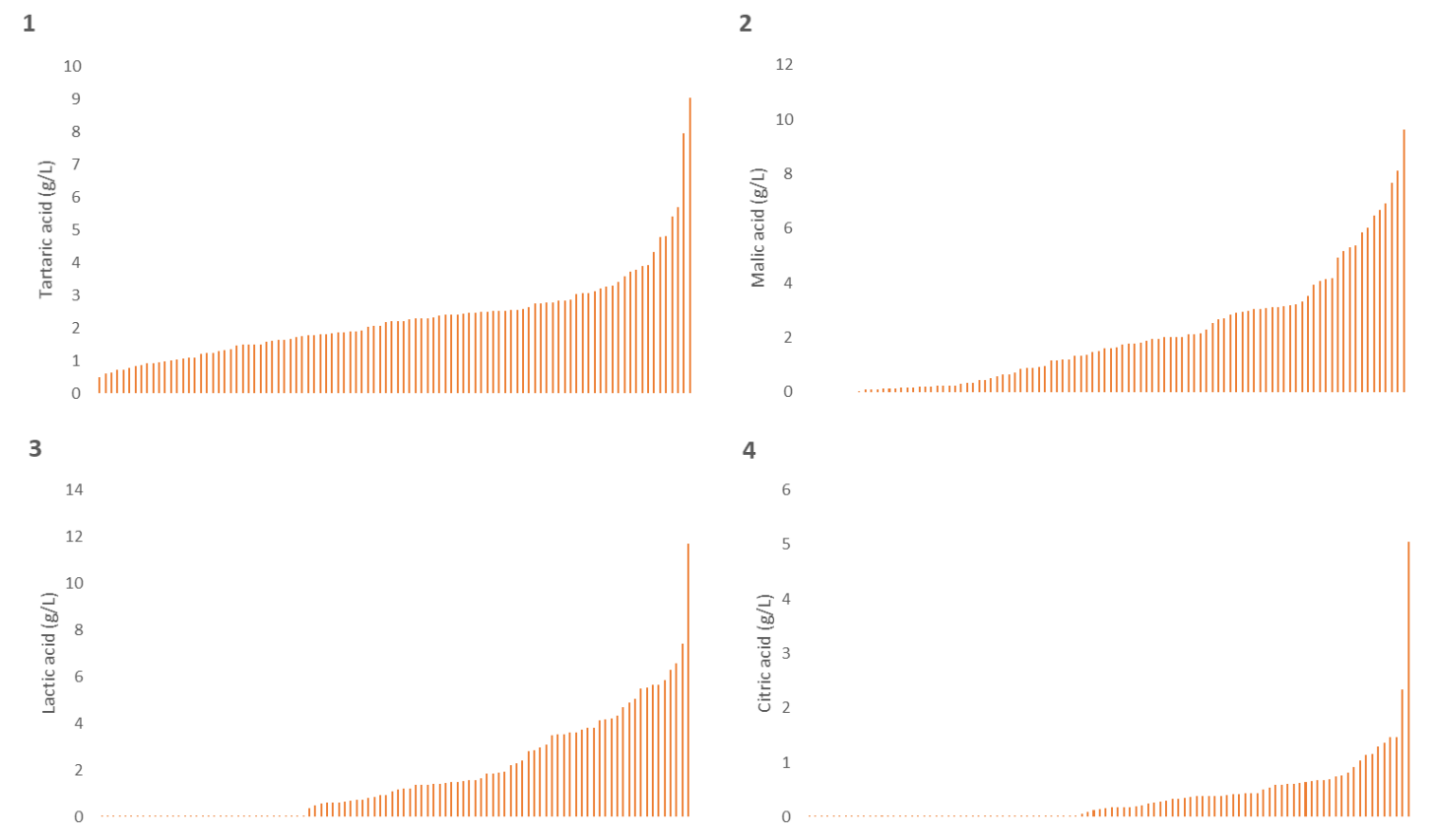

Figure 5. Means and standard deviations of organic acids per wine style. Population sizes: red $n=40$, rosé $n=9$, specialty $n=9$, white $n=46$.

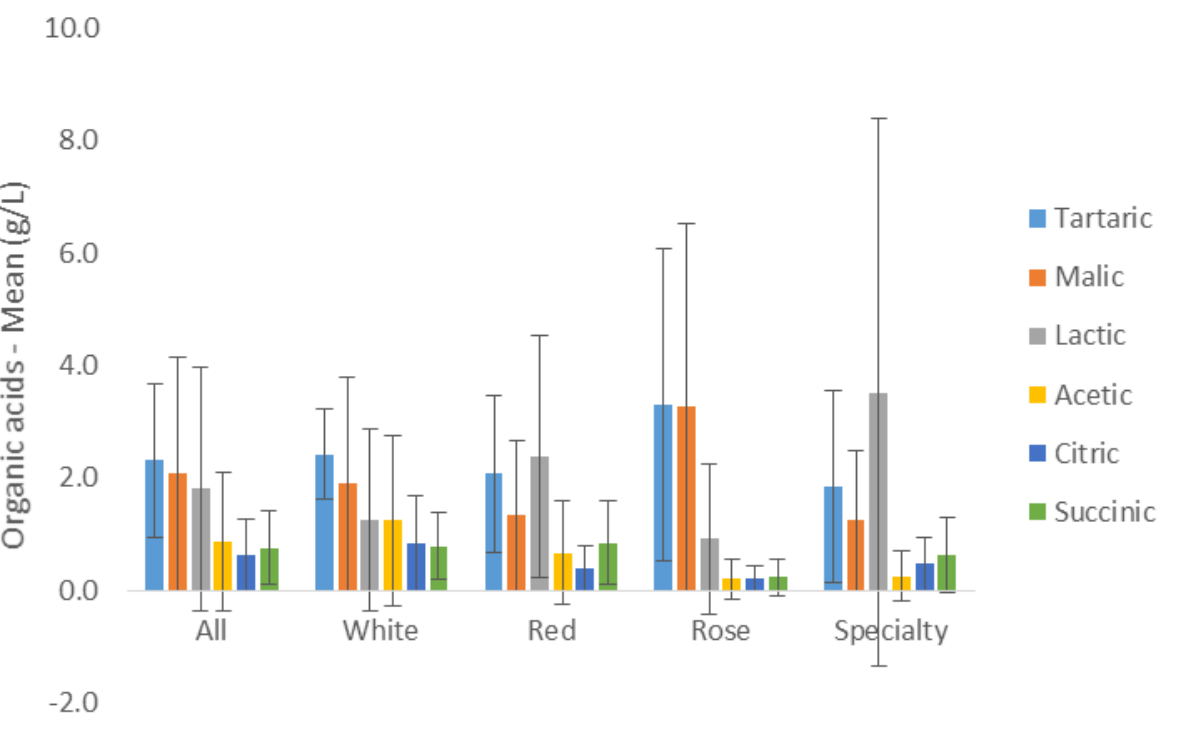


Figure 6. Concentration of (1) Free $\mathrm{SO}_{2}$ and (2) Total $\mathrm{SO}_{2}$ in $\mathrm{mg} / \mathrm{L}$ for different wine styles. Population sizes: red $n=40$, rosé $n=9$, specialty $n=9$, white $n=46$. Sulfur Dioxide measurements were performed via Aeration Oxidation.

1

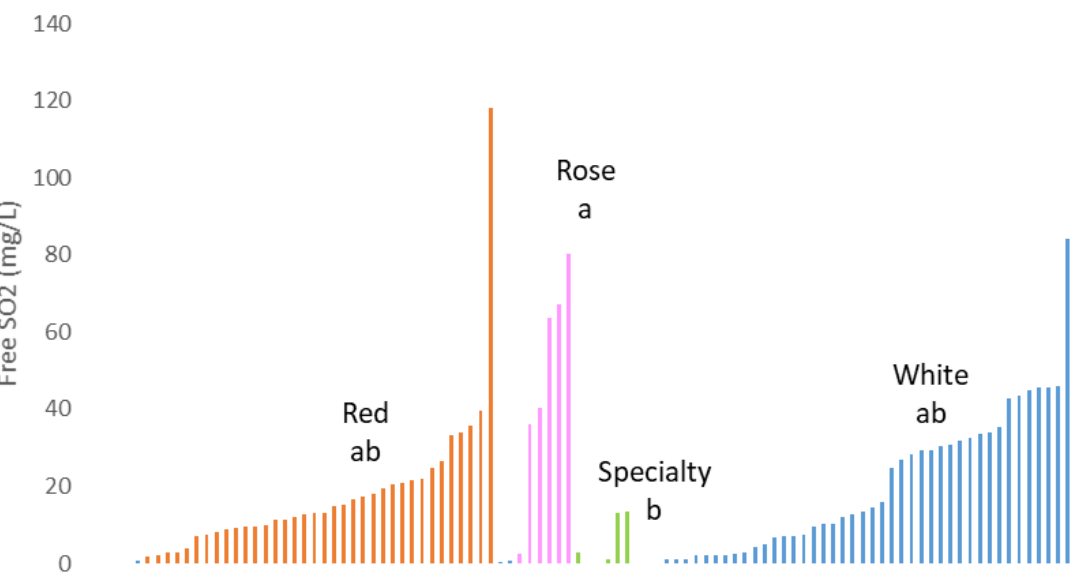

2

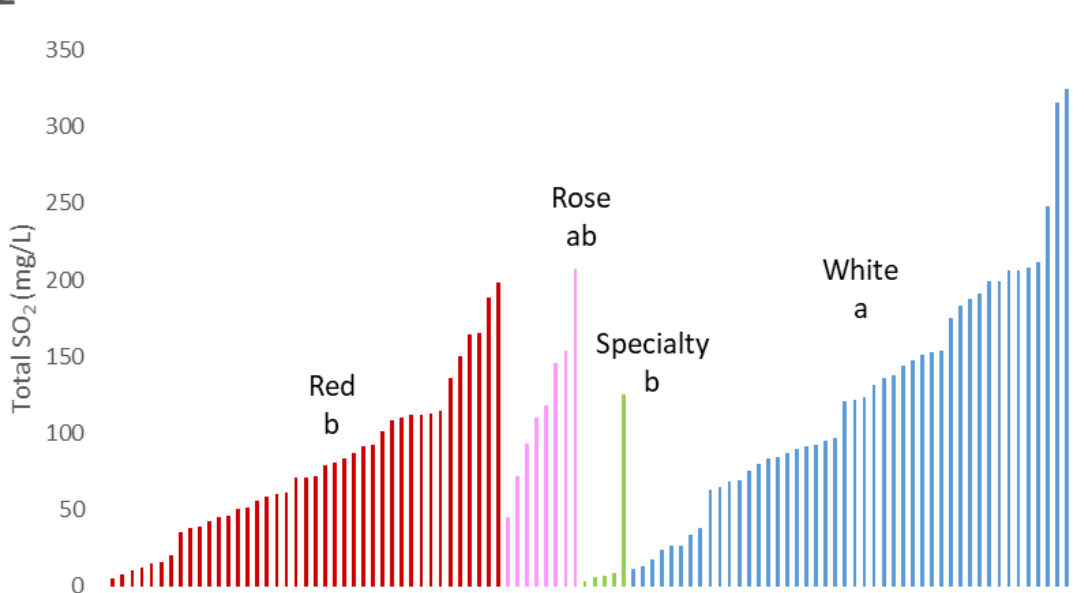




\section{Annexes}

Supplemental Table A. Basic statistics of wine styles versus categorical variables of assessment.

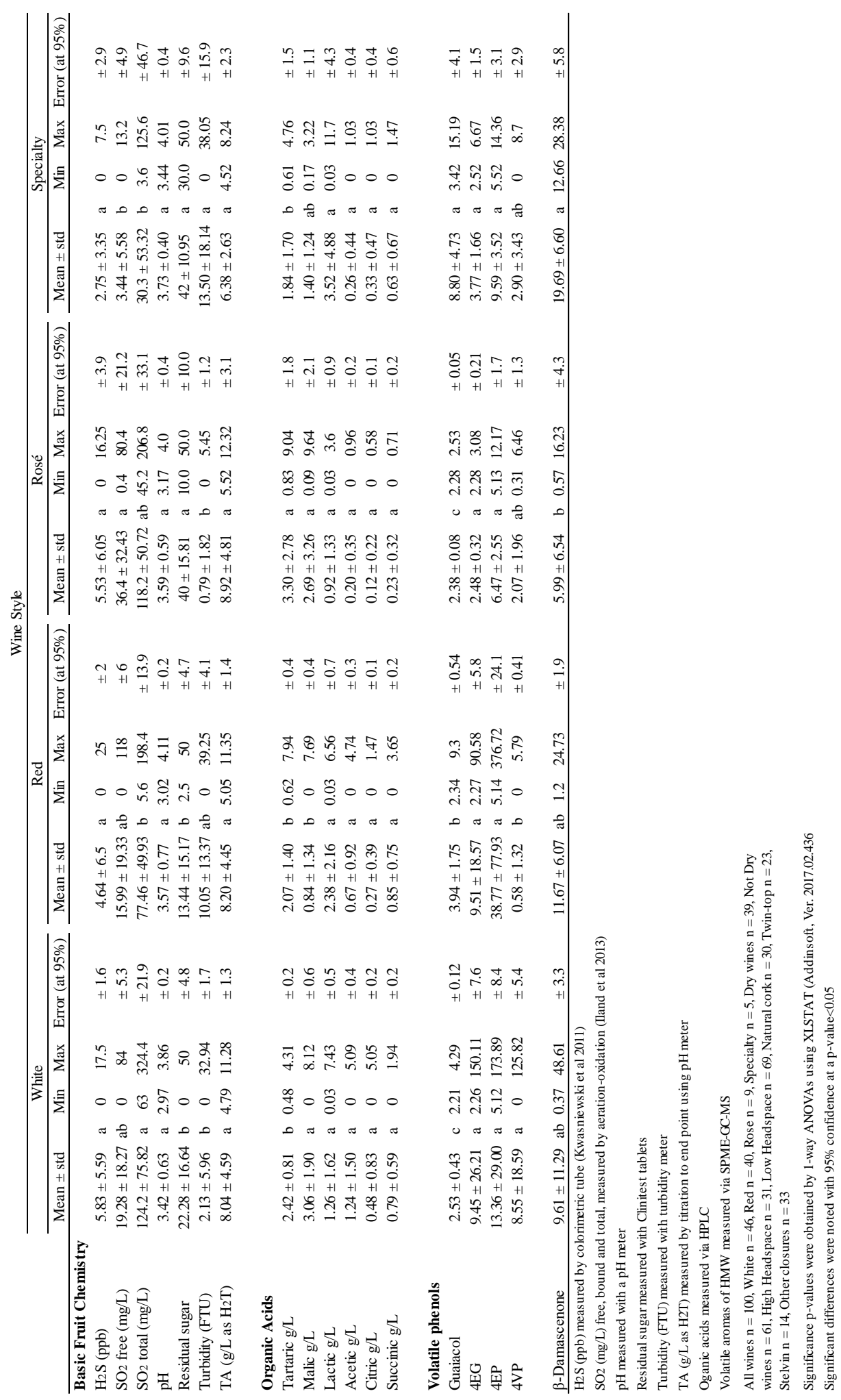


Supplemental Table B. Basic statistics of residual sugars versus categorical variables of assessment.

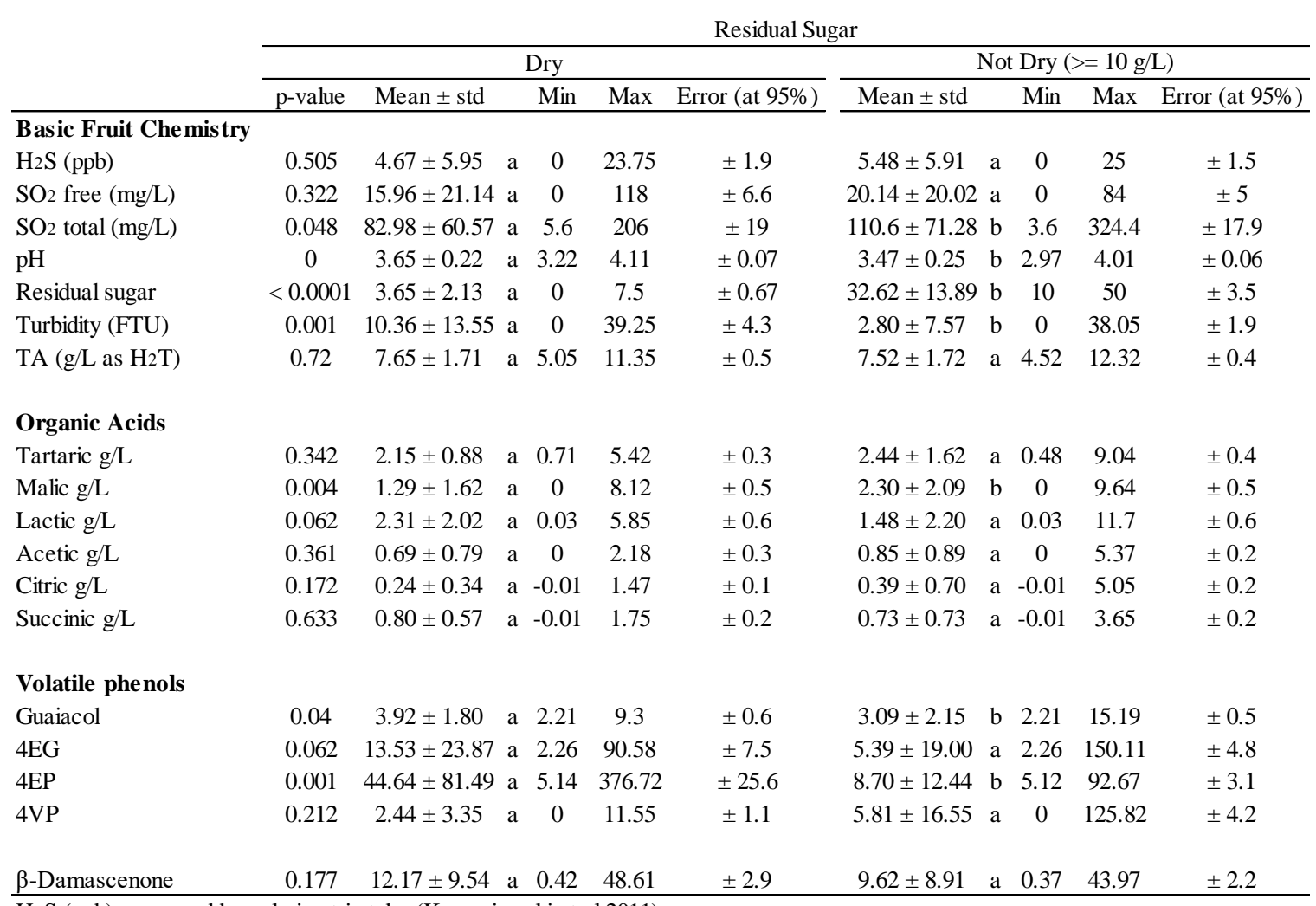

$\mathrm{H}_{2} \mathrm{~S}$ (ppb) measured by colorimetric tube (Kwasniewski et al 2011)

$\mathrm{SO}_{2}(\mathrm{mg} / \mathrm{L})$ free, bound and total, measured by aeration-oxidation (Iland et al 2013)

$\mathrm{pH}$ measured with a $\mathrm{pH}$ meter

Residual sugar measured with Clinitest tablets

Turbidity (FTU) measured with turbidity meter

$\mathrm{TA}\left(\mathrm{g} / \mathrm{L}\right.$ as $\left.\mathrm{H}_{2} \mathrm{~T}\right)$ measured by titration to end point using $\mathrm{pH}$ meter

Oganic acids measured via HPLC

Volatile aromas of HMW measured via SPME-GC-MS

All wines $n=100$, White $n=46$, Red $n=40$, Rose $n=9$, Specialty $n=5$, Dry wines $n$

$=39$, Not Dry wines $n=61$, High Headspace $n=31$, Low Headspace $n=69$, Natural

cork $n=30$, Twin-top $n=23$, Stelvin $n=14$, Other closures $n=33$

Significance p-values were obtained by 1-way ANOVAs using XLSTAT (Addinsoft, Ver. 2017.02.4.

Significant differences were noted with $95 \%$ confidence at a p-value $<0.05$

Wines classified in Dry and Not Dry according to the Commission Regulation (EC) No 753/2002 
Supplemental Table C. Basic statistics of fill volume versus categorical variables of assessment.

Fill Volume

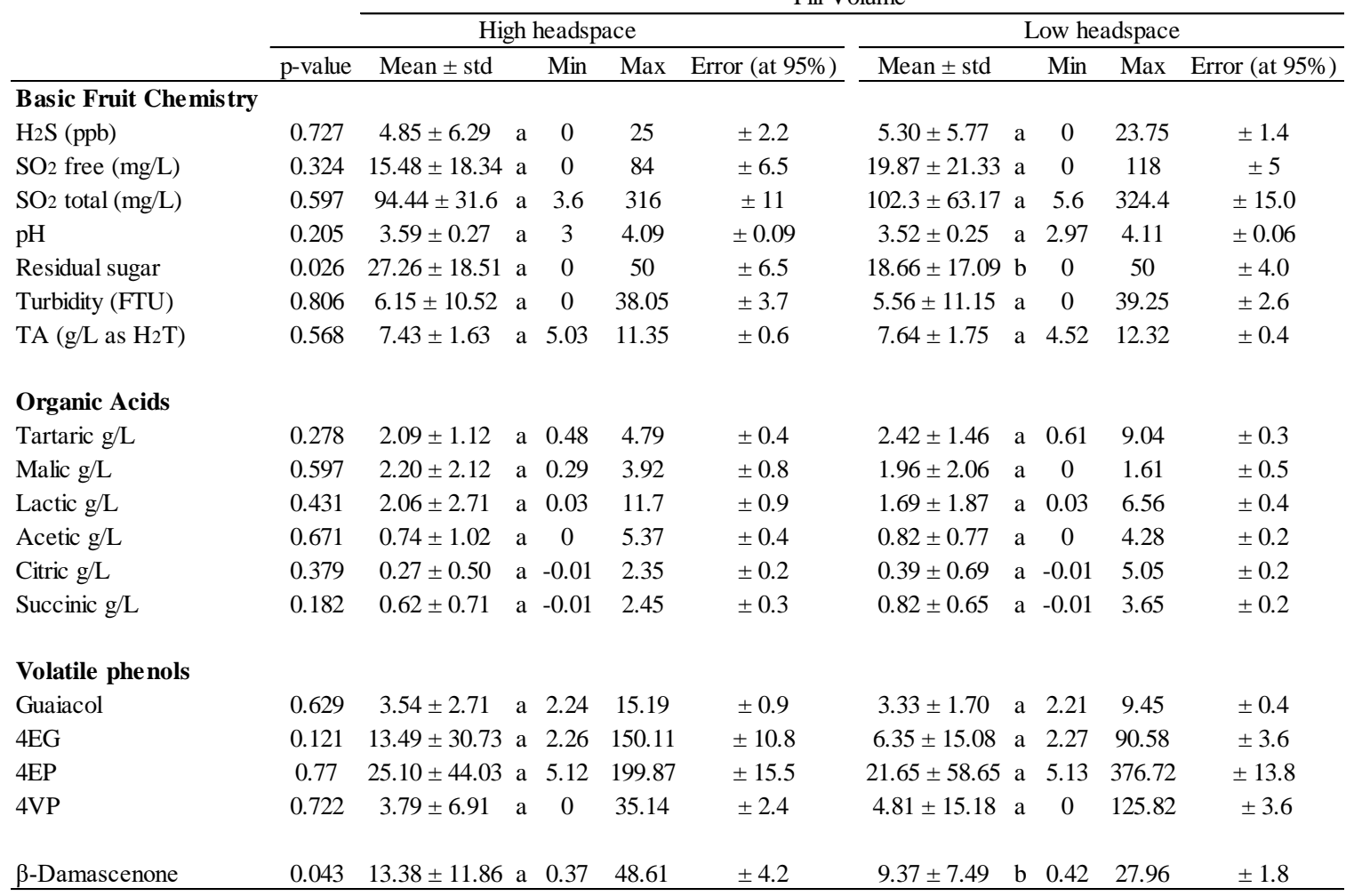

$\mathrm{H}_{2} \mathrm{~S}$ (ppb) measured by colorimetric tube (Kwasniewski et al 2011)

$\mathrm{SO}_{2}(\mathrm{mg} / \mathrm{L})$ free, bound and total, measured by aeration-oxidation (Iland et al 2013)

$\mathrm{pH}$ measured with a $\mathrm{pH}$ meter

Residual sugar measured with Clinitest tablets

Turbidity (FTU) measured with turbidity meter

$\mathrm{TA}\left(\mathrm{g} / \mathrm{L}\right.$ as $\left.\mathrm{H}_{2} \mathrm{~T}\right)$ measured by titration to end point using $\mathrm{pH}$ meter

Oganic acids measured via HPLC

Volatile aromas of HMW measured via SPME-GC-MS

All wines $n=100$, White $n=46$, Red $n=40$, Rose $n=9$, Specialty $n=5$, Dry wines $n=39$, Not

Dry wines $n=61$, High Headspace $n=31$, Low Headspace $n=69$, Natural cork $n=30$, Twin-top $n$

$=23$, Stelvin $n=14$, Other closures $n=33$

Significance p-values were obtained by 1-way ANOVAs using XLSTAT (Addinsoft, Ver. 2017.02.4

Significant differences were noted with $95 \%$ confidence at a $\mathrm{p}$-value $<0.05$ 
Supplemental Table D. Basic statistics of closure type versus categorical variables of assessment.

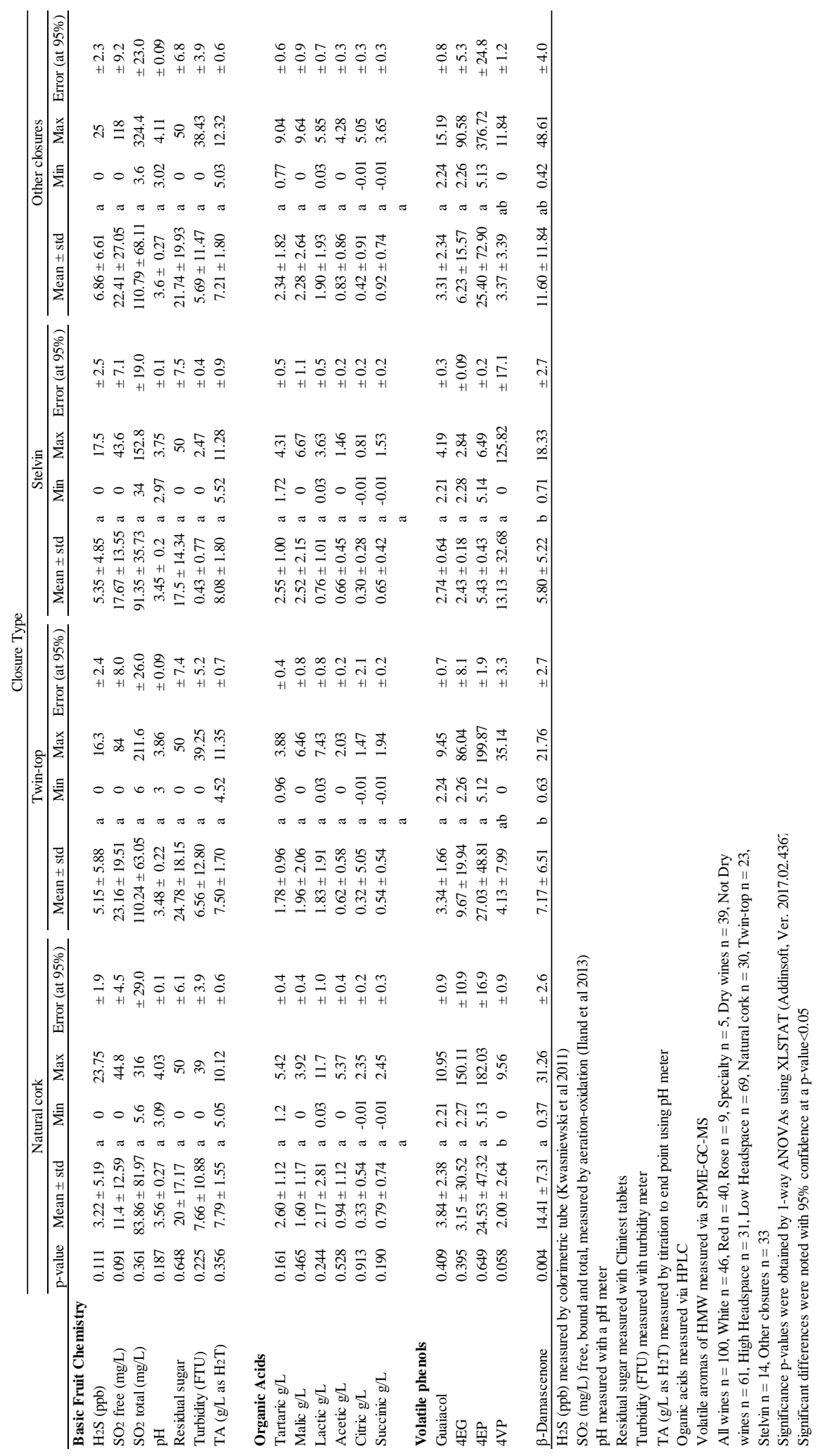


Supplemental Table E. R square values for all wines.

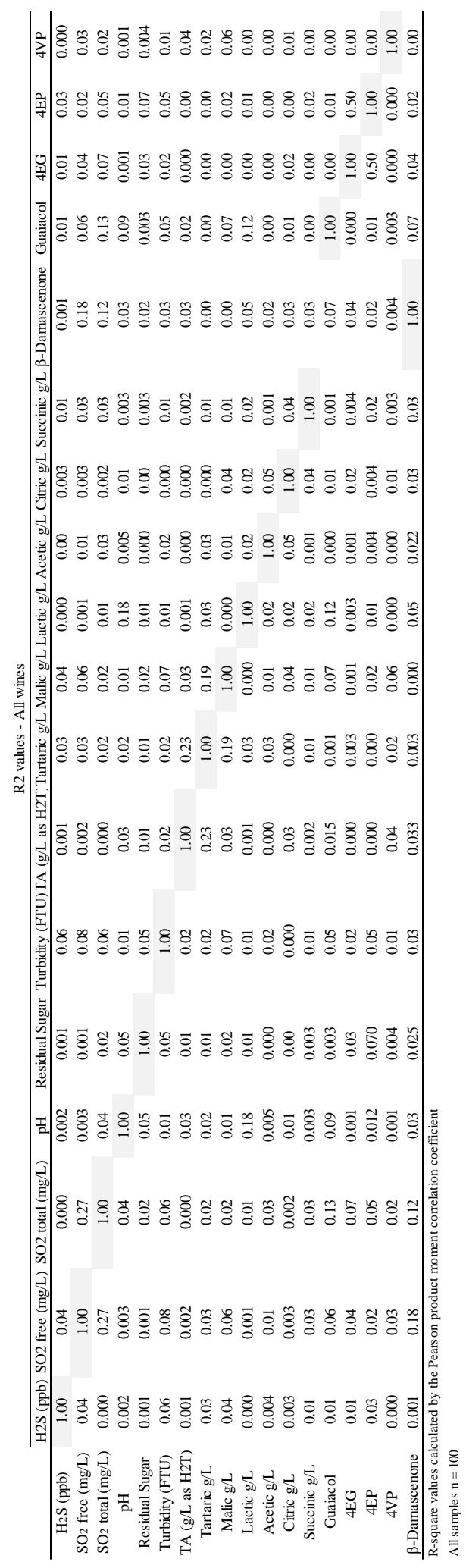


Supplemental Table F. R square values for white wines.

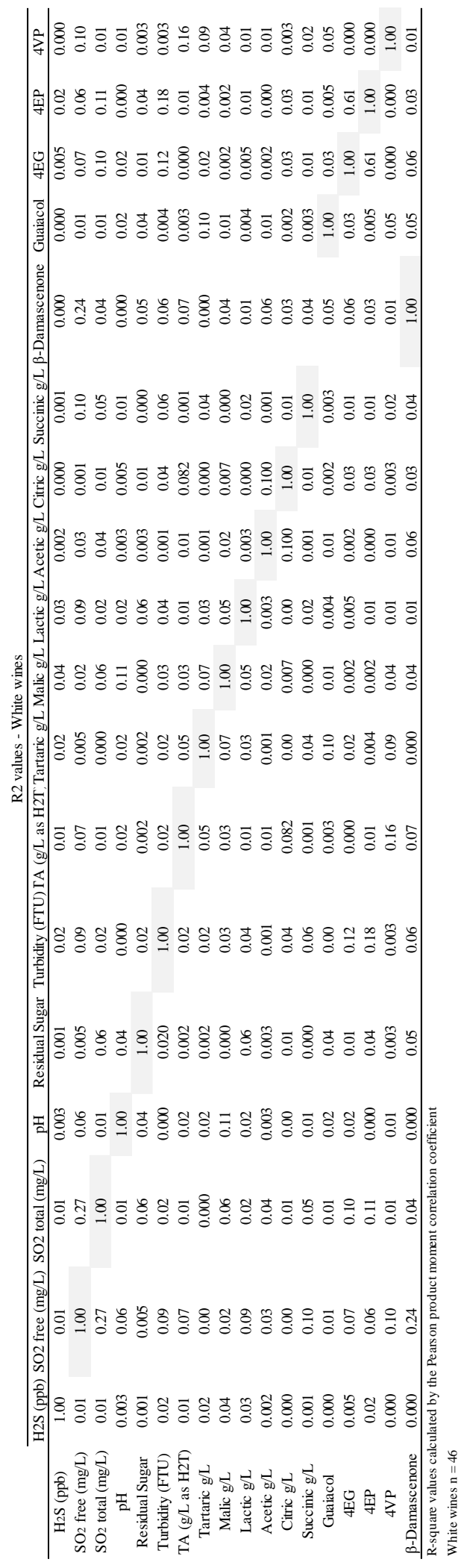


Supplemental Table G. R square values for red wines.

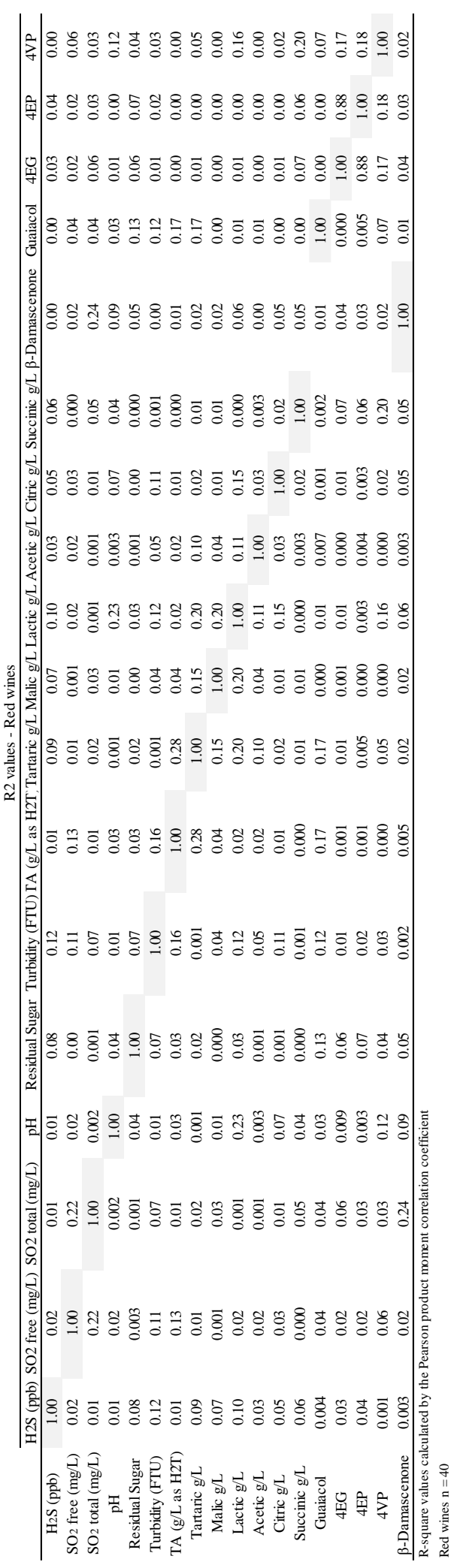


Supplemental Table H. R square values for rosé wines.

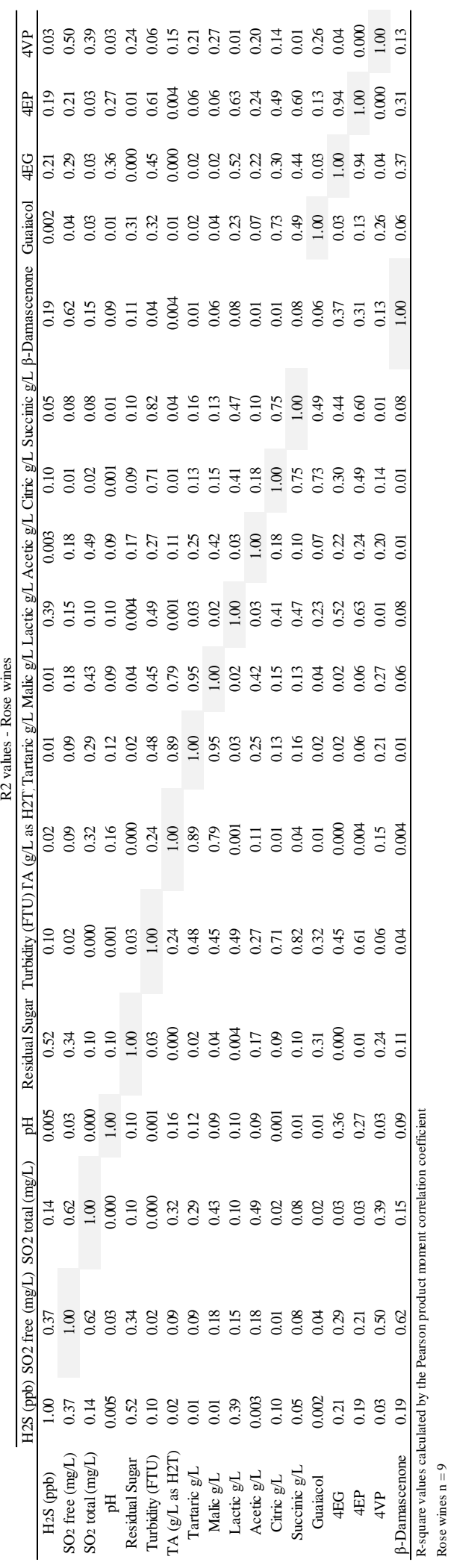


Supplemental Table I. R square values for specialty wines.

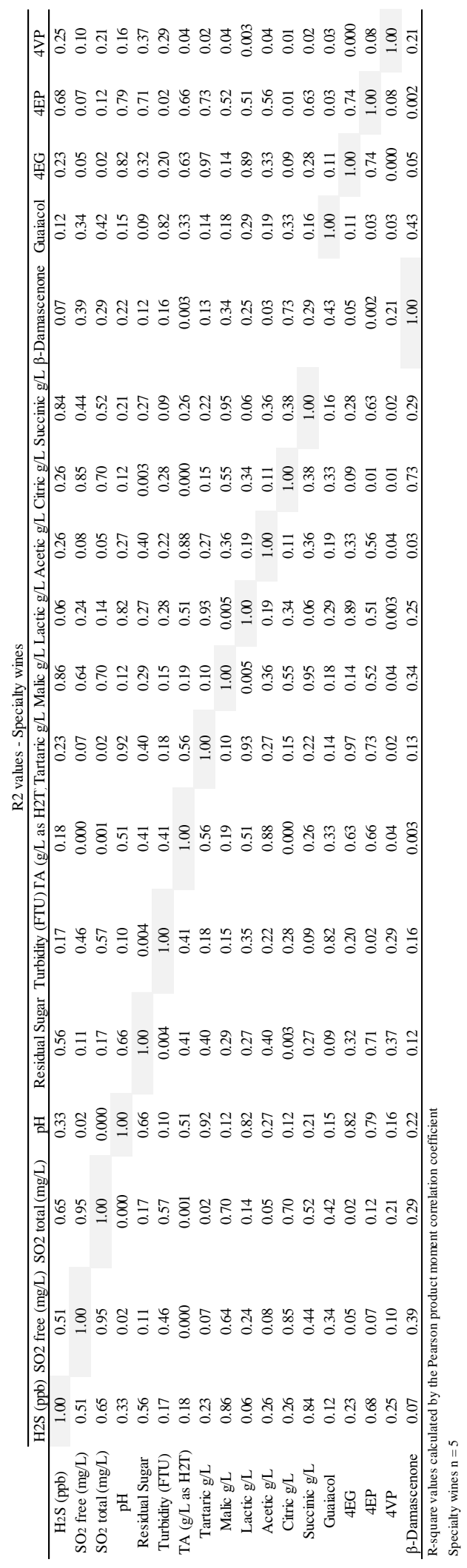


Supplemental Table J. Incidence of faults per wine.

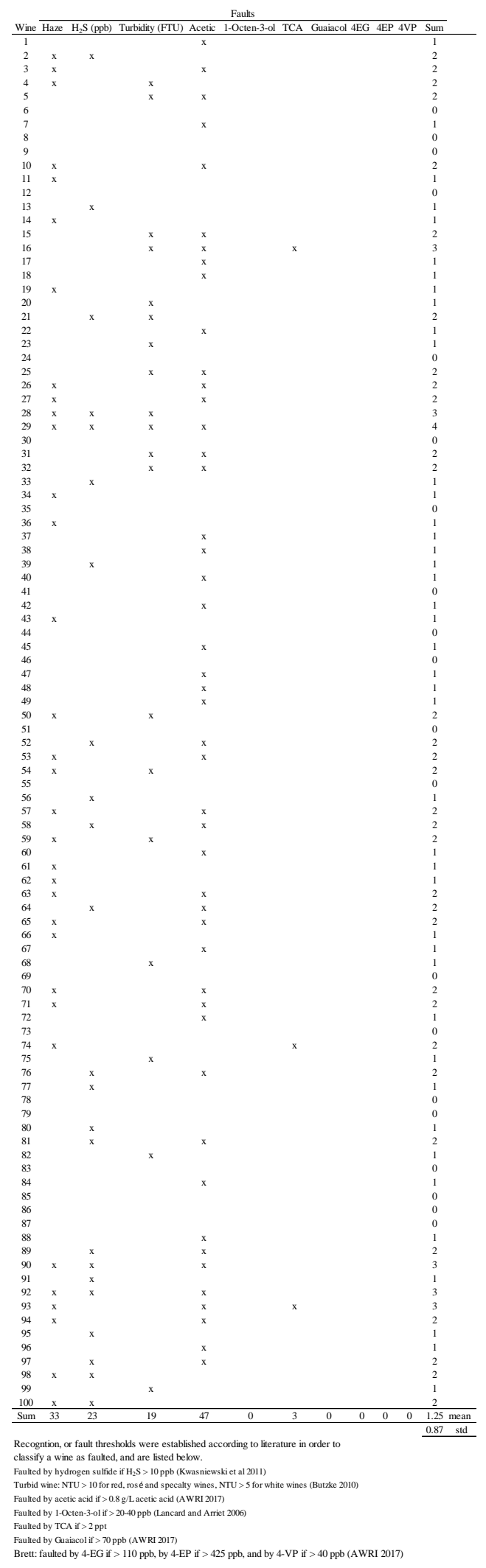


Supplemental Table K. Incidence of Risk Factors per wine.

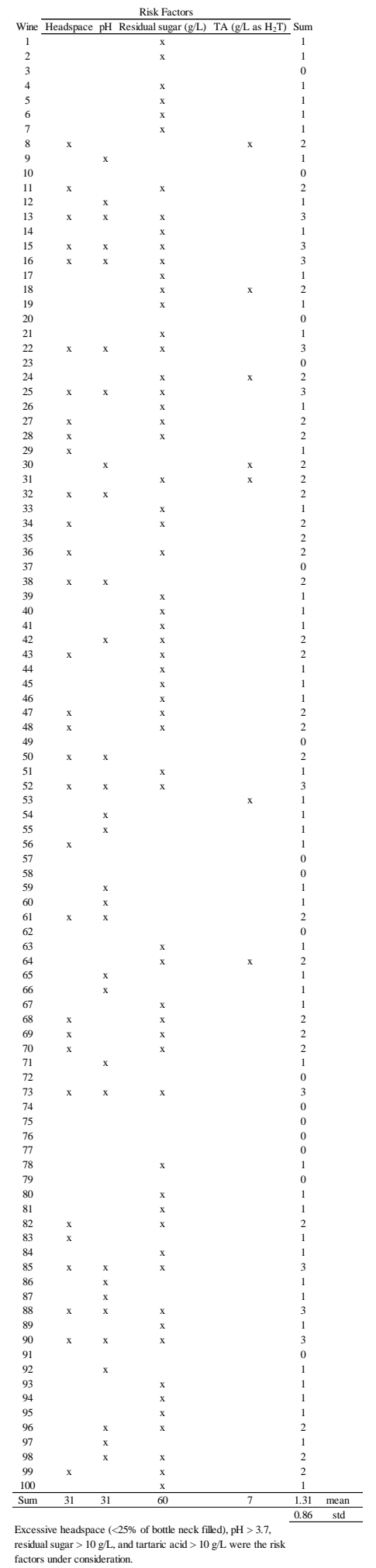


Supplemental Figure A. Concentration of residual sugars $(\mathrm{g} / \mathrm{L})$ in different wine styles.

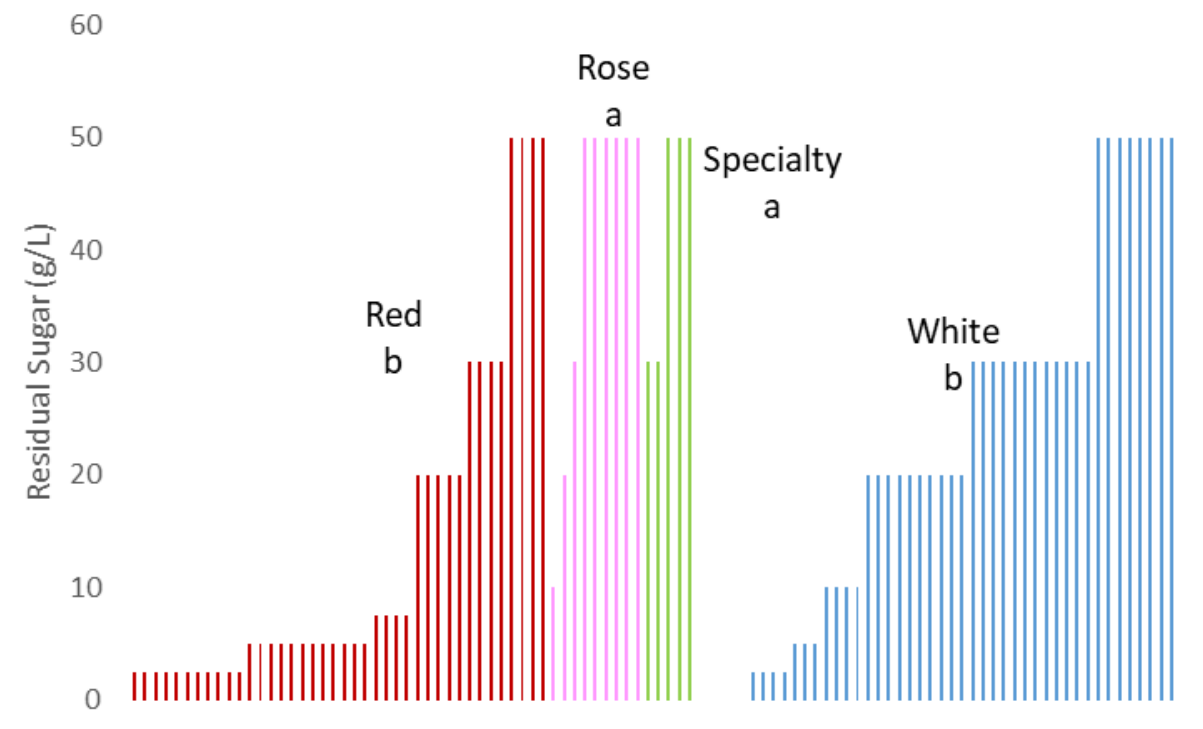

Supplemental Figure B. Incidence of faults and risk factors.
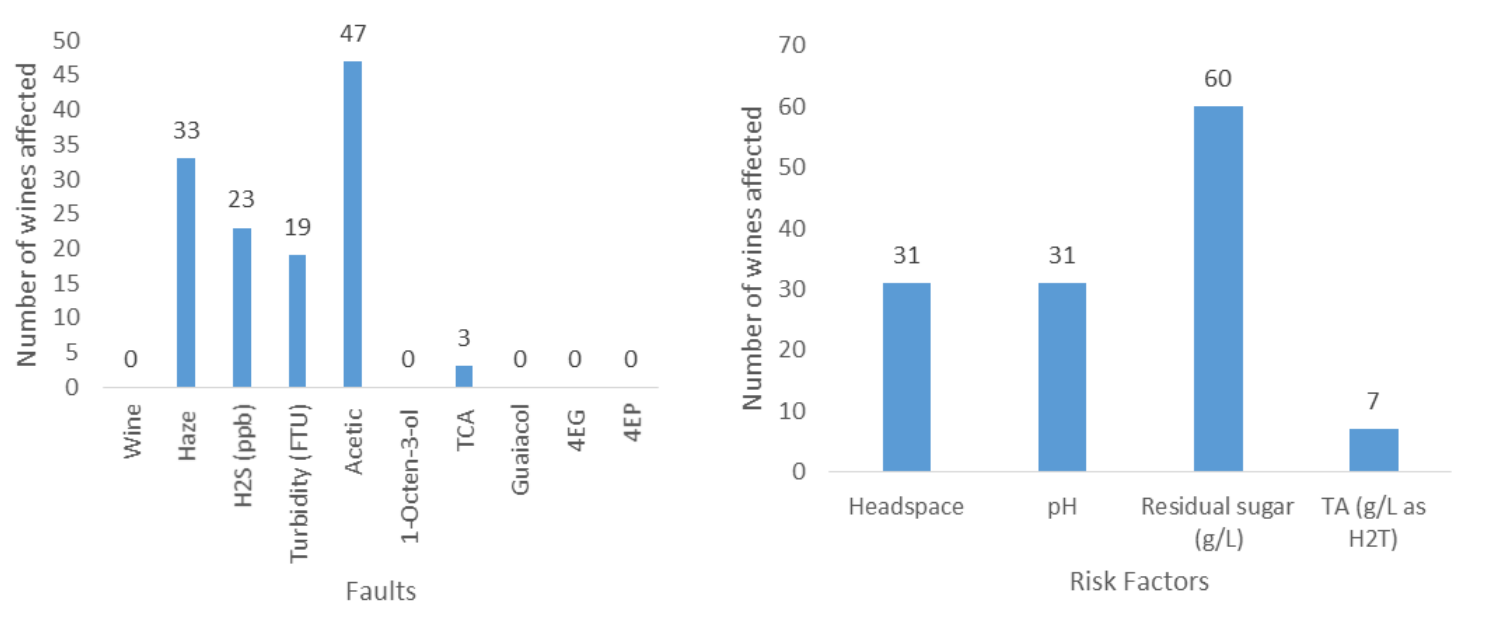
Supplemental Figure C. Incidence of Turbidity (NTU) in different wine styles.

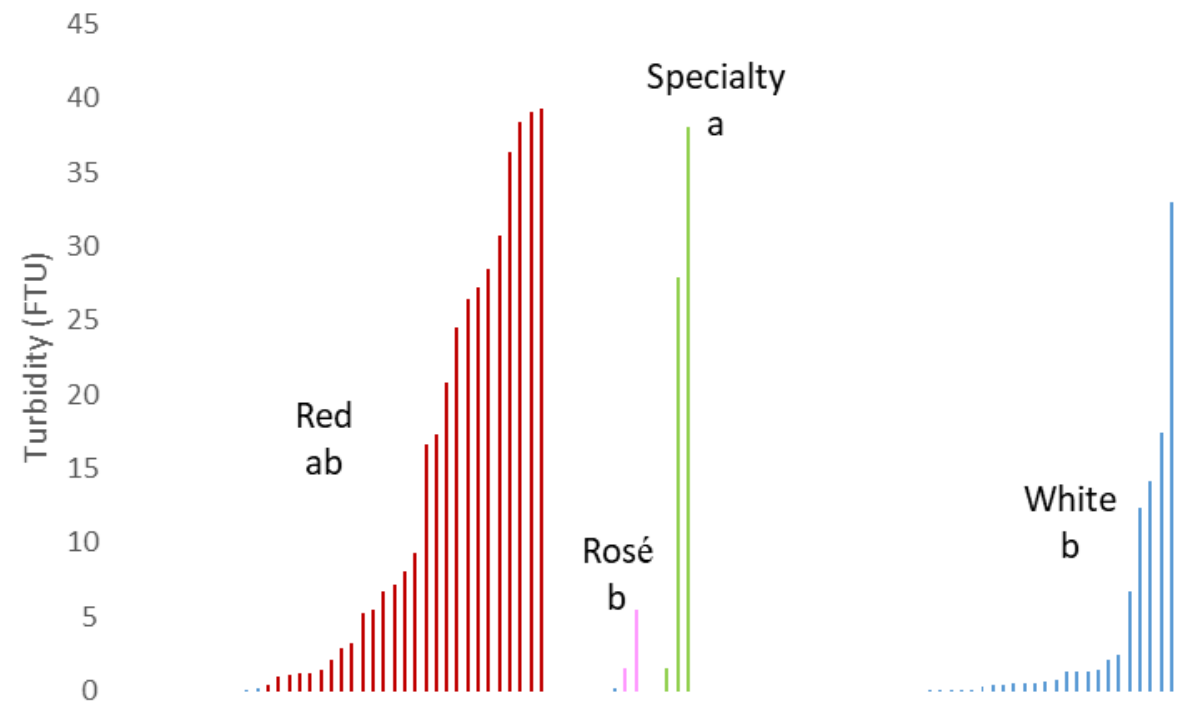

